UNIVERSIDADE ESTADUAL PAULISTA “JULIO DE MESQUITA FILHO” FACULDADE DE CIÊNCIAS AGRÁRIAS E VETERINÁRIAS CÂMPUS DE JABOTICABAL

\title{
QUALIDADE FÍSICA DE UM LATOSSOLO VERMELHO SOB SISTEMA DE SEMEADURA DIRETA.
}

Ricardo Falqueto Jorge

Engenheiro Agrônomo

JABOTICABAL - SÃO PAULO - BRASIL

2010 


\section{UNIVERSIDADE ESTADUAL PAULISTA “JULIO DE MESQUITA FILHO” FACULDADE DE CIÊNCIAS AGRÁRIAS E VETERINÁRIAS CÂMPUS DE JABOTICABAL}

\section{QUALIDADE FÍSICA DE UM LATOSSOLO VERMELHO SOB SISTEMA DE SEMEADURA DIRETA.}

Ricardo Falqueto Jorge

Orientador: Prof. Dr. José Eduardo Corá

Tese apresentada à Faculdade de Ciências Agrárias e Veterinárias - Unesp, Câmpus de Jaboticabal, como parte das exigências para a obtenção do título de Doutor em Agronomia (Produção Vegetal).

JABOTICABAL - SÃO PAULO - BRASIL

Janeiro de 2010 


\section{Jorge, Ricardo Falqueto}

J82q Qualidade física em um latossolo vermelho sob sistema de semeadura direta / Ricardo Falqueto Jorge. - - Jaboticabal, 2010

xii, 103 f. : il. ; $28 \mathrm{~cm}$

Tese (doutorado) - Universidade Estadual Paulista, Faculdade de Ciências Agrárias e Veterinárias, 2009

Orientador: José Eduardo Corá

Banca examinadora: Marlene Cristina Alves, Paulo Leonel Libardi, Jose Carlos Barbosa, Marcílio Vieira Martins Filho Bibliografia

1. Curva de retenção de água no solo. 2. Índice S. 3. Plantas de cobertura. I. Título. II. Jaboticabal - Faculdade de Ciências Agrárias e Veterinárias.

\section{CDU 631.43:631.584.4}

Ficha catalográfica elaborada pela Seção Técnica de Aquisição e Tratamento da Informação Serviço Técnico de Biblioteca e Documentação - UNESP, Câmpus de Jaboticabal. 


\section{UNIVERSIDAdE ESTADUAL PAULISTA \\ unesp \\ CAMPUS DE JABOTICABAL \\ FACULDADE DE CIÊNCIAS AGRARIAS E VETERINARIAS}

\section{CERTIFICADO DE APROVAÇÃO}

TÍTULO: QUALIDADE FISICA DE UM LATOSSOLO VERMELHO SOB SISTEMA DE SEMEADURA DIRETA.

AUTOR: $\quad$ RICARDO FALQUETO JORGE

ORIENTADOR: Dr. JOSÉ EDUARDO CORÁ

Aprovado como parte das exigências para obtenção do Título de DOUTOR em AGRONOMIA (PRODUÇÃO VEGETAL) pela Comissăo Examinadora:

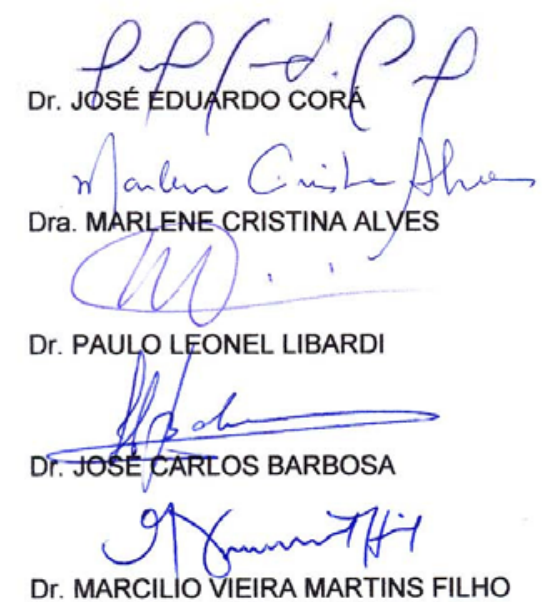

Data da realização: 27 de janeiro de 2010.

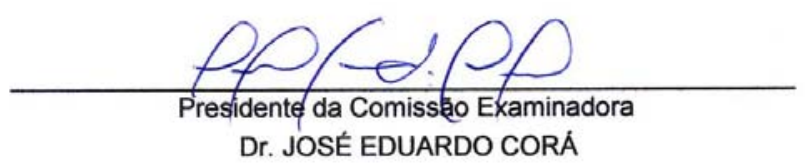




\section{DADOS CURRICULARES DO AUTOR}

RICARDO FALQUETO JORGE - Nascido dia 11 de junho de 1976, em Vitória, ES, cursou o ensino médio na EPSG Fioravante Caliman, em Venda Nova do Imigrante, ES, no período de 1992 a 1994. Em março de 1997, ingressou no Curso de Graduação em Agronomia pela Universidade Federal do Espírito Santo - Centro de Ciências Agrárias - Câmpus de Alegre, ES. Foi bolsista monitor da disciplina de Física do solo durante o período de agosto de 1999 a julho de 2001. Em setembro de 2001, obteve o título de Engenheiro Agrônomo. Iniciou em março de 2002 o curso de Mestrado em Agronomia (Ciência do Solo) na Universidade Federal de Uberlândia, onde foi bolsista CAPES. No dia 27 de fevereiro de 2004, submeteu-se à banca para a defesa da Dissertação e obteve o título de Mestre em Agronomia. Atuou como professor substituto na Escola Agrotécnica Federal de Uberlândia, junto à disciplina Capacidade de uso e manejo do solo, no período de maio de 2004 a outubro de 2005. Ingressou no curso de doutorado em Agronomia (Produção Vegetal), na Faculdade de Ciências Agrárias e Veterinárias, unidade da Universidade Estadual Paulista, Câmpus de Jaboticabal, em março de 2006, como bolsista CAPES. 
"Não se preocupe com o que a vida vai Ihe dar, mas sim com o que vais deixar de ensinamento para as vidas futuras. O Criador cuida bem de seus filhos. Para aquele que planta, jamais faltarão frutos. Mas aquele que abandona a árvore ao sol e ao vento e parte para cuidar do mundo encontrará a árvore seca ao voltar. E tenha certeza de que ficará sem alimento."

"Não ajunteis para vós tesouros da terra, onde as traças e o caruncho corroem e onde os ladrões arrombam e roubam, mas ajuntai para vós tesouros nos céus, onde nem traça, nem caruncho corroem e onde os ladrões não arrombam nem roubam; pois onde está o teu tesouro aí estará também teu coração."

Cesar Ramão (A semente de Deus) 
À minha amada família, Maria Luiza, Luciana, Nadir Jr. e à Cinara e familiares (Lindolfo, Neusa, Cristiane, Iran, Iran Filho e Amanda) pelo AMOR, CARINHO, APOIO e INCENTIVO por toda a minha vida... 


\section{AGRADECIMENTOS}

- A Deus e a Jesus Misericordioso, por guiar minha vida, concedendo-me saúde e mantendo-me no caminho da divina misericórdia.

- Ao meu orientador Prof. Dr. José Eduardo Corá, pelos princípios e ensinamentos proporcionados nesses anos de convivência.

- À FAPESP pelo apoio financeiro ao projeto e a CAPES pela concessão da bolsa de estudos.

- Aos Professores, pela participação na banca de defesa da tese, pela disposição e pelas sugestões para a melhoria desse trabalho.

- Aos Professores da FCAV, pela participação no Exame Geral de Qualificação e pelos conselhos e ensinamentos durante o curso de Doutorado.

- Aos companheiros, Adolfo (irmão) e Márcio, pela amizade e auxilio durante a condução do experimento e aos colegas José Marcos, Getulio e Marcos Sales pelo apoio durante o curso de Doutorado.

- Ao Prof. Dr. José Carlos Barbosa, pelo auxílio nas análises estatísticas.

- Aos funcionários do Departamento de Solos e Adubos, Afonso, Célia, Maria, Cláudia, Dibelli, Luis, Anderson, Mauro, Orivaldo, Dejair, Ademir e Hoster, pela prontidão nos momentos que precisei e pela amizade.

- Ao Marcelo Scatolin e aos funcionários da Fazenda de Ensino, Pesquisa e Produção da FCAV, pelo total auxílio durante a condução do experimento de campo.

- Ao coordenador do Programa de Pós-Graduação em Produção Vegetal, o professor Pedro Luís da Costa Aguiar Alves, pela atenção nos momentos que precisei.

- Aos estagiários Arthur, Thiago, Flávia e Júlia, pelo auxílio prestado durante a condução do experimento.

- Aos amigos da Pós-Graduação, Onã, Fernanda, Leomar, Juvenal, Amanda, Fabiana, Lílian, Adriana, Adriane, Anelisa, Tatiana, Ivana, Thiago, Andréia, Amaury, Anderson, Robson, Ancélio, Danilo, Liliane, Diego, Cristian, Jorge 
Wilson, e todos outros, que me proporcionaram momentos muito agradáveis durante nossa convivência.

- Às funcionárias da seção de Pós-Graduação e aos funcionários da Biblioteca da FCAV, pelo atendimento e auxílio.

- A todos meus Familiares (Vovó Eliza, Tios e Primos e a minha madrinha e familiares) e amigos pessoais, que sempre estiveram ao meu lado me apoiando e torcendo.

- E em especial, à minha namorada Cinara, por toda compreensão, carinho e amor, apoio e a força nos momentos difíceis e nas conquistas que vivenciamos.

- Enfim, a todos, que de alguma forma, contribuíram para esse acontecimento.

\section{MUITO OBRIGADO!!!}




\section{SUMÁRIO}

Página

RESUMO ...ix

SUMMARY ..xi

CAPÍTULO 1 - CONSIDERAÇÕES GERAIS. 1

CAPÍTULO 2 - NÚMERO MÍNIMO DE TENSÕES PARA DETERMINAÇÃO DA CURVA CARACTERÍSTICA DE RETENÇÃO DE ÁGUA NO SOLO 14

2.1. INTRODUÇÃO 15

2.2. MATERIAL E MÉTODOS 17

2.3. RESULTADOS E DISCUSSÃO 22

2.4. CONCLUSÕES 33

CAPÍTULO 3 - ÍNDICE S E ATRIBUTOS FÍSICOS DE UM LATOSSOLO VERMELHO SOB SISTEMA DE SEMEADURA DIRETA 34

3.1. INTRODUÇÃO 35

3.2. MATERIAL E MÉTODOS 39

3.3. RESULTADOS E DISCUSSÃO 45

3.4. CONCLUSÕES 62

4. REFERÊNCIAS 63

APÊNDICES .83 


\title{
QUALIDADE FÍSICA DE UM LATOSSOLO VERMELHO SOB SISTEMA DE SEMEADURA DIRETA
}

\begin{abstract}
RESUMO - Avaliar o nível de degradação imposta pelo uso agrícola tornou-se fundamental para estabelecer estratégias de manejo sustentáveis que mantenham a qualidade dos solos. A hipótese desse trabalho foi a de que o Latossolo Vermelho argiloso, em sequências de culturas de verão e inverno sob sistema de semeadura direta de longa duração, pode ter sua produtividade e qualidade física influenciada segundo o esquema de rotação de culturas adotado. $O$ presente estudo teve como objetivos: i) determinar o número mínimo de tensões para a determinação da curva de retenção de água no solo de maneira acurada e em menor tempo; ii) determinar o índice $S$ e caracterizar as transformações nos atributos do solo e iii) verificar a qualidade do solo correlacionando o índice $S$ com os atributos físicos do solo e com a produtividade das culturas. $O$ delineamento utilizado foi o de blocos em faixas com três repetições. Os tratamentos foram constituídos pela combinação de dois fatores: quatro sequências de culturas de verão (milho em monocultura - MV; soja em monocultura - SV; rotação soja/milho - RT; e rotação arroz/feijão/algodão - AF); e sete culturas de inverno (milho; girassol; nabo forrageiro; milheto; guandu, sorgo e crotalária). As camadas de solo foram avaliadas nas profundidades de $0-0,1 ; 0,1-0,2$; e $0,2-0,3 \mathrm{~m}$. O conteúdo de água foi medido nas tensões de $0 ; 10 ; 20 ; 40 ; 60 ; 80 ; 100 ; 200 ; 300 ; 500 ; 700 ; 1000 ; 3000$; 5000 e $15000 \mathrm{hPa}$. O índice $S$ foi determinado a partir dos parâmetros ajustados ao modelo de van Genuchten, e os atributos físicos do solo foram avaliados em função do esquema de rotação de culturas. Os dados foram submetidos à análise de variância (teste F) e suas médias comparadas pelo teste de Scott-Knott ( $5 \%$ de probabilidade). As curvas de retenção de água (CRA) ajustadas a partir das tensões: 0; 100; 300; $1000 \mathrm{e}$ $15000 \mathrm{hPa}$ ou $0 ; 80 ; 300 ; 700$ e $15000 \mathrm{hPa}$ não diferiram daquela ajustada a partir de 15 tensões. Isso indica que a CRA pode ser estabelecida em menor tempo mantendose sua acurácia. A seqüência de culturas de verão $A F$ proporcionou os maiores valores do índice $\mathrm{S}$. Para as sequências de culturas de inverno os maiores valores médios de $S$
\end{abstract}


foram observados nas culturas de crotalária e sorgo. Verificou-se que os menores valores do índice $S$ ocorreram na camada de 0,1-0,2 m. O índice $S$ foi eficiente na avaliação da qualidade física do solo, apresentando correlação significativa com os atributos físicos do solo, contudo, não foi verificada a relação do índice S com a produtividade das culturas.

Palavras-Chave: curva característica de retenção de água no solo, atributos físicos, índice S. 


\section{PHYSICAL QUALITY OF AN OXISOL (RED LATOSOL) UNDER NO-TILLAGE SYSTEM}

SUMMARY - Assess the degradation level imposed by the agricultural use has become essential to establish sustainable management practices to keep soil quality. The hypothesis of this study was that a Red Latosol (Oxisol), in summer crops sequences and winter crops sequences under no-tillage system of long duration, can have its physical quality and yield influenced according crop rotation. This study aimed to: i) determine the minimum number of tensions to determine the water retention curve (WRC) so accurately and in less time, ii) determine the index $S$ and characterize soil attributes changes, and iii) verify the soil quality by the correlation between the index $S$ and the soil physical attributes and crop yield. The experiment had a complete, in split block design with three replications. The summer crop sequences consisting the main plots were the following: MM - maize monocrop (Zea mays L.); SS - soybean monocrop (Glycine max L. Merrill); SM - soybean/maize rotation, both intercropped every other year; and RBC - rice/bean/cotton rotation, with rice (Oryza sativa L.), bean (Phaseolus vulgaris L.) and cotton (Gossypium hirsutum L.) in rotation. Winter crops consisted of maize, sunflower (Helianthus annuus L.), oilseed radish (Raphanus sativus L.), millet (Pennisetum americanum (L.) Leeke), pigeon pea (Cajanus cajan (L.) Millsp), grain sorghum (Sorghum bicolor (L.) Moench) and sunn hemp (Crotalaria juncea L.). In each growing season, the same winter crop was sown in the same plot. Soil samples were collected at layers $0-0.1,0.1-0.2$, and $0.2-0.3 \mathrm{~m}$. The water content was measured at tensions $0,10,20,40,60,80,100,200,300,500,700,1000,3000,5000$ and 15000 $\mathrm{hPa}$. The index $\mathrm{S}$ was determined from van Genuchten equation parameters and soil physical attributes were evaluated according crop rotation. Variance analysis for data was considered for statistical procedures and the means were submitted to the ScottKnott cluster analysis procedure ( $5 \%$ probability). The WRC adjusted from tensions: 0 , $100,300,1000$ and $15000 \mathrm{hPa}$ or $0,80,300,700$ and $15000 \mathrm{hPa}$ did not differ from that with 15 tensions. This indicates that the WRC can be established in less time 
maintaining its accuracy. The summer crops sequences RBC showed higher index $S$ values. For winter crops sequences, the highest index $S$ values were observed in sunn hemp and grain sorghum crops. The lowest index $S$ values were found at layer 0.1-0.2 $m$. The index $S$ was effective in assessing soil physical quality and it had a significant correlation with soil physical attributes. However, there was no relation to the index $S$ and crop yield.

Keywords: water retention curve, physical attributes, index S. 


\section{CAPÍTULO 1 - CONSIDERAÇÕES GERAIS}

O solo deve funcionar como um meio de crescimento para as plantas, fornecendo um suporte adequado, sem restrições para o desenvolvimento do seu sistema radicular e onde o fornecimento de água e nutrientes seja adequado. Dessa forma, a qualidade do solo pode ser mantida ou melhorada com uso de sistemas de manejo sustentáveis que colaboram para a manutenção de adequadas produtividades das culturas em longo prazo (GREGORICH, 2002; VEZZANI \& MIELNICZUK, 2009). Sob esse aspecto, as condições físicas do solo são essenciais para o crescimento das culturas, e determinam o fornecimento normal de água, nutrientes dissolvidos, gases e calor. Condições físicas do solo que possam prover essas respostas constituem "boa qualidade física do solo", segundo TOPP et al. (1997).

O sistema de semeadura direta (SSD) vem se destacando por constituir uma excelente alternativa de manejo conservacionista do solo, e vem sendo amplamente difundido no país, especialmente nas áreas produtoras de grãos, como na região do Cerrado (KLUTHCOUSKI et al., 2000; LEAL et al., 2008). Nesse sistema, os resíduos vegetais são mantidos na superfície, contribuindo continuamente com o aporte de matéria orgânica ao solo, a qual é responsável pela conservação e melhoria da qualidade física do solo (LAL \& GREENLAND, 1979; CASTRO FILHO et al., 1998; LLANILLO et al., 2006). A vegetação e seus resíduos protegem os agregados do solo do impacto da gota de chuva e dos ciclos de umedecimento e secagem (BASTOS et al., 2005). Ao mesmo tempo, o contínuo fornecimento de material orgânico, bem como secreções radiculares, serve de fonte de energia para a atividade microbiana, cujos subprodutos, constituídos de moléculas orgânicas em diversas fases de decomposição, atuam como agentes de formação e estabilização de agregados (ALLISON, 1973, PASSOS et al., 2007). Ao lado desses benefícios, manifesta-se também o efeito mecânico e físico das raízes sobre a formação dos agregados. As pressões de crescimento, formação de zonas de depleção de água e acumulação e precipitação de sais, decorrentes de fluxos ocasionados pela atividade da planta, são fenômenos 
importantes na formação e estabilização de agregados em zonas adjacentes às raízes (ALLISON, 1973; TISDALL \& OADES, 1982).

A intensa movimentação de máquinas e equipamentos agrícolas para a realização dos tratos culturais nas lavouras, aliado ao não-revolvimento dos solos no SSD e à ausência de rotação de culturas, tem trazido consequências negativas para a estrutura e uma aparente degradação dos solos. Na maioria dos SSD, a ausência quase que completa de preparo por longo tempo reduz o volume de macroporos e eleva a densidade do solo (BERTOL et al., 2001; SPERA et al., 2009) e a estabilidade dos agregados na superfície do solo (CARPENEDO \& MIELNICZUK, 1990; COSTA et al., 2003).

As alterações nos atributos físicos do solo submetido ao SSD podem variar, dependendo da textura e dos teores de matéria orgânica, da freqüência e tipo de cultivo (HAJABBASI et al., 1997), porém a sensibilidade dos indicadores da qualidade do solo deve ser capaz de detectar sutis mudanças nos sistemas de produção. $O$ índice $S$, proposto recentemente por DEXTER (2004 a), é um parâmetro utilizado como indicador da qualidade física e estrutural do solo. O valor de $S$ baseia-se fisicamente na curva de retenção de água no solo, a qual reflete a distribuição de poros do solo. Conforme DEXTER (2004 a) o índice S governa inúmeras propriedades físico-hídricas importantes para um adequado funcionamento físico do solo, sendo, portanto, um bom indicador da qualidade do solo.

A rotação de culturas em SSD altera diferentemente as propriedades do solo. Os benefícios da adoção das sequências de culturas são devidos à diferença de demanda nutricional entre as espécies cultivadas, profundidade de exploração do sistema radicular e de absorção de nutrientes do solo, susceptibilidade às pragas e doenças, ao controle de plantas daninhas, à fixação de nitrogênio pelas leguminosas e à redução das perdas do solo pela erosão. Todavia, há carência de informações, com base em experimentos de longa duração, sobre a qualidade de solos submetidos à SSD. A compreensão e a quantificação do impacto do uso e manejo do solo na sua qualidade são fundamentais no desenvolvimento e seleção de sistemas agrícolas sustentáveis (DEXTER \& YOUNGS, 1992), justificando assim, a importância do presente estudo. 


\section{QUALIDADE DO SOLO E MANEJO CONSERVACIONISTAS}

A avaliação das propriedades físicas, químicas e biológicas é usada para análise da qualidade do solo, que é meio para a produção vegetal e animal, para regular o fluxo de água no ambiente e para atuar como filtro ambiental na atenuação e degradação de componentes ambientalmente danosos ou perigosos (LARSON \& PIERCE, 1994). Nos sistemas agrícolas, a qualidade do solo é monitorada com vistas ao manejo do sistema para incentivar a produção, sem degradar os solos e o ambiente (GREGORICH, 2002). Neste sentido, um sistema de manejo poderá ser considerado sustentável se mantiver ou melhorar a qualidade do solo e do ambiente, bem como alcançar adequadas produtividades das culturas em longo prazo.

A manutenção da qualidade física do solo exerce papel vital, na produção sustentável de alimento. Uma visão holística do uso e manejo do solo faz-se necessária, para lidar com o aumento da pressão sobre os recursos para sustentabilidade produtiva de fibras e alimentos, com redução nos impactos ambientais adversos das práticas agrícolas (BRONICK \& LAL, 2005).

Conceitualmente, a qualidade do solo reflete-se em atributos inerentes ao solo que são estudados por meio das características do solo, utilizando-se de observações indiretas como retenção de água, compactação e fertilidade do solo. BRADY \& WEIL (2002) propõem uma definição para qualidade do solo como "uma medida da capacidade do solo em realizar funções ecológicas particulares, a qual reflete uma combinação das suas propriedades químicas, físicas e biológicas". Esses autores consideram que qualidade do solo reflete o grau de ajustamento do mesmo a qualquer função, ou seja, sua capacidade de desempenhar uma função dentro de seu ecossistema, para manter tanto a produtividade e a diversidade biológica, propiciando um ambiente com qualidade, provendo ao mesmo tempo meio saudável para existência das plantas e dos animais.

O sistema solo é dinâmico, e como base para a avaliação da sua qualidade em relação à sustentabilidade ambiental, os indicadores escolhidos devem ser aqueles que 
mais respondem ao uso e manejo e que causam maior impacto (LARSON \& PIERCE, 1994). Assim, um índice de qualidade do solo pode servir como indicador da capacidade do solo para a produção sustentável das culturas. O monitoramento da qualidade do solo é importante para detectar os problemas, e indicar ações corretivas necessárias (KARLEN \& STOTT, 1994).

Características indicadoras da qualidade do solo, para serem de utilidade prática, devem contemplar: propriedades e processos físicos, químicos e biológicos do solo; serem acessíveis aos usuários em termos de facilidade de medição, além de apresentarem o caráter de reprodutibilidade; serem aplicáveis em condições de campo, permitindo relacionar medidas obtidas em laboratório com o campo; possuírem critérios definidos para quantificar e interpretar seus valores; terem sensibilidade às variações de manejo e de clima, para permitir intervenções visando melhorar a qualidade do solo; permitirem avaliações de qualidade do solo de curto e de longo prazo, compondo bancos de dados pré ou pró-existentes (DORAN \& PARKIN, 1994; KARLEN \& STOTT, 1994; LARSON \& PIERCE, 1994; VEZZANI \& MIELNICZUK, 2009).

Contudo, uma definição para o tema qualidade do solo deve envolver a sua capacidade em sustentar a produção agrícola e a resistir à erosão. Devendo abordar ainda, a qualidade do ambiente em função da interação entre a qualidade do ar, da água e do solo, corroborando assim, para manutenção da qualidade do agroecossistema e promovendo o desenvolvimento das plantas e animais (DORAN \& PARKIN, 1994).

Os estudos sobre qualidade têm como base o uso de indicadores que monitoram atributos do solo relacionados à qualidade do ambiente agrícola. Estes indicadores avaliam as mudanças ocorridas nos atributos físicos, químicos e biológicos do solo (VEZZANI, 2001; D'ANDRÉA et al., 2002; BAYER et al., 2004; LOVATO et al., 2004; CONCEIÇÃO et al., 2005; SHUKLA et al., 2006; VEZZANI \& MIELNIEZUK, 2009).

Os atributos medidos para considerar a qualidade do solo são denominados de "indicadores". Dentre os atributos físicos são freqüentemente usados como indicadores para avaliar a qualidade do solo a textura, a densidade, a porosidade, a resistência do solo à penetração de raízes, a capacidade de retenção de água, a infiltração e 
transporte de água e a erosão (BRADY \& WEIL, 2002; D'ANDRÉA et al., 2002; CONCEIÇÃO et al., 2005; SHUKLA et al., 2006; ALVES et al., 2007). Dentre os atributos químicos citam-se $\mathrm{pH}$, disponibilidade de nutrientes, toxidez por alumínio e metais pesados (BAYER et al., 2004; LOVATO et al., 2004; LEAL et al., 2008) e dentre os atributos biológicos comumente utiliza-se da biomassa e matéria orgânica do solo (VEZZANI, 2001; WENDLING et al, 2005; VEZZANI \& MIELNIEZUK, 2009).

A preocupação com a qualidade do solo vem crescendo no Brasil, principalmente nas últimas décadas, com a adoção de técnicas de manejo que garantam a sustentabilidade do uso agrícola dos solos. Nesse contexto, o sistema de semeadura direta (SSD) tem se difundido e tornou-se uma boa opção, por ser uma técnica eficiente no controle das perdas de solo por erosão (DERPSCH et al., 1985; TORRES \& SARAIVA, 1998; LLANILLO et al., 2006). O interesse crescente neste sistema de cultivo está relacionado com a utilização permanente da cobertura do solo, associada ao uso e manejo conservacionistas que minimizam as perdas de solo por erosão (DERPSCH et al., 1985). Além da proteção do solo, outra característica importante do SSD reside no aumento dos teores de material orgânico, tendo como conseqüência alterações nas condições físico-químicas e biológicas do solo.

Apesar dos benefícios do SSD, tem-se observado, freqüentemente, redução da qualidade física dos solos em função de aumento da compactação superficial devido à ausência de revolvimento do solo e ao tráfego sistemático de máquinas e implementos (TORRES \& SARAIVA, 1998). Nos solos argilosos, a compactação é intensificada pelo excessivo tráfego sob condições de elevada umidade e pela ausência de rotação de culturas (OLIVEIRA et al., 2003).

Independente da distribuição espacial na paisagem e no perfil, a compactação do solo cria um ambiente desfavorável para o crescimento das plantas. A compactação promove alterações na estrutura do solo, uma vez que leva a um aumento da sua densidade associado à redução da porosidade, da continuidade dos poros e da permeabilidade (VOORHEES et al., 1978). Uma vez alteradas a porosidade e a densidade do solo, as suas propriedades físico-hídricas também irão variar. Em solos compactados, a redução no crescimento das plantas ocorre em associação com o 
aumento da resistência dos agregados na cama de semeadura e da resistência do solo à penetração de raízes (PASSIOURA \& GARDNER, 1990).

Em geral, os estudos avaliando a qualidade física dos solos se reportam às propriedades físicas com influência indireta sobre o desenvolvimento das plantas (CARDOSO et al., 1992; MARUN, 1996). A textura e a densidade do solo são utilizadas, isoladamente, como indicadores da qualidade física do solo, mas LETEY (1985) ressaltou que, apesar dessas propriedades condicionarem as práticas de manejo na agricultura, elas não estão diretamente relacionadas com a produtividade das culturas. O mesmo autor indicou que o potencial da água no solo, a taxa de difusão de oxigênio, a temperatura e a resistência mecânica para o crescimento das raízes e parte aérea, seriam indicadores mais adequados da qualidade física do solo para a produção das culturas, pois afetam diretamente o crescimento das plantas.

A degradação física do solo afeta diretamente a qualidade dos agroecossistemas (CARVALHO et al., 2004). O estudo da qualidade física do solo pode ser feito por meio das relações entre a massa e volume, pela da análise da densidade do solo (Ds), que é um dos atributos físicos mais empregados como indicador da sua qualidade (SILVA et al., 1994; De MARIA et al., 1999; IMHOFF et al. 2001; STONE \& SILVEIRA, 2001). De acordo com estes autores, práticas inadequadas de uso e manejo das áreas produtivas, como o preparo excessivo do solo, com uso de grade aradora contribui para alterar negativamente a Ds. O aumento nos valores de Ds tem causado diminuição da qualidade do solo (LIMA et al., 2005).

A Ds apresenta relação inversa à distribuição de poros do solo, ou seja, o aumento na Ds diminui a proporção de espaço vazio entre as partículas sólidas (poros) da relação massa/volume, afetando assim a porosidade, que também vem sendo usada como um indicador da qualidade do solo (SILVA et al., 1994; BEUTLER et al., 2001; OLIVEIRA et al., 2001; LIMA et al., 2005).

Segundo LIMA et al. (2005) a avaliação da porosidade do solo, por meio do estudo das classes de tamanho de poros, tem se mostrado um sensível indicador da sua qualidade, principalmente em seus estádios iniciais de deterioração. De acordo com LIMA et al. (2005), o monitoramento dos poros, classificados em seus estudos como 
bioporos, corroboram como fator essencial para a estimativa das condições do solo na análise da qualidade física dos sistemas produtivos, citando como exemplo a qualidade do solo sob citricultura.

Atributos físicos como a Ds e porosidade são fortemente influenciados pela classe textural (AZEVEDO \& BONUMÁ, 2004) e pelo teor de matéria orgânica do solo (Araújo et al., 2004). Um dos principais agentes de formação e estabilização dos agregados do solo é a matéria orgânica, que juntamente com óxidos de ferro e alumínio, conferem estabilidade ao solo (TISDALL \& OADES, 1982; CASTRO FILHO et al., 1998, 2002; PASSOS, 2000). Por esse motivo, entre outros, a matéria orgânica do solo também é considerada um eficiente indicador da qualidade do solo (VEZZANI, 2001; D'ANDRÉA et al., 2002; BAYER et al., 2004; LOVATO et al., 2004; CONCEIÇÃO et al., 2005; SHUKLA et al., 2006). Esse indicador reflete, com sensibilidade, as alterações induzidas ao solo pelas operações de preparo, como perda do seu aporte orgânico e decomposição acelerada dos resíduos vegetais após sua incorporação com o uso de aração e gradagem (CUNHA et al., 2001; BERTOL et al., 2004).

A formação dos agregados do solo deve-se principalmente pela ação das raízes e da macro-micro-fauna do solo, que ao se desenvolverem, promovem forças mecânicas que atuam na aproximação, organização e estruturação das partículas de areia, silte e argila presentes nos solos (TISDALL \& OADES, 1982). O arranjamento e agregação das partículas primárias nos solos (areia, silte e argila) formam a estrutura do solo, a qual também é considerado um indicador da qualidade do solo (SIX et al., 1999; MADARI et al., 2005; WENDLING et al, 2005). Contudo a estrutura é avaliada de maneira indireta, por meio da Ds, da porosidade e pela estabilidade de agregados do solo, que juntos refletem sensivelmente as alterações físicas sofridas pela estrutura conforme o manejo adotado no cultivo (D'ANDRÉA et al., 2002; ARGENTON et al., 2005).

Práticas inadequadas de uso e manejo das áreas produtivas, como o preparo excessivo do solo, com uso de grade aradora contribui para alterar negativamente a Ds. $O$ aumento nos valores de Ds dificulta a penetração das raízes no solo e tem causado diminuição da sua qualidade (STONE \& SILVEIRA, 2001; LIMA et al., 2005). A 
resistência do solo à penetração das raízes também é considerada por alguns autores, como indicador da qualidade do solo, pois, avalia o grau de compactação dos solos agrícolas (SILVA et al, 1994; TORMENA \& ROLOFF, 1996; De MARIA et al., 1999; ROSOLEM et al., 1999; BEUTLER et al., 2001; GUIMARÃES et al, 2002). A interação compactação/água/ar no solo influencia a resistência oferecida pelo solo à penetração das raízes, difusão do ar e disponibilidade de água e nutrientes para as plantas (SILVEIRA NETO et al., 2006).

A resistência tênsil dos agregados, outro componente da resistência do solo, é um dos atributos físicos amplamente utilizados como indicador da sua qualidade estrutural após as atividades de manejo (DEXTER \& KROESBERGEN, 1985, TORMENA et al., 2008a). Problemas no estabelecimento das culturas têm sido associados a condições físicas inadequadas da cama de semeadura decorrente de valores elevados de resistência dos agregados (LEY et al., 1993).

A avaliação da resistência tênsil é importante no estudo dos efeitos de sistemas de cultivo nas condições estruturais do solo e também pode ser utilizada para indicar as práticas de cultivo mais adequadas para efetuar o controle da qualidade física dos solos (TORMENA et al., 2008a). O grau de compactação do solo também poder ser analisado por meio da avaliação da resistência à penetração, que é fortemente influenciada pelo conteúdo de água no solo. Assim, quanto menor o teor da água no solo, maior será a sua resistência à penetração das raízes.

As informações sobre o assunto qualidade do solo são recentes, e de modo geral, monitoram as alterações nos atributos físicos, químicos e biológicos do solo (BRADY \& WEIL, 2002; D'ANDRÉA et al., 2002; BAYER et al., 2004; BEUTLER et al., 2004, 2005; CONCEIÇÃO et al., 2005; LIMA et al., 2005; WENDLING et al, 2005; SILVA et al., 2006a; VEZZANI \& MIELNICZUK, 2009). Atributos do solo estão diretamente ligados ao potencial produtivo das culturas, bem como, a sustentabilidade e qualidade física do recurso solo no ambiente agrícola. No meio cientifico há um consenso sobre a necessidade de adoção de um índice que reúna os indicadores de qualidade do solo (LEONARDO, 2002). Este índice deve ter a capacidade de medir e avaliar as mudanças nos atributos do solo, além de fornecer escala de valores a serem 
alcançados para manutenção de sua qualidade, devendo ainda, serem empregados na avaliação da interferência dos sistemas de produção que promovam menor impacto nos ecossistemas agrícolas (LEONARDO, 2002).

Neste contexto, o conhecimento da retenção de água no solo é essencial para a compreensão da infiltração, da redistribuição e da disponibilidade de água para as culturas (WALCZAK et al, 2006). A capacidade de um solo em reter e disponibilizar água para as plantas é representada pela sua curva de retenção de água (CRA). O estudo da CRA permite estabelecer um dos indicadores da qualidade física do solo. Mudanças condicionadas pela utilização agrícola dos solos podem modificar a qualidade do solo alterando as condições dos atributos químicos, físicos e biológicos do solo, afetando assim a CRA.

O índice S (Slope), recentemente proposto por DEXTER (2004a, b, c), é um parâmetro utilizado como indicador da qualidade física e estrutural do solo. $O$ valor de $S$ baseia-se fisicamente na CRA, a qual reflete a distribuição de poros do solo. Adotando o modelo capilar, a CRA é usualmente determinada através de medidas simultâneas do conteúdo de água $(U g)$ e da tensão da água no solo $(h)$ sob condições, teoricamente, de equilíbrio com um decréscimo lento e contínuo destas variáveis durante o processo. Neste contexto, e por descrever adequadamente a CRA, o modelo proposto por van GENUCHTEN (1980) é, provavelmente, a função matemática mais freqüentemente utilizada (DEXTER et al., 2008; TORMENA et al., 2008b). A determinação do valor do índice $S$ é feita com os dados de $U g(h)$ ajustados a uma função matemática e o "Slope" no ponto de inflexão da CRA calculado a partir das estimativas dos parâmetros da função. DEXTER (2004a) apresenta o desenvolvimento teórico para a obtenção do valor de $S$ a partir da definição da CRA, por meio do ajuste dos parâmetros do modelo de van GENUCHTEN (1980) aos dados de retenção de água no solo, calculado pela expressão matemática (Equação 1):

$\mathrm{S}=-\mathrm{n}\left(\mathrm{Ug}_{\mathrm{sat}}-\mathrm{Ug}_{\mathrm{res}}\right)\left[1+\frac{1}{\mathrm{~m}}\right]^{-(1+\mathrm{m})}$

em que: ${ }_{m=1-}\left(\frac{1}{n}\right)$, m e $n=$ coeficientes estimados do modelo (van GENUCHTEN, 1980); 
$U g_{\text {sat }}=$ saturação do solo; $U g_{\text {res }}$ conteúdo de água residual do solo.

$\mathrm{O}$ índice $\mathrm{S}$ é definido matematicamente como o valor da inclinação da curva de retenção no seu ponto de inflexão. $O$ valor do índice $S$ é um indicador da condição estrutural determinada pela microestrutura do solo que estabelece parte da porosidade estrutural, notadamente composta por uma rede de poros interligados (fendas, microfendas), sensíveis aos efeitos dos sistemas de uso e manejo do solo.

DEXTER (2004a) estabeleceu que os poros que ainda estão drenando (ou ocupados com água) no ponto de inflexão da CRA são considerados poros microestruturais (microfendas), que na sua totalidade determinam o "Slope" da CRA no ponto de inflexão. Este modelo sustenta a hipótese de que o índice $S$ governa inúmeras propriedades físico-hídricas importantes para um adequado funcionamento físico do solo. Segundo o autor, esse índice pode ser usado para avaliar a qualidade do solo em diferentes agrossistemas, em função das alterações no comportamento dos atributos relacionados à textura, densidade, porosidade, aporte orgânico, os quais estão ligados à dinâmica da água e estabilidade estrutural, como fendas, bioporos e poros macro e micro estruturais, resultantes do uso e manejo agrícola do solo (DEXTER, 2004a).

DEXTER \& BIRD (2001) afirmaram que o ponto de inflexão da CRA refere-se a ocasião em que a umidade retida no solo causa a menor deterioração estrutural no decorrer do manejo agrícola, podendo ser considerado como o momento ideal para cultivo do solo. Corroborando com esta afirmação, DEXTER \& BIRKAS (2004) E DEXTER et al. (2005) ressaltaram que o preparo do solo correlaciona-se negativamente com $\mathrm{S}$, pois, o teor de água no solo está intimamente ligado à sua degradação pelo manejo inadequado.

O sistema de manejo e preparo do solo é um grande modificador da condição estrutural do solo (PAGLIAI et al., 2004), mas é possível adotar práticas de manejo que minimizem seu efeito degenerativo, causando o mínimo de entropia aos sistemas produtivos, como é o caso das técnicas que envolvem o SSD.

O manejo intensivo do solo aumenta a Ds que tem relação inversa com $\mathrm{S}$ e a porosidade (DEXTER, 2004a). O índice $S$ avalia a porosidade estrutural do solo que corresponde aos poros interpartículas, fendas, bioporos e poros macroestruturais 
resultantes do uso e manejo, sendo o maior valor de índice $S$ equivalente a maior inclinação da CRA, indicando melhor distribuição de poros e maior quantidade de poros com maior diâmetro (DEXTER, 2004a).

Autores como GUPTA \& ALLMARAS (1987) E IMHOFF et al. (2001) relataram que a Ds, os macroporos e a relação macro:microporos, são atributos utilizados como indicadores da estabilidade e do estado estrutural do solo. DEXTER (2004a) observou que entre estes atributos a Ds proporcionou menor correlação com o índice $S$. CAMPBELL (1994) e BRONICK \& LAL (2005) afirmaram que pelo fato da Ds ser influenciada pelos constituintes do solo (dentre eles textura e matéria orgânica), esse parâmetro pode mostrar uma correlação limitada com o crescimento das plantas.

Mudanças na estrutura do solo pelo uso agrícola alteram a dinâmica do ar e da água no solo. A condutividade hidráulica do solo é um parâmetro que traduz a facilidade com que a água se movimenta ao longo do perfil de solo, e também pode ser usada na avaliação da qualidade do solo (LIMA et al., 2006). DEXTER (2004c) também relatou em seus estudos, que a condutividade hidráulica do solo tem correlação positiva com o índice S, pois há uma intima relação entre S e o comportamento da água no solo, que por sua vez dependem da qualidade estrutural do solo.

Os resultados apresentados por DEXTER (2004a) baseado em dados experimentais e estimativas de propriedades do solo, com funções de pedotransferência, comprovaram estas relações entre propriedades físicas do solo, justificando a utilização do índice $S$ como indicador da qualidade física e estrutural do solo. De acordo com DEXTER (2004a) um aumento nos valores do índice S (maior inclinação da CRA) indica que parte da porosidade do solo está organizada numa faixa mais estreita de tamanho de poros, definidas pela microestrutura do solo (DEXTER, 1988), estabelecendo condições estruturais que determinam um adequado funcionamento físico do solo.

Valores críticos do índice S foram sugeridos por DEXTER (2004a), o qual propôs que o valor do índice $S>0,035$ seja estabelecido como limite inferior a partir do qual as condições físicas são favoráveis para o crescimento das raízes. Segundo DEXTER (2004a), valores de $0,020<S<0,035$ são pouco favoráveis e $S<0,020$ são 
considerados altamente restritivos ao desenvolvimento radicular. Atualmente, estes limites são utilizados como valores do índice S para quantificar e monitorar os efeitos de sistemas de uso e manejo em termos da degradação e recuperação da qualidade física e estrutural dos solos.

O valor de "S" = 0,035 foi definido DEXTER (2004a), como a fronteira entre as condições adequadas e não-adequadas (ou impróprias) para a boa qualidade física do solo, abaixo da qual o desenvolvimento radicular sofre inibição. No Brasil não há uma indicação a este respeito. Assim, persiste aqui a necessidade de pesquisas que auxiliem a compreensão sobre o tema, e como o desenvolvimento e as produtividades das culturas se comportam diante desse valor de índice $S$, nas condições do clima brasileiro. Neste sentido, ANDRADE \& STONE (2009) verificaram que para as condições do cerrado brasileiro, o índice $S$ é altamente correlacionado com a densidade do solo, porosidade total e macroporosidade, mostrando tratar-se de um indicador adequado da qualidade física de solos. Segundo esses autores, o valor limite de $S=0,045$ mostrou-se adequado à divisão entre solo de boa qualidade estrutural e solo com tendências a se tornar degradado, enquanto valores de $S<0,025$ indicaram solos inteiramente degradados fisicamente. Portanto os resultados observados por Andrade \& Stone (2009) mostram-se diferentes dos valores propostos por DEXTER (2004a, b, c).

No Brasil, estudos referentes ao assunto, bem como o uso do tema qualidade do solo, ainda são incipientes e apresentam uma demanda científica. A estrutura do solo influencia diretamente a retenção de água, e é um dos parâmetros mais importantes para se avaliar a qualidade do solo, porque ela complementa o estudo de avaliação do arranjo entre sólidos e vazios. A formação e destruição da estrutura são processos dinâmicos e sua manutenção é, sem dúvida, um dos maiores objetivos quando se fala em qualidade do solo (TOPP et al., 1997). Esse contexto demonstra haver carência de informações sobre comportamento da estrutura do solo, principalmente a respeito da boa qualidade física do solo sob sequências de cultura de verão e inverno em SSD.

A hipótese do presente trabalho foi de que o índice $S$ seria capaz de detectar mudanças na estrutura do solo em função das sequências de culturas de verão e de inverno em SSD. O objetivo do presente trabalho foi quantificar os valores do índice $S$ 
em função das sequências de culturas em SSD, por meio de avaliações dos atributos indicadores da qualidade física de um Latossolo Vermelho argiloso situado em Jaboticabal-SP. Especificamente foram avaliados: i) o número mínimo de tensões para a determinação da curva de retenção de água no solo; ii) o índice S e sua correlação com os atributos físicos do solo e com a produtividade das culturas. 


\section{CAPÍTULO 2 - NÚMERO MÍNIMO DE TENSÕES PARA DETERMINAÇÃO DA CURVA CARACTERÍSTICA DE RETENÇÃO DE ÁGUA NO SOLO}

RESUMO - Para o conhecimento do comportamento físico-hídrico do solo é fundamental a determinação da curva de retenção de água (CRA). A aquisição de dados para obtenção da CRA envolve processos demorados e com custos elevados. Nesse sentido, a hipótese deste estudo foi a de que é possível determinar a CRA com um menor número de tensões reduzindo seu tempo de obtenção, sem, contudo, comprometer a acurácia dos resultados. Assim, o objetivo desse trabalho foi determinar quais tensões podem ser utilizadas para a determinação da CRA de maneira acurada e em menor tempo. Foram determinados os conteúdos de água retidos em amostras indeformadas de um Latossolo Vermelho eutrófico sob sistema de semeadura direta. As tensões utilizadas na determinação dos conteúdos de água foram: 0; 10;20;40; 60; 80; 100; 200; 300; 500; 700; 1000; 3000; 5000 e $15000 \mathrm{hPa}$. Os dados foram combinados e determinaram-se 450 CRAs ajustadas pelo modelo de van Genuchten. Os parâmetros $\alpha, m, n$ e $U g_{\text {res, }}$ gerados pelo modelo, foram submetidos à análise de variância (teste $\mathrm{F}$ ) e as médias comparadas pelo teste de Scott-Knott $(p=0,05)$. A hipótese deste estudo foi confirmada, ou seja, as combinações das tensões: 0; 80, 300, 700 e $15000 \mathrm{hPa}$ e 0; 100; 300; 1000 e 15000 hPa proporcionaram a determinação da curva característica de retenção de água do solo, ajustada pelo modelo de van Genuchten, com a mesma acurácia que uma curva com 15 tensões e em um período de tempo 5 vezes menor. $A$ tensão de $15000 \mathrm{hPa}$ é uma das tensões que deve estar contida na combinação de tensões a serem utilizadas para a determinação da CRA, quando se utiliza o modelo matemático de van Genuchten para ajuste dos dados. As CRAs, definidas com as combinações de tensões $(0 ; 60 ; 700 ; 15000 \mathrm{hPa}),(0 ; 80 ; 700 ; 15000 \mathrm{hPa}),(0 ; 100$; $1000 ; 15000 \mathrm{hPa}),(0 ; 20 ; 60 ; 100 ; 700 ; 15000 \mathrm{hPa}),(0 ; 80 ; 300 ; 700 ; 15000 \mathrm{hPa})$ e $(0 ;$ 100; 300; 1000; $15000 \mathrm{hPa}$ ), sendo os dados ajustados ao modelo de van Genuchten, proporcionaram estimativas dos conteúdos de água retidos no solo em diferentes 
tensões com a mesma acurácia, quando comparada a curva de referência partindo-se de um conjunto de 15 valores de tensões.

Palavras-Chave: modelo de van Genuchten, atributos físicos do solo, física do solo.

\subsection{INTRODUÇÃO}

Para a realização da fotossíntese com a subseqüente produção de carboidratos, fonte energética para o homem e para os animais, as plantas necessitam de água e nutrientes. Como apenas pequena quantidade de água pode ser armazenada dentro da própria planta, é a água armazenada no solo que permite a transpiração contínua por tempo maior, sem recarga por chuva ou irrigação (JON VAN LIER, 2000). Dessa forma, o solo, além de ser o ambiente de desenvolvimento das raízes, é também o reservatório natural de água e nutrientes para as plantas. Assim, o conhecimento da retenção de água no solo é essencial para a compreensão da infiltração, redistribuição e disponibilidade de água para as culturas (WALCZAK et al., 2006).

A capacidade de um solo em reter e disponibilizar água para as plantas é representada pela sua curva de retenção de água (CRA), que é a relação entre o conteúdo de água no solo e a tensão na qual ela está retida. Dessa forma, a CRA é elaborada pela determinação do conteúdo de água no solo em diferentes tensões. Normalmente, as tensões utilizadas para a determinação da CRA são selecionadas de forma arbitrária (SILVA et al., 2006a). Assim sendo, a variabilidade metodológica usada para medir a CRA é grande. De acordo com SILVA et al. (2006a), geralmente, são usados de seis a oito pontos de tensão na determinação da CRA, dependendo do modelo matemático adotado. Como não há uma padronização dos valores de tensão a serem utilizados, SILVA et al. (2006a) sugerem que a CRA deve ser determinada com o maior número de tensões possíveis. DEXTER et al. (2007) e MACHADO et al. (2008), em trabalhos que se utilizaram da CRA, a elaboraram utilizando onze tensões, 
enquanto BLAINSKI et al. (2008) e SILVA et al. (2008) utilizaram doze para sua determinação.

$\mathrm{Na}$ literatura são encontrados vários modelos matemáticos para o ajuste da CRA (DOURADO-NETO et al., 2000). O modelo proposto por van GENUCHTEN (1980) é, provavelmente, o mais utilizado para predizer os parâmetros que descrevem a CRA (DEXTER et al., 2008; TORMENA et al., 2008). Matematicamente, quanto maior for o número de tensões utilizadas na determinação do conteúdo de água, melhor será o ajuste do modelo aos dados e, consequentemente, a acurácia e representatividade da CRA. Entretanto, a utilização de um maior número de tensões para determinar a CRA torna o método lento e oneroso (HODNETT \& TOMASELLA, 2002; SILVA et al., 2006a). Adicionalmente, com a utilização de um grande número de tensões, aumenta-se o risco de alteração da estrutura do solo das amostras, devido à maior freqüência de manipulação das mesmas, o que acarretará baixa qualidade dos dados (MORAES et al., 1993).

O tempo para a determinação da CRA também aumenta em decorrência das tensões utilizadas. Para o método que utiliza a câmara de pressão de Richards para a determinação da CRA, o qual tem sido um dos mais utilizados (MACHADO, et al., 2008; SILVA et al., 2008; TORMENA et al., 2008), as amostras de solo atingem o equilíbrio físico-hídrico em menor tempo, quando submetidas às menores tensões ( $\leq 100 \mathrm{hPa})$, quando comparado às maiores tensões (> $100 \mathrm{hPa}$ ). Desse modo, para a determinação da CRA em menor tempo, deve-se priorizar, na medida do possível, um número maior de tensões de menores valores ( $\leq 100 \mathrm{hPa})$.

A utilização arbitrária de um determinado conjunto de tensões, sem um critério de seleção definido, pode resultar em uma estimativa da CRA não representativa do solo. Por isso, é fundamental a definição do número mínimo de tensões que resulte na determinação acurada da CRA, em menor intervalo de tempo. Nesse sentido, a hipótese deste estudo foi a de que é possível determinar a CRA com um menor número de tensões reduzindo seu tempo de obtenção, sem, contudo, comprometer a acurácia dos resultados. Assim, o objetivo desse trabalho foi determinar quais tensões podem 
ser utilizadas para a determinação da curva de retenção de água no solo de maneira acurada e visando menor tempo.

\subsection{MATERIAL E MÉTODOS}

O estudo foi realizado em amostras de solo retiradas em um experimento conduzido sob sistema de semeadura direta (SSD), desde o ano de 2002, no município

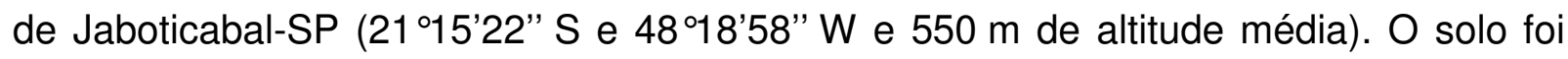
classificado como um Latossolo Vermelho eutrófico típico (LVe), de acordo com os critérios do Sistema Brasileiro de Classificação de Solos (EMBRAPA, 2006).

Amostras deformadas de solo foram retiradas na camada de 0-0,3 $\mathrm{m}$ para caracterização granulométrica, seguindo método proposto pela EMBRAPA (1997), cujos dados estão apresentados na Tabela 1.

Tabela 1. Valores médios, mínimos e máximos das quantidades de areia, silte e argila das amostras do Latossolo Vermelho eutrófico utilizadas na elaboração das curvas características de retenção de água do solo

\begin{tabular}{cccc}
\hline & Areia & $\begin{array}{c}\text { Silte } \\
\mathrm{g} \mathrm{kg}^{-1}\end{array}$ & Argila \\
\cline { 2 - 4 } Média geral & & 70 & 566 \\
Mínimo & 364 & 20 & 379 \\
Maximo & 199 & 114 & 720 \\
Desvio padrão & 567 & 21 & 87 \\
CV (\%) & 102 & 30 & 15 \\
\hline
\end{tabular}

Para a elaboração da curva característica de retenção de água do solo, em outubro de 2006, foram coletadas, nas camadas de $0,0-0,1 ; 0,1-0,2$ e 0,2-0,3 m do solo, um total de 189 amostras indeformadas de $0,05 \mathrm{~m}$ de diâmetro e 0,05 $\mathrm{m}$ de altura, utilizando-se anéis volumétricos. As amostras foram provenientes de 21 parcelas correspondentes a três blocos (repetições) de um dos tratamentos do experimento de longa duração (iniciado em 2002), conduzido em sistema de semeadura direta (CORÁ, 2006), mencionado anteriormente. O tratamento se constitui de uma seqüência de 
cultura de verão e sete culturas de inverno. A cultura de verão é a soja em monocultura (SV) e as culturas de inverno as seguintes: milho, girassol, nabo forrageiro, milheto, guandu, sorgo e crotalária, sendo cultivadas nas mesmas parcelas todos os anos. As amostras foram coletadas em replicatas. Portanto, totalizando 189 amostras indeformadas do solo (21 parcelas $\mathrm{x}$ três profundidades $\mathrm{x}$ três replicações).

As amostras foram colocadas para serem saturadas por água durante $24 \mathrm{~h}$, por meio da elevação gradual de uma lâmina de água até atingir cerca de $2 / 3$ da altura do anel. Em seguida, cada amostra foi submetida progressivamente às tensões: $0 ; 10 ; 20$; 40; 60; 80 e 100 hPa, utilizando-se mesa de tensão, e 200; 300; 500; 700; 1000; 3000; 5000 e 15000 hPa, utilizando-se câmara de pressão de Richards com placa porosa (KLUTE, 1986). A retenção de água nas tensões de 3000; 5000 e $15000 \mathrm{hPa}$ foram determinadas em amostras deformadas de solo, seguindo método proposto pela EMBRAPA (1997), no qual uma porção de terra fina seca ao ar, passada em peneira de $2 \mathrm{~mm}$ e acondicionadas em anel de borracha ou de PVC com 0,01 $\mathrm{m}$ de altura, é colocada diretamente sobre a placa porosa. Ao atingirem o equilíbrio hídrico em cada tensão, cada amostra foi pesada e, após serem submetidas à última tensão, foram secas em estufa a $105^{\circ} \mathrm{C}$ durante 24 h para determinação do conteúdo de água retido em cada tensão (GARDNER, 1986). Cada posição amostrada foi representada pelo dado médio das três replicas retiradas nas 21 parcelas e três profundidades, formando desse modo 63 amostras representativas da área em estudo. O conteúdo de água médio retido nas 63 amostras indeformadas de solo (médias das três replicatas) em cada uma das tensões aplicadas estão apresentados na Tabela 2.

\section{Modelos para o ajuste da curva de retenção de água no solo}

O conteúdo de água retido em cada uma das quinze tensões medidas nas 63 amostras indeformadas de solo foi utilizado para verificar a eficiência dos modelos sugeridos por DOURADO NETO et al. (2000), para o ajuste da curva de retenção de água (CRA). Os modelos matemáticos (Equações 1 a 8) testados foram: 
Modelo matemático:

van GENUCHTEN (1980)

$\mathrm{Ug}=\mathrm{Ug}_{\text {res }}+\frac{\mathrm{Ug}_{\text {sat }}-\mathrm{Ug}_{\text {res }}}{\left[1+(\alpha \mathrm{h})^{\mathrm{n}}\right]^{\mathrm{m}}}$

em que: $\alpha(\mathrm{hPa})$, n e m são parâmetros da curva de retenção de água no solo; $h$ é a tensão da água no solo (centímetros de coluna de água); Ug $g_{\text {sat }}$ e Ugres são o conteúdo de água na saturação e residual $\left(\mathrm{kg} \mathrm{kg}^{-1}\right)$, respectivamente.

BROOKS \& COREY (1964)

$\mathrm{Ug}=\mathrm{Ug}_{\text {res }}+\frac{\mathrm{Ug}_{\mathrm{sat}}-\mathrm{Ug}_{\text {res }}}{(\alpha \mathrm{h})^{\lambda}}$

em que: a e $\lambda$ são parâmetros da curva de retenção de água no solo;

DRIESSEN (1986)

$\mathrm{Ug}=\mathrm{Ug}_{\mathrm{sat}} \mathrm{h}^{-\gamma \cdot \ln (\mathrm{h})}$

em que: a e $\lambda$ são parâmetros da curva de retenção de água no solo;

Exponencial (BRUCE \& LUXMORE, 1986)

$\mathrm{Ug}=-\frac{1}{\beta} \ln \left(\frac{\mathrm{h}}{\alpha}\right)$

em que: $\alpha$ e $\beta$ são parâmetros da curva de retenção de água no solo;

FARREL \& LARSON (1972)

$\mathrm{Ug}=\left(\mathrm{Ug}_{\text {sat }}-\mathrm{Ug}_{\text {res }}\right)\left[1-\frac{1}{\alpha} \ln \left(\frac{\mathrm{h}}{\mathrm{h}_{\text {crit }}}\right)\right]+\mathrm{Ug}_{\text {res }}$

em que: $h_{\text {crit }}$ é a tensão critica da água no solo (centímetros de coluna de água);

LIBARDI et al. (1979)

$\mathrm{Ug}=\mathrm{Ug}_{\mathrm{res}}+\frac{1}{\beta} \ln \left(\frac{\mathrm{h}}{\alpha}+1\right)$

Potencial (BRUCE \& LUXMORE, 1986)

$\mathrm{Ug}=\left(\frac{\mathrm{h}}{\alpha}\right)^{-\frac{1}{\beta}}$ 
SIMMONS et al. (1974)

$\mathrm{Ug}=\mathrm{Ug}_{\mathrm{sat}}+\frac{1}{\beta} \ln \left(\frac{\mathrm{h}}{\alpha}+1\right)$

Os parâmetros dos modelos foram estimados pelo programa SWRC (DOURADO NETO et al., 2000). Cada amostra correspondeu a um bloco experimental, pois todos os tratamentos (modelos matemáticos) foram testados em cada amostra. Cada um dos modelos teve sua eficiência avaliada pela sua soma dos quadrados dos desvios (SQD), soma de quadrados das regressões (SQReg) e coeficiente de ajuste (CA). Os resultados da SQD, SQReg e CA dos modelos foram submetidos à análise de variância (teste F), seguindo esquema de blocos casualizados. Quando o valor de $F$ foi significativo a $5 \%$ de probabilidade, as médias foram submetidas ao teste de Scottknott, a $5 \%$ de probabilidade.

Tabela 2. Valores médios, mínimos e máximos do conteúdo de água $\left(\mathrm{kg} \mathrm{kg}^{-1}\right)$ retido nas amostras utilizadas na elaboração das curvas características de retenção de água do solo, em função das tensões aplicadas

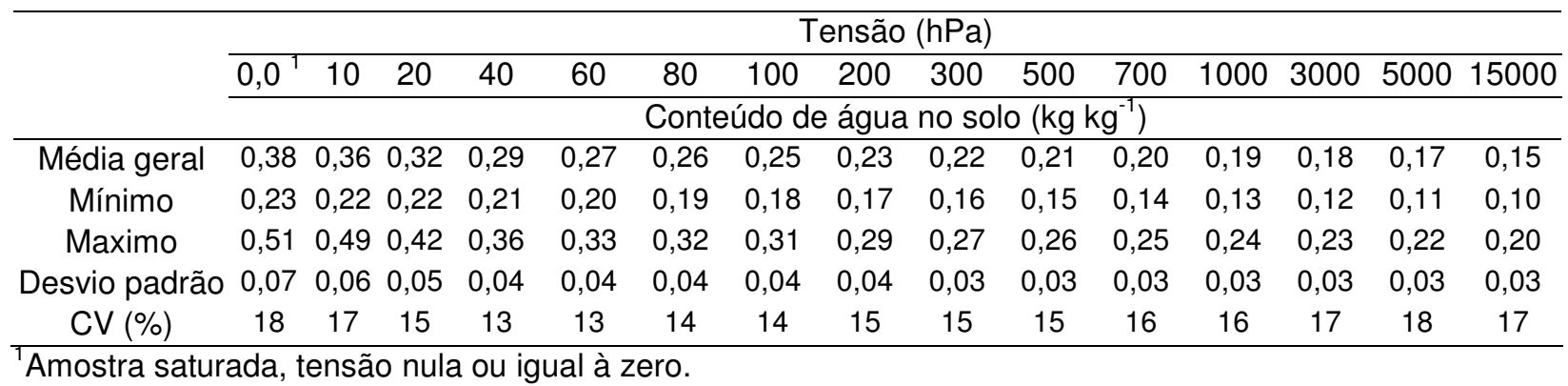

Tensões para determinação da curva de retenção de água no solo

Para verificar qual o menor número de tensões necessárias para determinar a CRA em menor tempo mantendo-se a acurácia, utilizou-se de dados de retenção de água no solo de 63 amostras do LVe sob SSD conduzido nas parcelas cultivadas com a seqüência de culturas de verão com soja. Com as 15 tensões medidas $(0 ; 10 ; 20 ; 40$; 
$60 ; 80 ; 100 ; 200 ; 300 ; 500 ; 700 ; 1000 ; 3000 ; 5000$ e $15000 \mathrm{hPa}$ ) foram feitas 450 combinações de tensões para o ajuste da CRA.

O conteúdo de água na saturação (tensão zero hPa) foi mantido para todas as combinações dos pontos utilizados nas curvas. O critério para escolha das tensões foi o de utilização do maior número possível de pontos de menores tensões $(<200 \mathrm{hPa})$, pois, quanto maior a tensão aplicada, maior é o tempo necessário para a obtenção dos dados e maiores são os problemas causados pelo efeito da histerese (MORAES et al., 1993).

A combinação que considerou as 15 tensões foi denominada curva $C 1$ e utilizada como referência para a comparação dos dados. Nove curvas com 14 tensões foram feitas excluindo-se uma das seguintes tensões de $C 1$ : 10; 80; 100; 500; 700; 1000; 3000; 5000 e 15000 hPa. Foram obtidas onze curvas com 13 tensões, excluindo-se um dos seguintes pares de tensões de C1: 20 e 500; 300 e 700; 3000 e 5000; 1000 e 3000; 700 e 1000; 500 e 1000; 500 e 700; 10 e 700; 10 e 5000; 10 e 3000 ou 1000 e $15000 \mathrm{hPa}$. Dezenove curvas foram determinadas com 12 tensões excluindo-se um dos seguintes conjuntos de três tensões de C1: (10; 500; 5000), (10; 200; 500), (10; 300; 500), (200; 500; 15000), (300; 500; 15000), (1000; 3000; 15000), (40; 500; 5000), (40; 200 ; 500), (40; 300; 500), (100; 200; 500), (100; 300; 500), (100; 300; 700), (200; 500; 700), (500; 1000; 5000), (1000; 3000; 5000), (200; 500; 3000), (200; 500; 5000), (1000; 5000 e 15000), e (3000; 5000 e $15000 \mathrm{hPa})$. As demais curvas de retenção de água (CRAs) foram determinadas excluindo-se tensões da curva $\mathrm{C} 1$ de forma aleatória, visando um número maior possível de pontos de menor tensão (Tabela 1a). Dessa maneira, 24 curvas foram determinadas com 11 tensões, 36 curvas com 10 tensões, 51 curvas com nove tensões, 61 curvas com oito tensões, 71 curvas com sete tensões, 64 curvas com seis tensões, 55 curvas com cinco tensões, 43 curvas com quatro tensões e cinco curvas com três tensões $(0 ; 10 ; 15000),(0 ; 20 ; 15000),(0 ; 60 ; 15000),(0 ; 80$; $15000)$ e $(0 ; 100 ; 15000) \mathrm{hPa}$, totalizando as 450 CRAs.

Os dados do conteúdo de água retido em cada tensão $(U g)$ foram ajustados pelo modelo de van GENUCHTEN (1980) (equação 1), para cada uma das 450 CRAs avaliadas. 
Os parâmetros do modelo de van GENUCHTEN (1980) foram estimados minimizando a soma dos quadrados dos desvios em relação à umidade, pelo método iterativo de Newton-Raphson (DOURADO NETO et al., 1990). Cada amostra correspondeu a um bloco experimental, pois todos os tratamentos (450 combinações) foram testados em cada amostra, visando isolar as diferenças entre amostras. Cada parâmetro do modelo de van GENUCHTEN (1980), para cada uma das 450 curvas, foi comparado ao parâmetro equivalente da curva $\mathrm{C} 1$. Os parâmetros foram submetidos à análise de variância (teste F), seguindo esquema de blocos casualizados. Quando o valor de $\mathrm{F}$ foi significativo a $5 \%$ de probabilidade, as médias foram submetidas ao teste de Scott-knott, a $5 \%$ de probabilidade. Para validar os resultados obtidos no presente estudo, ou seja, a eficiência relativa das CRAs, com menor número de tensões, comparativamente a curva de referência $(C 1)$, utilizou-se de outro conjunto de dados, (outras 63 amostras, média de três replicas), referentes a outro tratamento do experimento de longa duração, o qual é constituído por diferente seqüência de culturas de verão e inverno.

\subsection{RESULTADOS E DISCUSSÃO}

\section{Eficiência de Modelos na estimativa da Curva de retenção de água no solo}

Quando comparada a eficiência dos modelos matemáticos, apresentados por DOURADO NETO et al. (2000), para estimar a curva característica de retenção de água no solo verificou-se que o modelo de van GENUCHTEN (1980) foi o que melhor ajustou-se aos dados de retenção de água no solo (Tabela 3). O referido modelo diferiu estatisticamente dos demais modelos analisados, sendo o que apresentou a menor soma de quadrados dos desvios (SQD), a maior soma de quadrados de regressão (SQReg) e o maior coeficiente de ajuste (CA), o que confirmou sua eficácia em predizer a retenção de água no solo em estudo. COSTA et al. (2008) corroboram os resultados, 
pois verificaram que o modelo van GENUCHTEN (1980) apresentou-se ligeiramente melhor que o modelo de BROOKS E COREY (1964), modificado por HUSTSON \& CASS (1987). Contudo, GERSCOVICH (2001) verificou que os modelos Van GENUCHTEN (1980), BROOKS E COREY (1964) também indicaram um bom ajuste, no entanto, esses modelos não foram os que apresentaram os melhores resultados, independentemente do tipo de solo.

Desse modo, detectou-se que o modelo de van GENUCHTEN (1980) foi o que explicou da variação da retenção de água no solo, confirmando o que afirmam MACHADO et al. (2008), que verificaram que $99 \%$ da retenção de água no solo foi explicada pelo modelo de van GENUCHTEN (1980).

Tabela 3. Parâmetros estatísticos utilizados para comparação dos modelos matemáticos usados na determinação da curva de retenção de água no solo

\begin{tabular}{|c|c|c|c|c|c|c|}
\hline Tratamentos & & & statístic & & & \\
\hline Modelos matemáticos & SQD & & SQReg & & $\mathrm{CA}$ & \\
\hline Van Genuchten (1980) & 0,001 & e & 0,064 & a & 0,987 & a \\
\hline Brooks \& Corey (1964) & 0,005 & c & 0,060 & c & 0,935 & b \\
\hline Driessen (1986) & 0,011 & a & 0,054 & e & 0,852 & d \\
\hline Exponencial (Bruce \& Luxmore, 1986) & 0,006 & b & 0,058 & d & 0,914 & c \\
\hline Farrel \& Larson (1972) & 0,004 & d & 0,061 & b & 0,951 & b \\
\hline Libardi et al. (1979) & 0,004 & d & 0,061 & b & 0,946 & b \\
\hline Potencial (Bruce \& Luxmore, 1986) & 0,003 & d & 0,061 & b & 0,946 & b \\
\hline Simmons et al. (1974) & 0,004 & d & 0,061 & b & 0,947 & b \\
\hline C.V. (\%) & 5,3 & & 3,9 & & 3,9 & \\
\hline Teste $\mathrm{F}^{2}$ & $94,0^{* *}$ & & $93,7^{* *}$ & & $72,7^{* *}$ & \\
\hline
\end{tabular}

\section{Tensões para determinação da curva de retenção de água no solo}

Verificou-se uma considerável variação nos teores de argila do solo (379 a 720 $\mathrm{g} \mathrm{kg}^{-1}$ de argila) na área experimental (Tabela 1), o que proporcionou ajuste dos dados ao modelo matemático, as curvas de retenção de água no solo (CRA), a partir de dados obtidos sob uma ampla variação textural, o que tornam os resultados mais 
representativos. Como já verificado em outros trabalhos (HODNETT \& TOMASELLA, 2002; SILVA et al., 2008) e, o que corrobora os resultados obtidos no presente estudo, observou-se que quanto maior o teor de argila, maior foi o conteúdo de água retido no solo, para as diferentes tensões (Figura 1). SILVA et al. (2008) salientaram a forte influência do teor de argila na retenção de água no solo, em trabalho realizado com Latossolo Vermelho distrófico e com Latossolo Vermelho eutroférrico. Nesse sentido, a Figura 1 permite verificar a dependência do conteúdo de água no solo em relação ao teor de argila.

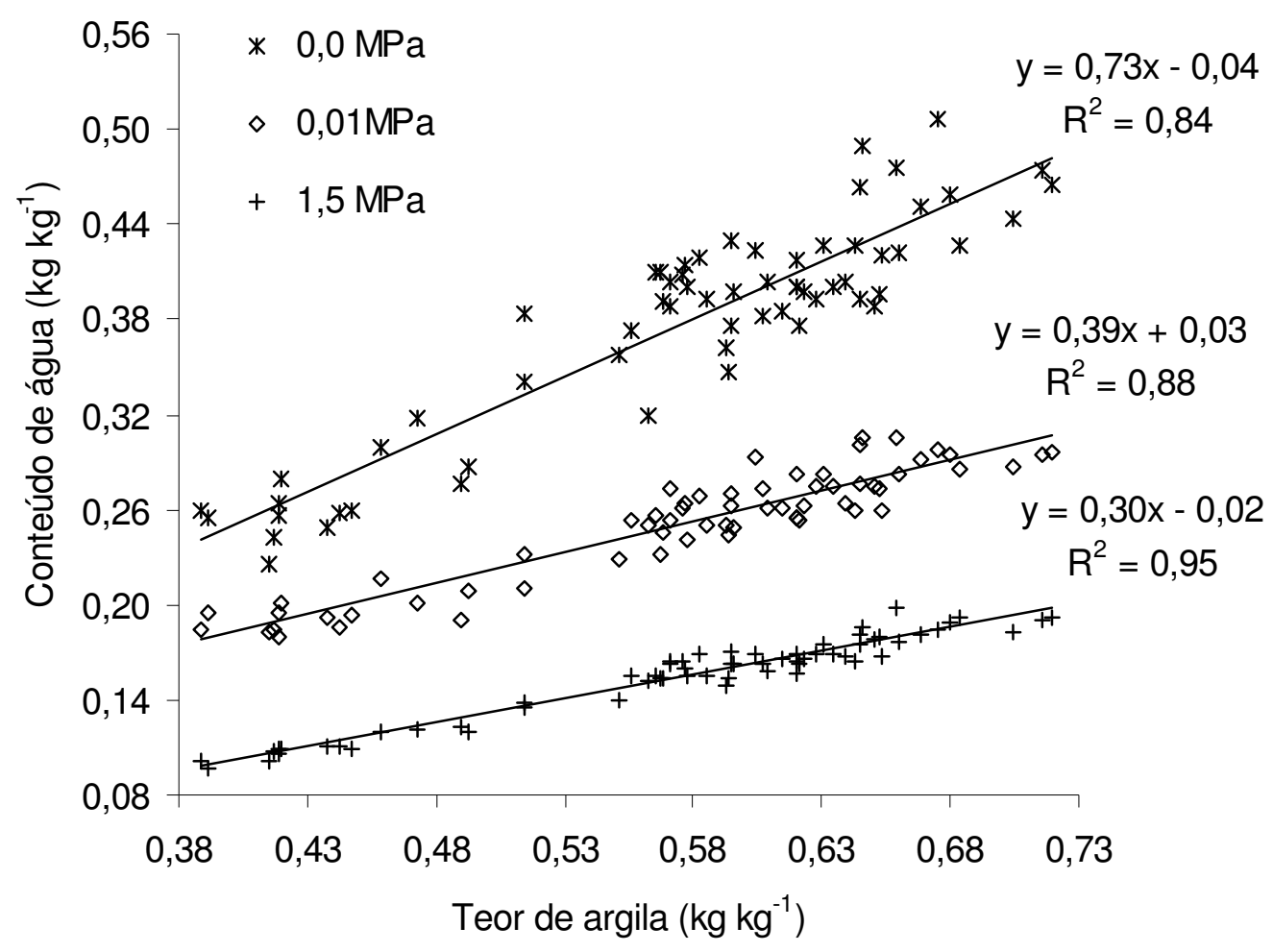

Figura 1. Figura mostrando a relação entre o teor de argila do solo e o conteúdo de água retida no solo nas tensões de 0; 100 e $15000 \mathrm{hPa}$.

Verificou-se que as combinações de valores de tensões e o número de tensões utilizadas influenciaram no ajuste dos dados ao modelo matemático de van Genuchten (Tabela 4 e 5). Somente um número reduzido de combinações de tensões (Tabela 5) proporcionou que todos os parâmetros do modelo de van Genuchten ( $\alpha, n, m$ e $\left.U g_{r e s}\right)$ 
apresentassem valores estatisticamente iguais $(p<0,01)$ àqueles da curva $C 1$, considerada como referência (Tabela 4). O critério de seleção utilizado para escolha das curvas estatisticamente iguais à $\mathrm{C} 1$ foi o de que todos os valores dos parâmetros do modelo de van Genuchten ( $\alpha, m, n$ e $U g_{\text {res }}$ ) fossem estatisticamente iguais (Tabela 2a), pelo teste de Scott-Knott $(p<0,05)$. Desse modo, as CRAs que apresentaram pelo menos um dos parâmetros do modelo de van Genuchten com valor diferente do seu respectivo na curva $\mathrm{C} 1$ foram consideradas estatisticamente diferentes de C1 (Tabela 4).

Verificou-se ainda, no presente estudo, que entre as 450 combinações de tensões propostas, aquelas que apresentaram valores de $\alpha, m, n$ e $U g_{\text {res }}$ estatisticamente diferentes daqueles da C1 (Tabela 4), não possuíam na combinação de valores de tensões propostas, a tensão de 15000 hPa (Tabela 5). Mesmo quando foi utilizada uma combinação com elevado número de tensões (12 tensões), esse fato ficou confirmado no presente estudo, o que explica a diferença observada entre as curvas na Figura 3 c, principalmente, a partir da tensão de $200 \mathrm{hPa}$.

No presente estudo, esse fato implica em afirmar que o modelo não estimou, adequadamente, o conteúdo de água retido do solo na tensão de 15000 hPa e que, ao se utilizar o modelo de van Genuchten para elaboração de uma curva característica de retenção de água do solo, deve-se incluir a tensão de $15000 \mathrm{hPa}$ no conjunto de tensões utilizadas para tal. Caso contrário é provável que se obtenham resultados incorretos de avaliação da retenção de água pelo solo e, conseqüentemente, da disponibilidade de água para as plantas. Assim como, incertezas na determinação de indicadores da qualidade física do solo derivados da CRA, como o índice S proposto por DEXTER (2004).

As combinações com os menores números de tensões e que proporcionaram valores dos parâmetros do modelo de van Genuchten ( $\alpha, m, n$ e $U g_{\text {res }}$ ) estatisticamente iguais àqueles da curva de referência $\mathrm{C} 1$ foram: 0; 80; 300; 700 e $15000 \mathrm{hPa}$ e 0; 100; 300; 1000 e $15000 \mathrm{hPa}$. (Tabela 4). Ou seja, as CRAs, definidas com uma dessas combinações de tensões, sendo os dados ajustados ao modelo de van Genuchten, possibilitaram, portanto, estimativas dos conteúdos de água retidos no solo em 
diferentes tensões, estatisticamente iguais àquelas encontradas quando se utilizou a curva de referência $\mathrm{C} 1$, com um conjunto de 15 valores de tensão, sendo eles: 0; 10; 20; 40; 60; 80; 100; 200; 300; 500; 700; 1000; 3000; 5000 e 15000 hPa (Figura 3 a).

Tabela 4. Valores médios dos parâmetros do modelo de van GENUCHTEN (1980) usados na determinação da curva de retenção de água no solo em função do número de tensões

\begin{tabular}{|c|c|c|c|c|c|c|c|}
\hline \multirow[b]{4}{*}{ Número de Tensões das Curvas } & \multicolumn{7}{|c|}{ Parâmetros do modelo de van GENUCHTEN (1980) } \\
\hline & \multirow{2}{*}{$\begin{array}{r}\alpha \\
h P a^{-1}\end{array}$} & \multirow{2}{*}{$\begin{array}{c}\mathrm{m} \\
-\end{array}$} & & \multirow{3}{*}{\multicolumn{2}{|c|}{$\begin{array}{c}n \\
-\end{array}$}} & \multirow{2}{*}{\multicolumn{2}{|c|}{$\begin{array}{r}\text { Ugres } \\
\mathrm{kg} \mathrm{kg}^{-1}\end{array}$}} \\
\hline & & & & & & & \\
\hline & \multicolumn{5}{|c|}{ Parâmetros estatisticamente iguais aos da $\mathrm{C} 1^{1}$} & & \\
\hline $15(\mathrm{C} 1)$ & $0,073 \mathrm{~g}$ & 0,292 & $\mathrm{y}$ & 1,413 & w & 0,154 & d \\
\hline 12 & $0,073 \mathrm{~g}$ & 0,292 & y & 1,414 & w & 0,154 & d \\
\hline 12 & $0,073 \mathrm{~g}$ & 0,292 & y & 1,415 & w & 0,154 & $d$ \\
\hline 11 & $0,074 \mathrm{~g}$ & 0,290 & y & 1,410 & w & 0,154 & $d$ \\
\hline 10 & $0,074 \mathrm{~g}$ & 0,289 & y & 1,409 & w & 0,154 & d \\
\hline 9 & $0,073 \mathrm{~g}$ & 0,289 & y & 1,407 & w & 0,154 & d \\
\hline 9 & $0,073 \mathrm{~g}$ & 0,292 & $y$ & 1,415 & w & 0,154 & $d$ \\
\hline 9 & $0,073 \mathrm{~g}$ & 0,289 & $y$ & 1,407 & w & 0,154 & $d$ \\
\hline 9 & $0,073 \mathrm{~g}$ & 0,289 & y & 1,409 & w & 0,154 & $d$ \\
\hline 5 & $0,074 \mathrm{~g}$ & 0,291 & $y$ & 1,412 & w & 0,154 & d \\
\hline \multirow[t]{2}{*}{5} & $0,075 \mathrm{~g}$ & 0,292 & $y$ & 1,413 & w & 0,154 & d \\
\hline & \multicolumn{7}{|c|}{ Um dos parâmetros estatisticamente diferentes aos da C1 } \\
\hline 11 & $0,073 \mathrm{~g}$ & 0,293 & $\mathrm{x}$ & 1,417 & w & 0,154 & $d$ \\
\hline 10 & $0,072 \mathrm{~h}$ & 0,291 & y & 1,413 & w & 0,154 & d \\
\hline 9 & $0,072 \mathrm{~h}$ & 0,292 & y & 1,415 & w & 0,154 & d \\
\hline 8 & 0,078 e & 0,291 & y & 1,413 & w & 0,154 & d \\
\hline 7 & $0,074 \mathrm{~g}$ & 0,295 & $\mathrm{x}$ & 1,421 & w & 0,154 & d \\
\hline 6 & $0,074 \mathrm{~g}$ & 0,296 & $x$ & 1,421 & w & 0,154 & d \\
\hline 5 & $0,076 \mathrm{f}$ & 0,293 & $x$ & 1,416 & w & 0,154 & $d$ \\
\hline 5 & 0,078 e & 0,292 & $y$ & 1,413 & w & 0,154 & $d$ \\
\hline 5 & $0,075 \mathrm{f}$ & 0,294 & $x$ & 1,417 & w & 0,154 & $d$ \\
\hline 5 & $0,077 \mathrm{f}$ & 0,291 & $y$ & 1,412 & w & 0,154 & $d$ \\
\hline 5 & $0,073 \mathrm{~g}$ & 0,294 & $x$ & 1,417 & w & 0,154 & $d$ \\
\hline 5 & $0,073 \mathrm{~g}$ & 0,300 & w & 1,430 & w & 0,154 & d \\
\hline 4 & $0,077 \mathrm{f}$ & 0,293 & y & 1,415 & w & 0,154 & d \\
\hline 4 & $0,073 \mathrm{~g}$ & 0,295 & $x$ & 1,419 & w & 0,154 & d \\
\hline \multirow[t]{2}{*}{4} & $0,074 \mathrm{~g}$ & 0,293 & $x$ & 1,416 & w & 0,154 & d \\
\hline & \multicolumn{7}{|c|}{ Todos os parâmetros estatisticamente diferentes aos da C1 } \\
\hline 12 & 0,055 I & 0,451 & e & 1,829 & f & 0,203 & $a$ \\
\hline 12 & $0,063 \mathrm{j}$ & 0,355 & $\mathrm{n}$ & 1,554 & $\mathrm{n}$ & 0,177 & $\mathrm{~b}$ \\
\hline 12 & $0,067 \mathrm{i}$ & 0,329 & $r$ & 1,493 & r & 0,169 & c \\
\hline Média geral & 0,070 & 0,311 & & 1,464 & & 0,157 & \\
\hline Mínimo & 0,014 & 0,274 & & 1,380 & & 0,154 & \\
\hline Máximo & 0,095 & 0,651 & & 2,869 & & 0,203 & \\
\hline Desvio Padrão & 0,01 & 0,05 & & 0,16 & & 0,06 & \\
\hline CV (\%) & 15,60 & 5,21 & & 3,40 & & 1,17 & \\
\hline Teste F & $73,9^{\star *}$ & $485,2^{* *}$ & & $622,2^{*}$ & & $718,2^{* *}$ & \\
\hline
\end{tabular}

${ }^{1}$ C1: curva de referência, ajustada a partir de 15 valores de tensão. Médias seguidas de mesma letra na coluna fazem parte do mesmo grupo estatístico (Scott-knott $p>0,05)$. ${ }^{*}$ significativo a $1 \%$ de probabilidade. 
Tabela 5. Tensões (hPa) utilizadas para o ajuste do modelo de van GENUCHTEN (1980) apresentadas na Tabela 4

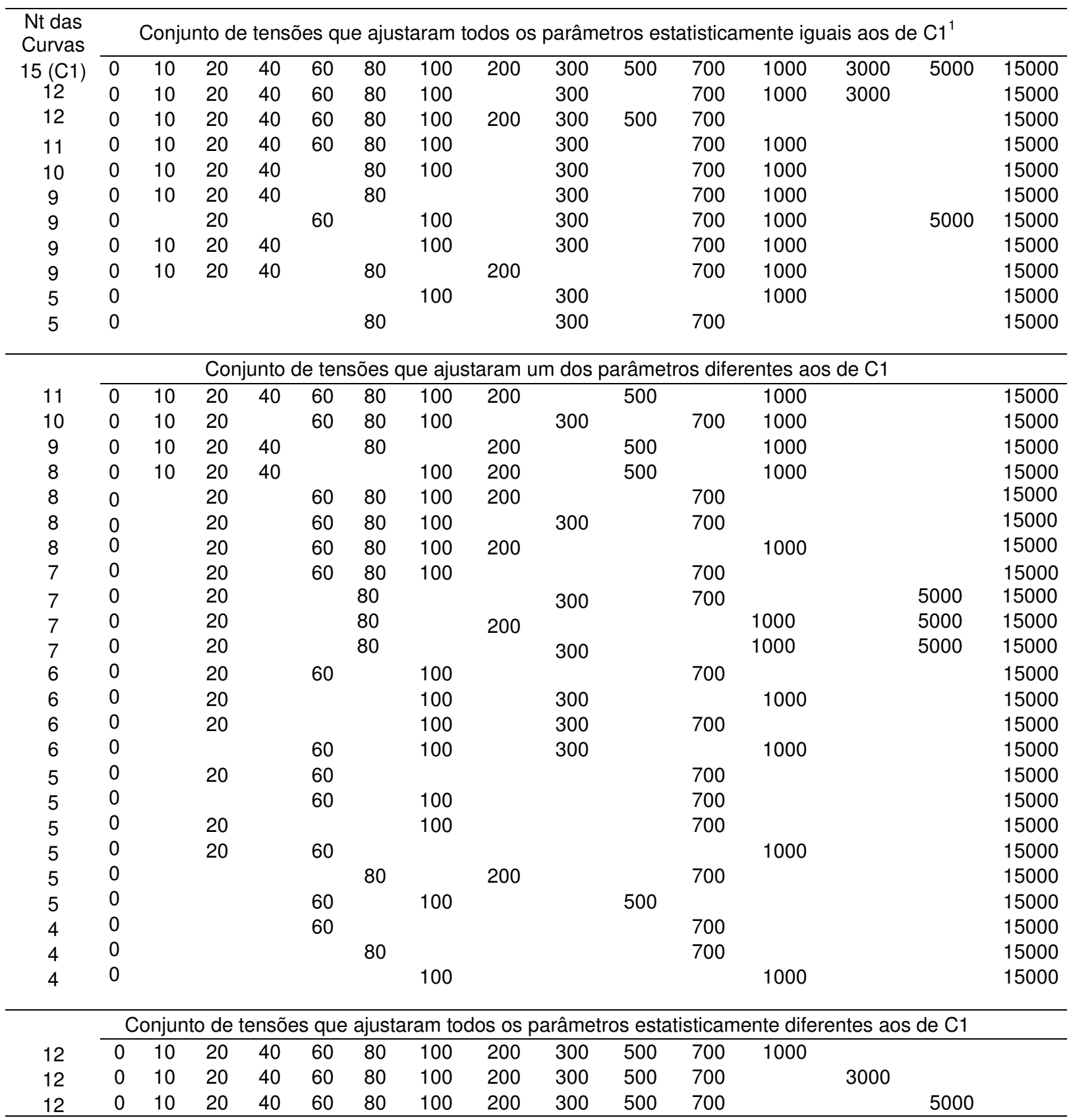

Nt: número de tensões. ${ }^{1} \mathrm{C} 1$ : curva de referência, ajustada a partir de 15 valores de tensão.

Entretanto, no presente estudo, no qual cada amostra, com dimensões de 0,05 m de diâmetro e $0,05 \mathrm{~m}$ de altura, foi submetida, sucessivamente, a todas as tensões 
propostas em cada combinação, o tempo gasto para elaboração de $\mathrm{C} 1$ foi de, aproximadamente, 150 dias. Já para a elaboração das CRAs, utilizando-se qualquer um dos seguintes conjuntos de tensões $(0 ; 80 ; 300 ; 700$ e $15000 \mathrm{hPa}),(0 ; 100 ; 300 ; 1000$ e $15000 \mathrm{hPa}$ ), foi de aproximadamente 30 dias, ou seja, um tempo cinco vezes menor do que aquele gasto na elaboração da curva $\mathrm{C} 1$.
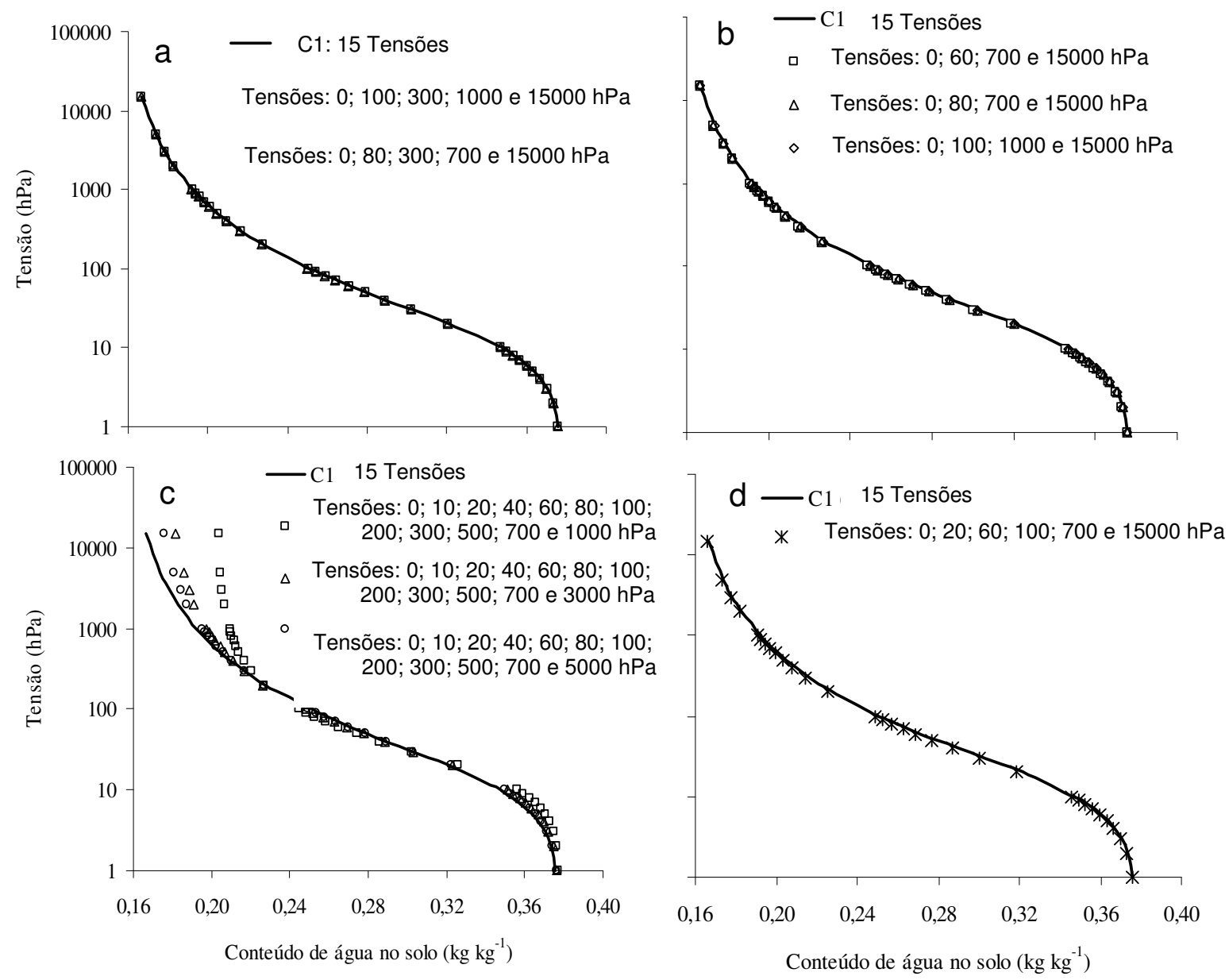

Figura 3. Curvas de retenção de água no solo com: (a) todos os parâmetros iguais aos da curva 1, (b e d) com pelo menos um dos parâmetros diferentes aos de $\mathrm{C} 1 \mathrm{e}$ (c) com todos parâmetros diferentes aos de $\mathrm{C} 1$, ajustados pelo modelo de van GENUCHTEN (1980).

Verificou-se, ainda, que as combinações com as tensões 0; 60; 700 e $15000 \mathrm{hPa}, 0 ; 80 ; 700$ e $15000 \mathrm{hPa}$, e $0 ; 100 ; 1000$ e $15000 \mathrm{hPa}$, todas com quatro 
valores de tensões, e a combinação 0; 20; 60; 100; 700 e 15000 hPa, com seis tensões, quando os dados de cada combinação foram ajustados ao modelo de van Genuchten, proporcionaram CRAs que apresentaram um dos parâmetros do modelo $(\alpha, m, n$ e $U g_{\text {res }}$ ) estatisticamente diferente do seu respectivo na curva de referência $\mathrm{C} 1$ (Tabela 4). Entretanto, essas CRAs proporcionaram estimativas dos conteúdos de água retidos no solo em diferentes tensões, estatisticamente iguais àquelas encontradas quando se utilizou a curva de referência C1 (Tabela 6 e Figuras 3 b e d). Utilizando-se qualquer uma dessas combinações, o tempo necessário para elaboração da CRA foi de, aproximadamente, 7 a 10 dias menor, quando comparado ao tempo necessário para se elaborar as CRAs, utilizando-se as combinações 0; 80; 300; 700 e $15000 \mathrm{hPa}$ ou $0 ; 100 ; 300 ; 1000$ e $15000 \mathrm{hPa}$, as quais apresentaram todos os valores dos parâmetros do modelo de van Genuchten ( $\alpha, m, n$ e $U g_{\text {res }}$ ) estatisticamente iguais àqueles da curva de referência $\mathrm{C} 1$.

O menor tempo se deve a substituição de tensões de menores valores ( $\leq 100 \mathrm{hPa}$ ), em detrimento a tensões de maiores valores (> $100 \mathrm{hPa})$, por ocasião da escolha da combinação de tensões utilizadas. Para as tensões de menores valores, o equilíbrio hídrico das amostras é atingido em menor tempo, ou seja, aproximadamente um dia para cada tensão em mesa de tensão de areia (LIMA \& SILVA, 2008). Portanto, diminuindo o tempo e os custos para a determinação da parte inicial da CRA, o que possibilita a otimização do processo.

No entanto, para a determinação do conteúdo de água retido entre as tensões de 100 e 1000 hPa é necessário a utilização do aparelho extrator de Richards, o que torna a determinação da CRA um processo mais demorado, quando se utiliza maior números de tensões de maior valor. Para esse intervalo de tensões, o equilíbrio hídrico das amostras indeformadas de solo (anéis de altura e diâmetro de 0,05 $\mathrm{m}$ ) pode demorar até 30 dias para ser atingido para cada tensão, dependendo da textura do solo. No presente estudo, o tempo gasto para que o equilíbrio hídrico das amostras fosse atingido foi de aproximadamente 20 dias para cada tensão aplicada.

Apesar de ser considerada tensão de alto valor, o equilíbrio hídrico das amostras de solo submetidas à tensão de $15000 \mathrm{hPa}$ na câmara de Richards, foi atingido, no 
presente estudo, em tempo relativamente curto, ou seja, de aproximadamente três dias. Isso foi possível porque foram utilizadas amostras indeformadas de solo com 0,01 m de altura. Para tensões com valores maiores que $1000 \mathrm{hPa}$ pode-se utilizar amostras deformadas de terra com menores alturas, as quais são acondicionadas em anéis de borracha ou PVC, e submetidas às tensões diretamente sobre a placa porosa, utilizada na câmara de Richards (EMBRAPA, 1997). Dessa maneira, as amostras atingem o equilíbrio hídrico em menor tempo, quando comparado ao tempo, relativamente maior (aproximadamente vinte dias), para a determinação do conteúdo de água, em amostras indeformadas de solo, acondicionadas em anéis volumétricos com altura da amostra de $0,05 \mathrm{~m}$. Porém, esse procedimento é recomendado somente para determinação de conteúdos de água em amostras de solo nas tensões maiores que $1000 \mathrm{hPa}$ (EMBRAPA, 1997), pois, a retenção de água nesses casos tem maior relação com o teor de argila do solo do que com sua estrutura (HODNETT \& TOMASELLA, 2002; SILVA et al., 2008).

Tabela 6. Valores médios da retenção de água no solo calculados pelo modelo de van GENUCHTEN (1980) em diferentes tensões em função do conjunto de tensões utilizadas para o ajuste dos parâmetros da curva de retenção de água no solo

\begin{tabular}{ccccccccc}
\hline & \multicolumn{10}{c}{ Tensão $(\mathrm{hPa})$} \\
\cline { 2 - 9 } Número de Tensões das Curvas & 10 & 20 & 60 & 100 & 200 & 300 & 1000 & 15000 \\
\hline $15(\mathrm{C} 1)^{1}$ & 0,35 & 0,32 & 0,27 & 0,25 & 0,23 & 0,22 & 0,19 & 0,17 \\
$6^{2}$ & 0,35 & 0,32 & 0,27 & 0,25 & 0,23 & 0,22 & 0,19 & 0,17 \\
$5^{3}$ & 0,35 & 0,32 & 0,27 & 0,25 & 0,23 & 0,22 & 0,19 & 0,17 \\
$4^{4}$ & 0,35 & 0,32 & 0,27 & 0,25 & 0,23 & 0,22 & 0,19 & 0,17 \\
$\mathrm{CV}^{5}$ & 1,2 & 1,5 & 1,4 & 1,3 & 1,3 & 1,2 & 1,1 & 1,1 \\
\hline
\end{tabular}

1, 2, 3 e 4 : Valores médios estimados pelos parâmetros do modelo de van Genuchten (1980) ajustados à Curva C1 (15 tensões: 0 ; 10 . $20 ; 40 ; 60 ; 80 ; 100 ; 200 ; 300 ; 500 ; 700 ; 1000 ; 3000 ; 5000$ e $15000 \mathrm{hPa})$; Curva com seis tensões $(0 ; 20 ; 60 ; 100 ; 700$ e 15000 hPa); Curvas com cinco tensões $(0 ; 100 ; 300 ; 1000$ e $15000 \mathrm{hPa}$; ou $0 ; 80 ; 300 ; 700$ e $15000 \mathrm{hPa})$ e Curvas com quatro tensões $(0 ; 60$; 700e $15000 \mathrm{hPa}$; 0; 80; 700 e $15000 \mathrm{hPa}$; ou 0; 100; 1000 e $15000 \mathrm{hPa}$ ), respectivamente. ${ }^{5}$ : Coeficiente de variação da estimativa dos valores de retenção de água no solo para as combinações de curvas.

$\mathrm{Na}$ literatura, são escassas as informações sobre quais tensões devem ser usadas na determinação da CRA. SILVA et al. (2006a), ao avaliarem quais e quantas tensões devem ser levadas em conta na determinação da CRA de solos sob Cerrado, utilizando centrífuga, recomendaram oito tensões, sendo elas: 10;30;60;100;350; 
840; 6110 e $15150 \mathrm{hPa}$. Os autores afirmaram ainda, que curvas com menos de oito tensões não devem ser utilizadas.

A EMBRAPA (1997) recomenda, para a determinação da CRA, obtida com aparelho de extrator de Richards, as seguintes tensões: 100; 330; 1000; 5000 e $15000 \mathrm{hPa}$. No presente estudo, verifcou-se que o tempo gasto para determinar as CRAs, utilizando-se qualquer um dos seguintes conjuntos de tensões: $(0 ; 80 ; 300 ; 700$ e $15000 \mathrm{hPa}),(0 ; 100 ; 300 ; 1000$ e $15000 \mathrm{hPa}),(0 ; 20 ; 60 ; 100 ; 700$ e $15000 \mathrm{hPa})$ foi menor que o tempo necessário para a determinação da CRA, utilizando-se o conjunto de tensões recomendado pela EMBRAPA (1997) e com a mesma acurácia que C1.

Visando validar os resultados obtidos no presente estudo, ou seja, a eficiência relativa das CRAs, com menor número de tensões e mesma acurácia, quando comparadas com a curva de referência (C1), utilizou-se novo conjunto de dados (outras 63 amostras), referente a outro tratamento do experimento de longa duração, o qual é constituído por diferente seqüência de culturas de verão e inverno. Portanto, valores dos conteúdos de água retidos no solo em diferentes tensões, provenientes de amostras indeformadas do solo de outro tratamento, foram ajustados ao modelo de van Genuchten, utilizando-se os seguintes conjuntos de tensões: $(0 ; 80 ; 300 ; 700$ e $15000 \mathrm{hPa}),(0 ; 100 ; 300 ; 1000$ e $15000 \mathrm{hPa}),(0 ; 20 ; 60 ; 100 ; 700$ e $15000 \mathrm{hPa}),(0 ; 60$; 700 e $15000 \mathrm{hPa}),(0 ; 80 ; 700$ e $15000 \mathrm{hPa})$ e $(0 ; 100 ; 1000$ e $15000 \mathrm{hPa})$, os quais se mostraram, inicialmente, eficientes para estimar o conteúdo de água retido no solo, quando comparados a curva de referência $\mathrm{C} 1$, porém, com um menor número de tensões e em menor período de tempo.

Verificaram-se diferentes valores dos parâmetros $m$ e $n$ do modelo de van Genuchten, quando comparados àqueles da curva de referência $\mathrm{C} 1$, para as combinações com quatro valores de tensões $(0 ; 60 ; 700$ e $15000 \mathrm{hPa}, 0 ; 80 ; 700$ e $15000 \mathrm{hPa}$ e $0 ; 100 ; 1000$ e $15000 \mathrm{hPa})$ e com seis valores $(0 ; 20 ; 60 ; 100 ; 700$ e $15000 \mathrm{hPa}$ ). Para as combinações $0 ; 80 ; 300 ; 700 ; 15000 \mathrm{hPa}$ e 0; 100; 300; 1000 e $15000 \mathrm{hPa}$, os valores dos parâmetros de van Genuchten foram iguais aos respectivos da curva C1 (Tabela 7). 
Tabela 7. Valores médios dos parâmetros do modelo de van GENUCHTEN (1980) usados para validação das combinações com menor número de tensões

\begin{tabular}{|c|c|c|c|c|c|c|c|c|}
\hline Número de Tensões das Curvas & $\begin{array}{c}\alpha \\
\mathrm{hPa}^{-1}\end{array}$ & & $\begin{array}{l}m \\
-\end{array}$ & & $\begin{array}{l}n \\
-\end{array}$ & & $\begin{array}{c}U g_{\text {res }} \\
\mathrm{kg} \mathrm{kg}^{-1}\end{array}$ & \\
\hline $15(\mathrm{C} 1)^{1}$ & 0,081 & $a$ & 0,283 & $b$ & 1,396 & $b$ & 0,148 & a \\
\hline $6^{2}$ & 0,085 & a & 0,288 & a & 1,405 & a & 0,148 & a \\
\hline $5^{3}$ & 0,083 & a & 0,283 & $b$ & 1,395 & $b$ & 0,148 & a \\
\hline $4^{4}$ & 0,082 & a & 0,288 & a & 1,405 & a & 0,148 & $\mathrm{a}$ \\
\hline $\mathrm{CV} \%{ }^{5}$ & 13 & & 2,9 & & 1,2 & & 0,1 & \\
\hline Teste F & 1,7 & ns & 9,7 & ** & 9,18 & ** & 0,1 & ns \\
\hline
\end{tabular}

1, 2, 3 e 4 : Valores médios estimados dos parâmetros do modelo de van Genuchten (1980) ajustados à Curva C1 (15 tensões: $0 ; 10$ $20 ; 40 ; 60 ; 80 ; 100 ; 200 ; 300 ; 500 ; 700 ; 1000 ; 3000 ; 5000$ e $15000 \mathrm{hPa})$; Curva com seis tensões (0; 20; 60; $100 ; 700$ e 15000 hPa); Curvas com cinco tensões $(0 ; 100 ; 300 ; 1000$ e $15000 \mathrm{hPa}$; ou 0; 80; 300; 700 e $15000 \mathrm{hPa})$ e Curvas com quatro tensões (0; 60; 700 e $15000 \mathrm{hPa}$; 0; 80; 700 e $15000 \mathrm{hPa}$; ou 0; 100; 1000 e $15000 \mathrm{hPa}$ ), respectivamente. ${ }^{5}$ : Coeficiente de variação dos parâmetros de van Genuchten (1980), para validação das combinações de curvas.

Quando se observam os dados apresentados na Tabela 8, entretanto, verificamse que esses conjuntos de tensões proporcionaram estimativas dos conteúdos de água retidos no solo, estatisticamente iguais àquelas encontradas quando se utilizou a curva de referência $\mathrm{C} 1$. Esse fato demonstra, portanto, que, mesmo utilizando-se outro conjunto de dados, os resultados foram semelhantes aqueles observados com 0 conjunto de dados inicial, o que valida os resultados encontrados no presente estudo.

Tabela 8. Valores médios da retenção de água no solo calculados pelo modelo de van GENUCHTEN (1980) em diferentes tensões em função das combinações com menor número de tensões utilizadas para validação do ajuste dos parâmetros da curva de retenção de água no solo

\begin{tabular}{cccccccccc}
\hline & \multicolumn{10}{c}{ Tensão $(\mathrm{hPa})$} \\
\cline { 2 - 9 } Número de Tensões das Curvas & 10 & 20 & 60 & 100 & 200 & 300 & 1000 & 15000 \\
\hline $15(\mathrm{C} 1)^{1}$ & 0,34 & 0,31 & 0,26 & 0,25 & 0,22 & 0,21 & 0,19 & 0,16 \\
$6^{2}$ & 0,33 & 0,31 & 0,26 & 0,24 & 0,22 & 0,21 & 0,19 & 0,16 \\
$5^{3}$ & 0,34 & 0,31 & 0,26 & 0,25 & 0,22 & 0,21 & 0,19 & 0,16 \\
$4^{4}$ & 0,34 & 0,31 & 0,26 & 0,24 & 0,22 & 0,21 & 0,19 & 0,16 \\
$\mathrm{CV}^{4}$ & 1,5 & 1,3 & 1,2 & 1,3 & 1,4 & 1,4 & 1,6 & 1,8 \\
\hline
\end{tabular}

1, 2, 3 e 4 : Valores médios estimados pelos parâmetros do modelo de van Genuchten (1980) ajustados à Curva C1 (15 tensões: 0 ; 10 ; $20 ; 40 ; 60 ; 80 ; 100 ; 200 ; 300 ; 500 ; 700 ; 1000 ; 3000 ; 5000$ e $15000 \mathrm{hPa})$; Curva com seis tensões $(0 ; 20 ; 60 ; 100 ; 700$ e 15000 hPa); Curvas com cinco tensões $(0 ; 100 ; 300 ; 1000$ e $15000 \mathrm{hPa}$; ou $0 ; 80 ; 300 ; 700$ e $15000 \mathrm{hPa})$ e Curvas com quatro tensões (0; 60 ; 700 e $15000 \mathrm{hPa} ; 0 ; 80 ; 700$ e $15000 \mathrm{hPa}$; ou 0; 100; 1000 e $15000 \mathrm{hPa}$ ), respectivamente. ${ }^{5}$ : Coeficiente de variação da estimativa dos valores de retenção de água no solo para validação das combinações de curvas. 
Esse fato implica em afirmar que é possível estimar o conteúdo de água retido no solo, utilizando-se uma curva característica de retenção de água do solo com menor número de tensões e em menor período de tempo com acurácia adequada. Contudo, é essencial definir quais as tensões que serão utilizadas no modelo matemático de van Genuchten, que proporcionem resultados e custos desejados.

\subsection{CONCLUSÕES}

1. A hipótese deste estudo foi confirmada, ou seja, para as condições do presente estudo, as combinações das tensões: 0; 80, 300, 700 e $15000 \mathrm{hPa}$ e 0; 100; 300; 1000 e $15000 \mathrm{hPa}$ proporcionaram a determinação da curva característica de retenção de água do solo, ajustada pelo modelo de van Genuchten, com a mesma acurácia que uma curva com 15 tensões e em um período de tempo 5 vezes menor.

2. A tensão de $15000 \mathrm{hPa}$ é uma das tensões que deve estar contida na combinação de tensões a serem utilizadas para a determinação da curva característica de retenção de água, quando se utiliza o modelo matemático de van Genuchten para ajuste dos dados.

3. As curvas características de retenção de água do solo, definidas com as combinações de tensões $(0 ; 60 ; 700 ; 15000 \mathrm{hPa}),(0 ; 80 ; 700 ; 15000 \mathrm{hPa}),(0 ; 100$; $1000 ; 15000 \mathrm{hPa}),(0 ; 20 ; 60 ; 100 ; 700 ; 15000 \mathrm{hPa}),(0 ; 80 ; 300 ; 700 ; 15000 \mathrm{hPa})$ e $(0$; $100 ; 300 ; 1000 ; 15000 \mathrm{hPa}$ ), sendo os dados ajustados ao modelo de van Genuchten, proporcionaram estimativas dos conteúdos de água retidos no solo em diferentes tensões com a mesma acurácia, quando comparada a curva de referência partindo-se de um conjunto de 15 valores de tensões. 


\title{
CAPÍTULO 3 - ÍNDICE S E ATRIBUTOS FÍSICOS DE UM LATOSSOLO VERMELHO SOB SISTEMA DE SEMEADURA DIRETA
}

\begin{abstract}
RESUMO - A avaliação da qualidade dos solos sob uso agrícola tornou-se fundamental para estabelecer estratégias de manejo sustentáveis. A hipótese desse trabalho foi a de que o Latossolo Vermelho argiloso, em sequências de culturas sob sistema de semeadura direta de longa duração, pode ter sua produtividade e qualidade física influenciada segundo o esquema de rotação de culturas adotado. O presente estudo teve como objetivos: i) determinar o índice $S$ e caracterizar as transformações nos atributos do solo e ii) verificar a qualidade do solo correlacionando o índice S com os atributos físicos do solo e com a produtividade das culturas. O delineamento utilizado foi o de blocos em faixas com três repetições. Os tratamentos foram constituídos pela combinação de dois fatores: quatro sequências de culturas de verão (milho em monocultura - MV; soja em monocultura - SV; rotação soja/milho - RT; e rotação arroz/feijão/algodão - AF); e sete culturas de inverno (milho; girassol; nabo forrageiro; milheto; guandu, sorgo e crotalária). As camadas de solo foram avaliadas nas profundidades de $0-0,1 ; 0,1-0,2$; e 0,2-0,3 m. Os dados foram submetidos à análise de variância (teste F) e suas médias comparadas pelo teste de Scott-Knott (5\% de probabilidade). A seqüência de culturas de verão AF proporcionou os maiores valores do índice $S$. Para as sequências de culturas de inverno os maiores valores médios de $S$ foram observados nas culturas de crotalária e sorgo. Verificou-se que os menores valores do índice $S$ ocorreram na camada de 0,1-0,2 m. O índice $S$ foi eficiente na avaliação da qualidade física do solo, apresentando correlação significativa com os atributos físicos do solo, contudo, não foi verificada a relação do índice S com a produtividade das culturas.
\end{abstract}

Palavras-Chave: sequência de culturas, atributos físicos, índice S. 


\subsection{INTRODUÇÃO}

A adoção de práticas conservacionistas de uso do solo vem crescendo nas últimas décadas. O sistema de semeadura direta (SSD) tem se destacado como prática manejo para a conservação da água e do solo. No SSD o preparo ou a mobilização do solo é realizada apenas na linha de semeadura, tendo como um dos objetivos a manutenção da cobertura vegetal sobre o solo, acarretando menores perdas de solo por erosão, além de tornar o processo de semeio mais rápido. Esse aspecto assume grande importância na semeadura de safrinha ou culturas de inverno, onde o período de cultivo no outono/inverno é bastante curto, principalmente pela falta de chuvas.

Em SSD, a adoção de sistemas de rotação de culturas tem sido preconizada para o manejo físico, químico e biológico do solo. Do ponto de vista da física do solo, tem-se estimulado a adoção da rotação de culturas para manter e/ou aumentar os teores de matéria orgânica, criar poros biológicos, melhorar a estrutura e manter palha suficiente na superfície do solo (ANDRADE et al., 2009). A bioporosidade criada pela atividade radicular e mesofauna do solo e a possibilidade das raízes de algumas culturas penetrarem camadas mais compactadas, têm sido o motivo de se considerar a rotação de culturas fundamental em SSD. Estratégias de manejo que mantêm ou adicionam carbono ao solo, têm bom potencial para a melhoria da qualidade física do solo para o crescimento das plantas (ANDRADE et al., 2009).

O revolvimento mínimo do solo no SSD favorece ao acúmulo de material orgânico na superfície do solo, resultando em menores taxas de decomposição do material orgânico e em menores perdas por erosão (ANDRADE et al., 2009). O resíduo vegetal deixado superficialmente, decompõe mais lentamente quando não é incorporado, porque fica menos exposto aos microrganismos do solo (BAYER \& MIELNICZUK, 1997). Conforme BAYER \& MIELNICZUK (1997); CORAZZA et al. (1999); AMADO et al. (2001) a matéria orgânica do solo também fica menos exposta ao ataque dos microrganismos, pois sem o revolvimento do solo, não há quebra das estruturas que a protegem fisicamente dos agentes decompositores; possibilitando assim, aumento nos teores de matéria orgânica da camada superficial de solo no SSD. 
De acordo com BAYER et al. (2000) e AMADO et al. (2001) a quantidade de resíduo vegetal deixado na superfície e a quantidade de matéria orgânica acumulada no solo, são dependentes da sequência de culturas adotadas no SSD, pois sistemas que incluem culturas de verão e inverno com alta produção de matéria seca e culturas com baixa relação $\mathrm{C} / \mathrm{N}$ resultam, geralmente, em maiores acúmulos de matéria orgânica no solo. Em sua revisão, ANDRADE et al. (2009), ao citarem outras pesquisas relataram que os resíduos vegetais de leguminosas têm grande importância como fornecedores de $\mathrm{N}$, podendo contribuir para a diminuição da acidez do solo e da relação $\mathrm{C} / \mathrm{N}$ da matéria orgânica do solo (HARGROVE, 1986). Porém, e em contrapartida, os resíduos vegetais das gramíneas promovem a melhoria da qualidade do solo, por possuírem maior conteúdo de lignina, possibilitando aumento de ácidos carboxílicos e ácidos húmicos nos substratos (PRIMAVESI, 1982), favorecendo a estruturação e a estabilidade dos agregados do solo (FASSBENDER \& BORNEMISZA, 1994), tornandoo menos suscetível à compactação.

Segundo ANDRADE \& STONE (2009) a qualidade de um solo, geralmente é considerada sob três aspectos principais: físico, químico e biológico, em que a qualidade física assume importância na avaliação do grau de degradação do solo e na identificação de práticas de uso sustentáveis. De acordo com DEXTER (2004a) e ANDRADE \& STONE (2009), embora se admita que a verdadeira preocupação esteja com a qualidade física, esta tem afetado bastante a qualidade química e biológica, já que uma depende da outra, ou seja, melhorando a qualidade física de determinado solo indiretamente se está contribuindo para a melhoria das suas condições biológicas e químicas.

A qualidade física do solo se pode manifestar de várias maneiras (ANDRADE \& STONE, 2009). Exemplos de má qualidade física dos solos estão relacionados, geralmente, a baixa capacidade de infiltração de água e seu escoamento superficial, a baixa aeração do solo, o sistema radicular reduzido e a dificuldade de mecanização. A boa qualidade física do solo é verificada quando os solos exibem condição oposta ou ausência desses problemas (ANDRADE \& STONE, 2009). Frequentemente, um solo apresenta todos esses problemas físicos simultaneamente, o que é importante ressaltar 
é que todos esses sintomas têm uma causa em comum, à degradação da estrutura do solo (DEXTER, 2004a). A estrutura de um solo degradado pode comprometer o desenvolvimento das plantas e, conseqüentemente, a produção agrícola (RICHART et al., 2005; CAVALIERI et al., 2009).

Nos estudos sobre qualidade física do solo atributos como a densidade e da porosidade do solo são frequentemente estudados, pois esses atributos exercem influência sobre o crescimento e desenvolvimento das plantas (ANDRADE \& STONE, 2009). No entanto, diferentes pesquisas têm demonstrado falta de coerência, sobretudo quando se trata do nível crítico da densidade do solo para determinada classe textural (RICHART et al., 2005).

De acordo com ANDRADE \& STONE (2009), os valores críticos dos atributos físicos variam com as condições do estudo. Porém, segundo KIEHL (1979) a densidade do solo situa-se no intervalo de 1,1 a $1,6 \mathrm{Mg} \mathrm{m}^{-3}$ em solos minerais e assume valores superiores a $1,6 \mathrm{Mg} \mathrm{m}^{-3} \mathrm{em}$ solos arenosos. Nesse sentido, BEUTLER et al. (2005) observaram que a densidade ótima para o cultivo da soja é de $1,23 \mathrm{Mg} \mathrm{m}^{-3}$ para solos franco-argilo-arenosos.

Assim como a densidade, a porosidade é outro atributo físico do solo que sofre alterações com a degradação da estrutura do solo (ANDRADE \& STONE, 2009), resultando em sua compactação o que ocasiona redução do volume de macroporos e mudanças na continuidade e distribuição de poros (DEXTER, 2004a). STONE et al. (2002) verificaram que a compactação do solo aumentou sua resistência à penetração $e$ reduziu a porosidade total e a macroporosidade. Houve ainda, redução no tamanho dos poros para o fluxo de água, reduzindo a condutividade hidráulica do solo. SILVA et al. (2006b) também observaram aumento na resistência à penetração e redução da condutividade hidráulica com o aumento da compactação do solo.

ANDRADE \& STONE (2009) descreveram em suas revisões que segundo KIEHL (1979), o solo ideal para a produção agrícola deve apresentar porosidade total próxima a $0,50 \mathrm{~m}^{3} \mathrm{~m}^{-3}$ e uma distribuição percentual de $34 \%$ para macroporos e $66 \%$ para microporos. BAVER et al. (1972) registraram que para que haja desenvolvimento satisfatório de sistemas radiculares, a porosidade de aeração deve estar em torno de 
$0,10 \mathrm{~m}^{3} \mathrm{~m}^{-3}$. Assim, além de reduzir a quantidade de água disponível o solo degradado reduz a taxa de difusão do oxigênio e aumenta a resistência do solo à penetração de raízes, o que pode limitar o crescimento das plantas mesmo que haja disponibilidade de água na faixa de potencial considerada como água disponível. Assim, para melhor caracterizar os efeitos de uso e manejo que influenciam a degradação e a qualidade física do solo, são necessárias medidas integradoras das modificações decorrentes, ou seja, as relativas à taxa de difusão do oxigênio e à impedância mecânica sobre os sistemas radiculares (ARAÚJO et al., 2004).

Um novo índice que interage com vario atributos físicos foi proposto por DEXTER (2004a, b, c) para avaliação da qualidade física do solo. Denominado pelo autor de índice $S$ (S de "slope" = declividade), $S$ foi definido como a declividade da curva característica de retenção da água do solo em seu ponto de inflexão. DEXTER (2004a) sugere, ainda, que o índice $S$ é de cálculo fácil, representa a distribuição do tamanho de poros de maior freqüência e torna possível a comparação direta de diferentes solos e dos efeitos de diferentes práticas de manejo na qualidade física do solo.

Conforme DEXTER (2004a), o limite entre solos com boa e pobre qualidade estrutural ocorre no valor aproximado de $S=0,035$. Nenhuma mudança brusca nos atributos do solo se dá neste valor (ANDRADE \& STONE, 2009), mas ele é consistente com a experiência de campo com solos bem diferentes. Valores de $S<0,020$ estão claramente associados às más condições físicas do solo DEXTER (2004a). Contudo, esses valores de $S$ são referentes a resultados de solos europeus.

Segundo ANDRADE \& STONE (2009), o índice S é altamente correlacionado com a densidade do solo, porosidade total e macroporosidade, mostrando tratar-se de um indicador adequado da qualidade física de solos de cerrado. Para ANDRADE \& STONE (2009), o valor limite de $S=0,045$ mostrou-se adequado à divisão entre solo de boa qualidade estrutural e solo com tendências a se tornar degradado, enquanto valores de S 0,025 indicam solos inteiramente degradados fisicamente.

Contudo, o índice $S$ foi testado em condições de manejo bem diferentes, como em sistemas de cultivo convencional versus SSD. Assim, persiste a duvida, bem como 
a carência de pesquisas sobre o assunto. $O$ índice $S$ poderia verificar as alterações na qualidade física do solo, em função do esquema de seqüência de cultura sob SSD.

A hipótese do presente trabalho foi de que o índice $S$ seria capaz de detectar mudanças na estrutura do solo em função das sequências de culturas de verão e de inverno em SSD. O objetivo do presente trabalho foi quantificar os valores do índice $S$ em função das sequências de culturas em SSD, de um Latossolo Vermelho argiloso situado em Jaboticabal-SP, o índice S e sua correlação com os atributos físicos do solo e com a produtividade das culturas.

\subsection{MATERIAL E MÉTODOS}

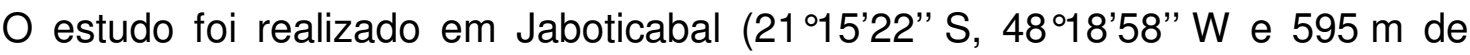
altitude média). O clima do local foi classificado como tropical megatérmico ou Aw, segundo critérios de Köppen (clima tropical com inverno seco e quente, com temperatura média do mês mais frio acima de $18^{\circ} \mathrm{C}$ ). A precipitação anual média (1971-2006) é de 1417 mm, com distribuição anual mostrando concentração no período de outubro-março e relativa seca no período de abril-setembro.

O solo da área experimental foi classificado, de acordo com os critérios do Sistema Brasileiro de Classificação de Solos (EMBRAPA, 2006), como um Latossolo Vermelho eutrófico (LVe), textura argilosa e relevo suave ondulado. Antes da instalação do experimento, a área experimental foi utilizada para a produção de soja e milho em sistema de cultivo convencional por período de aproximadamente 20 anos. Os resultados das análises químicas do solo, realizadas antes da instalação do experimento, encontram-se na Tabela 1.

$\mathrm{Na}$ implantação do experimento, em setembro de 2002, realizaram-se operações de subsolagem a 0,4 $\mathrm{m}$ de profundidade e calagem para elevação da saturação por bases do solo para 70\%. Em julho de 2005, efetuou-se calagem superficial, utilizandose calcário com PRNT de 70\%, aplicado na dose de 1,0 $\mathrm{Mg} \mathrm{ha}^{-1}$, sem a incorporação do corretivo. 
Tabela 1. Atributos químicos do solo, nas camadas 0-0,2 e 0,2-0,4 m de profundidade, antes da instalação do experimento.

\begin{tabular}{ccccccccccc}
\hline Camada & $\begin{array}{c}\mathrm{pH} \\
\left(\mathrm{CaCl}_{2}\right)\end{array}$ & M.O. & $\mathrm{P}($ resina $)$ & $\mathrm{K}$ & $\mathrm{Ca}$ & $\mathrm{Mg}$ & $\mathrm{H}+\mathrm{Al}$ & $\mathrm{SB}$ & $\mathrm{CTC}$ & $\mathrm{V}$ \\
\hline$(\mathrm{m})$ & - & $\left(\mathrm{g} \mathrm{dm}^{-3}\right)$ & $\left(\mathrm{mg} \mathrm{dm}^{-3}\right)$ & & --1 & & & & & \\
$0-0,2$ & 5,0 & 19 & 13 & 4,1 & 15 & 9 & 34 & 28,1 & 62,1 & 45 \\
$0,2-0,4$ & 4,8 & 17 & 26 & 2,9 & 16 & 7 & 34 & 25,9 & 59,9 & 43 \\
Média & 4,9 & 18 & 19 & 3,5 & 15 & 8 & 34 & 27,0 & 61,0 & 44 \\
\hline
\end{tabular}

\section{Descrição da área experimental}

O delineamento utilizado no experimento foi o de blocos em faixas com três repetições. Os tratamentos foram constituídos pela combinação de quatro sequências de culturas de verão e sete culturas de inverno, totalizando 28 parcelas por bloco experimental (Figura 1).

As sequências de culturas de verão, semeadas em outubro/novembro, foram: monocultura de milho (Zea mays L.) - MV; monocultura de soja (Glicine max (L.) Merrill) - SV; cultivos intercalados ano a ano de soja e milho - RT; seqüência de cultivos de arroz (Oryza sativa L.)/feijão (Phaseolus vulgaris L.)/algodão (Gossypium hirsutum L.)/feijão/arroz/algodão - AF.

As sequências de culturas de inverno, semeadas em fevereiro/março e repetidas em todos os anos nas mesmas parcelas, foram: milho, girassol (Helianthus annuus L.), nabo forrageiro (Raphanus sativus L.), milheto (Pennisetum americanum (L.) Leeke), feijão guandu (Cajanus cajan (L.) Millsp), sorgo granífero (Sorghum bicolor (L.) Moench) e crotalária (Crotalaria juncea L.). As sequências de culturas de verão e de inverno repetiram-se nas mesmas parcelas desde a implantação do experimento até a semeadura das culturas no ano agrícola referente ao presente estudo (Tabela 2).

Cada parcela correspondeu a $40 \mathrm{~m}$ de comprimento por $15 \mathrm{~m}$ de largura. As bordaduras das parcelas corresponderam aos $10 \mathrm{~m}$ iniciais e finais do comprimento e aos 2,5 m das laterais, ficando a área útil de cada parcela com $200 \mathrm{~m}^{2}$ (20 m x $\left.10 \mathrm{~m}\right)$. As dimensões das parcelas, com essas bordaduras foram planejadas para viabilizar a 
mecanização de todas as operações exigidas durante a condução do experimento (CORÁ, 2006).

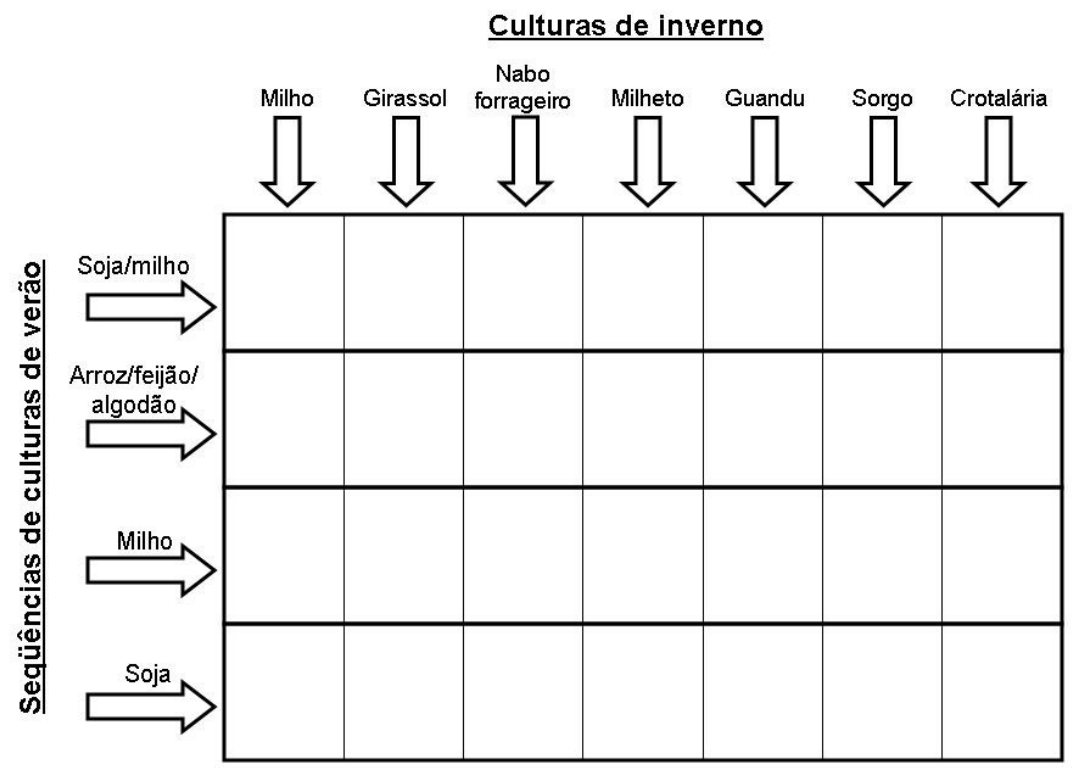

Figura 1. Esquema do bloco experimental. Disposição das parcelas pelo cruzamento das faixas constituídas pelas sequências de culturas de verão e as culturas de inverno.

Em outubro do ano agrícola 2006/2007 foram retiradas, amostras indeformadas de solo, em anéis metálicos $(0,05 \mathrm{~m}$ de diâmetro e $0,05 \mathrm{~m}$ de altura), nas camadas de 0-0,1; 0,1-0,2; e 0,2-0,3 m e em número de três replicações por parcela, que após preparo, foram levadas para o laboratório, mantidas em geladeira $\left( \pm 5^{\circ} \mathrm{C}\right)$, para posterior avaliação dos atributos físicos.

\section{Determinação da retenção de água e dos atributos físicos do solo}

No laboratório, as amostras indeformadas de solo foram preparadas e colocadas para serem saturadas por água durante $24 \mathrm{~h}$. A saturação foi realizada em bandeja, por meio da elevação gradual de uma lâmina de água até atingir cerca de 2/3 da altura do anel. Em seguida, as amostras foram submetidas progressivamente às tensões de 0 ; 10; 20; 40; 60; 80 e 100 hPa, utilizando mesa de tensão, e 200; 300; 500; 700; 1000; 3000; 5000 e 15000 hPa, em câmara de pressão de Richards com placa porosa 
(KLUTE, 1986). A retenção de água nas tensões de 3000; 5000 e $15000 \mathrm{hPa}$ foram determinadas em amostras deformadas de solo (EMBRAPA, 1997).

Tabela 2. Histórico das sequências de culturas de verão e de inverno, desde a implantação do experimento

\begin{tabular}{|c|c|c|c|c|c|c|c|c|c|c|}
\hline \multirow{3}{*}{$\begin{array}{l}\text { Faixas } \\
\text { de } \\
\text { verão }\end{array}$} & \multicolumn{10}{|c|}{ Anos agrícolas } \\
\hline & \multicolumn{2}{|c|}{$2002 / 2003$} & \multicolumn{2}{|c|}{$2003 / 2004$} & \multicolumn{2}{|c|}{$2004 / 2005$} & \multicolumn{2}{|c|}{$2005 / 2006$} & \multicolumn{2}{|c|}{$2006 / 2007$} \\
\hline & Verão & Inverno & Verão & Inverno & Verão & Inverno $^{1}$ & Verão & Inverno & Verão & Inverno \\
\hline \multirow{7}{*}{$S V$} & \multirow{7}{*}{ Soja } & Milho & & Milho & \multirow{7}{*}{ Soja } & - & & Milho & \multirow{7}{*}{ Soja } & Milho \\
\hline & & Girassol & & Girassol & & - & & Girassol & & Girassol \\
\hline & & Nabo & & Nabo & & - & & Nabo & & Nabo \\
\hline & & Milheto & Soja & Milheto & & - & Soja & Milheto & & Milheto \\
\hline & & Guandu & & Guandu & & - & & Guandu & & Guandu \\
\hline & & Sorgo & & Sorgo & & - & & Sorgo & & Sorgo \\
\hline & & Crotalária & & Crotalária & & - & & Crotalária & & Crotalária \\
\hline \multirow{7}{*}{$M V$} & \multirow{7}{*}{ Milho } & Milho & & Milho & \multirow{7}{*}{ Milho } & - & & Milho & \multirow{7}{*}{ Milho } & Milho \\
\hline & & Girassol & & Girassol & & - & & Girassol & & Girassol \\
\hline & & Nabo & & Nabo & & - & & Nabo & & Nabo \\
\hline & & Milheto & Milho & Milheto & & - & Milho & Milheto & & Milheto \\
\hline & & Guandu & & Guandu & & - & & Guandu & & Guandu \\
\hline & & Sorgo & & Sorgo & & - & & Sorgo & & Sorgo \\
\hline & & Crotalária & & Crotalária & & - & & Crotalária & & Crotalária \\
\hline \multirow{7}{*}{$R V$} & \multirow{7}{*}{ Soja } & Milho & & Milho & \multirow{7}{*}{ Soja } & - & & Milho & \multirow{7}{*}{ Soja } & Milho \\
\hline & & Girassol & & Girassol & & - & & Girassol & & Girassol \\
\hline & & Nabo & & Nabo & & - & & Nabo & & Nabo \\
\hline & & Milheto & Milho & Milheto & & - & Milho & Milheto & & Milheto \\
\hline & & Guandu & & Guandu & & - & & Guandu & & Guandu \\
\hline & & Sorgo & & Sorgo & & - & & Sorgo & & Sorgo \\
\hline & & Crotalária & & Crotalária & & - & & Crotalária & & Crotalária \\
\hline \multirow{7}{*}{$A F$} & \multirow{7}{*}{ Arroz } & -1 & & Milho & \multirow{7}{*}{ Algodão } & - & & Milho & \multirow{7}{*}{ Arroz } & -1 \\
\hline & & - & & Girassol & & - & & Girassol & & - \\
\hline & & - & & Nabo & & - & & Nabo & & - \\
\hline & & - & Feijão & Milheto & & - & Feijão & Milheto & & - \\
\hline & & - & & Guandu & & - & & Guandu & & - \\
\hline & & - & & Sorgo & & - & & Sorgo & & - \\
\hline & & - & & Crotalária & & - & & Crotalária & & - \\
\hline
\end{tabular}

': Devido às condições hídricas ou ao ciclo prolongado das culturas, não foi possível a semeadura das culturas de inverno, permanecendo as parcelas em pousio.

Ao atingirem o equilíbrio hídrico em cada tensão, as amostras foram pesadas, e após serem submetidas a última tensão, foram secas em estufa a $105^{\circ} \mathrm{C}$ durante $24 \mathrm{~h}$ 
para determinação do conteúdo de água retido em cada tensão (GARDNER, 1986). Os dados dessas amostras foram utilizados para determinação da curva característica de retenção de água no solo (KLUTE, 1986), bem com da densidade do solo (BLAKE \& HARTGE, 1986), porosidade total (Pt), micro (Mi) e macro (Ma) porosidade (DANIELSON \& SUTHERLAND, 1986), servindo ainda para a realização das análises subsequentes conforme descrito a seguir.

\section{Determinação do índice S}

Com os dados da retenção de água, os parâmetros ajustados segundo modelo proposto por van GENUCHTEN (1980) das curvas de retenção de água foram utilizados no cálculo do índice "S". A partir dos coeficientes ajustados no modelo foi calculado o índice "S" (DEXTER, 2004a), conforme a equação 1:

$\mathrm{S}=-\mathrm{n}\left(\mathrm{Ug}_{\mathrm{sat}}-\mathrm{Ug}_{\mathrm{res}}\right)\left[1+\frac{1}{\mathrm{~m}}\right]^{-(1+\mathrm{m})}$

em que: ${ }_{m=1-\left(\frac{1}{n}\right)}, \mathrm{n}=$ coeficiente estimado do modelo (van GENUCHTEN, 1980); Ug $g_{\text {sat }}$ saturação do solo; Ug $_{\text {res }}$ = conteúdo de água residual do solo.

Conforme DEXTER (2004 a) os dados de retenção de água devem ser ajustados pela equação de van GENUCHTEN (1980) para obtenção do ponto de inflexão da CRA, usado na determinação do índice $S$, pois "S" foi calculado como o valor da inclinação, em modulo, da tangente à CRA no seu ponto de inflexão. Os resultados obtidos foram submetidos à análise de variância (teste $F$ ), seguindo esquema em faixas com dois fatores (sequências de culturas de verão e de inverno) com parcelas subdivididas, cuja divisão das parcelas correspondeu às camadas de solo amostradas. Quando o valor de $\mathrm{F}$ foi significativo a $5 \%$ de probabilidade, as médias foram submetidas ao teste de Scott-Knott, a $5 \%$ de probabilidade.

Realizou-se ainda, nas parcelas anteriormente citadas no presente estudo, porém em amostras deformadas de solo, análises físicas complementares para fins de determinar: textura, argila dispersa em água (ADA), grau de floculação (GF) e índice de estabilidade de agregados (IEA). Para análise textural utilizou-se do método da pipeta 
(CAMARGO et al., 1986) modificado, pois, foram acrescidos às amostras areia, para auxiliar na dispersão mecânica do solo (CORÁ et al., 2009). Para análise da ADA e cálculo do GF utilizou-se do método descrito por CAMARGO et al. (1986).

Para determinação da estabilidade de agregados em água utilizou-se o método descrito por KEMPER \& ROSENAU (1986). Os agregados de cada amostra de solo das parcelas analisadas no presente estudo, que passaram pela peneira com aberturas de $2 \mathrm{~mm}$ e que foram retidos em peneira com aberturas de $1 \mathrm{~mm}$ foram separados para análise. Dessa amostra, foi pesada uma alíquota de $4 \mathrm{~g}$ e transferida para peneira com aberturas de 0,25 mm. Essa peneira foi levada para o aparelho oscilação vertical em água (YODER, 1936), ajustado para 35 ciclos $\mathrm{min}^{-1}$, com amplitude de oscilação de $1,3 \mathrm{~cm}$, durante $3 \mathrm{~min}$. Após a análise, os agregados retidos na peneira com aberturas de $0,25 \mathrm{~mm}$ foram transferidos para latas de alumínio. Essas latas foram previamente pesadas e identificadas. Posteriormente, as latas com os agregados foram levadas à estufa a $105{ }^{\circ} \mathrm{C}$ por $24 \mathrm{~h}$. Para correção de umidade das amostras, $4 \mathrm{~g}$ de solo de cada amostra foi levado para estufa e também seca a $105^{\circ} \mathrm{C}$ por $24 \mathrm{~h}$.

Além disso, considerando-se que partícula primária não deve ser considerada como agregado (KEMPER \& ROSENAU, 1986), foi feita a subtração das quantidades de areia com diâmetro maior que $0,25 \mathrm{~mm}$, limite inferior da classe de agregados estáveis em água. Para determinação dessas quantidades, $2 \mathrm{~g}$ da fração retida na peneira foram transferidas para frascos para a dispersão lenta em agitador rotatório de Wiegner, a 60 ciclos por min, por $16 \mathrm{~h}$, usando $100 \mathrm{~mL}$ de $\mathrm{NaOH} 0,1 \mathrm{~mol} \mathrm{~L}^{-1}$. Posteriormente, a suspensão foi passada na peneira de $0,25 \mathrm{~mm}$ que retiveram os agregados durante o peneiramento úmido. $O$ material retido nessa peneira foi transferido para béqueres, levados para estufa a $105^{\circ} \mathrm{C}$ por $24 \mathrm{~h}$ e pesados.

Com os dados de massa de agregados retidos na peneira com aberturas de $0,25 \mathrm{~mm}$ e a massa de areia $>0,25 \mathrm{~mm}$, calculou-se o índice de estabilidade de agregados (IEA), em porcentagem, como descrito por KEMPER (1965), da seguinte forma:

$$
\mathrm{IEA}=100 * \quad \frac{\text { (massa de agregados }>0,25 \mathrm{~mm})-(\text { massa de areia }>0,25 \mathrm{~mm})}{(\text { massa da amostra seca })-(\text { massa de areia }>0,25 \mathrm{~mm})}
$$


Os resultados obtidos foram submetidos à análise de variância (teste $F$ ), seguindo esquema em faixas com dois fatores (sequências de culturas de verão e de inverno) com parcelas subdivididas, cuja divisão das parcelas correspondeu às camadas de solo amostradas. Quando o valor de $F$ foi significativo a $5 \%$ de probabilidade, as médias foram submetidas ao teste de Scott-Knott, a $5 \%$ de probabilidade.

\section{Relações do índice $S$ com os atributos físicos do solo e produtividade das culturas sob sistema de semeadura direta}

No mesmo ano agrícola foi realizada avaliação da produtividade das culturas de verão MV, SV, RT e AF (MARCELO et al., 2009). Os dados dessas avaliações, bem como os dados dos atributos físicos do solo foram correlacionados com os resultados do índice $S$, verificando como a produção das culturas foi influenciada pela qualidade física do solo, em função dos efeitos dos esquemas de sequências de culturas sob sistema de semeadura direta. Foram realizados testes de correlação de Pearson a $5 \%$ de probabilidade entre os valores do índice S com os atributos físicos e com produtividade das culturas.

\subsection{RESULTADOS E DISCUSSÃO}

\section{Aspectos da textura do solo sob sistema de semeadura direta}

Os resultados relacionados a argila total, argila dispersa em água (ADA) e grau de floculação (GF) foram apresentados e discutidos separadamente em função das sequências de culturas de verão e de inverno e das camadas de solo, devido a não interação significativa entre estes fatores (Tabela 3). Nota-se que não houve diferenças 
significativas nos valores de argila, porém, os resultados de ADA e GF foram alterados em função das sequências de culturas de verão, independentemente das sequências de culturas de inverno e camada analisada. $O$ efeito das sequências de culturas de inverno foi observado apenas sobre o GF.

Para os atributos físicos do solo argila, ADA e GF foram observadas diferenças significativas entre as camadas de solo, independentemente das sequências de culturas de verão e de inverno utilizada (Tabela 3). Em função do aumento da profundidade analisada, observou-se um acréscimo nos valores dos atributos argila e ADA, a partir da superfície do solo, ocorrendo o inverso para o GF.

As sequências de culturas de inverno não exerceram influência sobre os teores de ADA. Possivelmente, estes resultados se devem aos poucos anos de cultivo do SSD (quatro anos), ou seja, o tempo não foi suficiente para que as diferentes plantas de cobertura exercessem seus efeitos sobre a dispersão do solo. Contudo, ALBUQUERQUE et al. (2005) verificaram que a dispersão do solo foi influenciada pela cultura intercalar e camada em análise. Isso indica que os esquemas de rotação em que se utilizam plantas de cobertura do solo, podem promover mudanças físicas que causem alterações no grau de dispersão do solo.

Com relação às camadas estudadas, pode-se observar que houve um aumento do conteúdo de argila e ADA e a diminuição do GF da superfície para as camadas inferiores. Em seus estudos, SILVA et al. (2000) observaram que os valores do GF na camada subsuperficial foram bastante elevados em relação aos da camada superficial, sendo a diferença significativa. Esses resultados mostram-se contrários aos observados no presente estudo.

MARTINS \& ROSA JUNIOR (2005) observaram que o GF está intimamente relacionado com a matéria orgânica do solo, porque, à medida que essa diminui o GF também decresce. Esses pesquisadores verificaram ainda, que com a redução dos valores de matéria orgânica, que ocorreu com o aumento da profundidade há um aumento nos valores de GF. 
Tabela 3. Valores médios de argila total, argila dispersa em água e grau de floculação do Latossolo Vermelho, em função dos cultivos e camadas de solo sob sistema de semeadura direta

\begin{tabular}{|c|c|c|c|}
\hline Cultivo de Verão (V) & Argila total & $\mathrm{ADA}^{1}$ & $\begin{array}{c}\text { GF } \\
\%\end{array}$ \\
\hline Soja/Milho & 568 & $427 \mathrm{~b}$ & $24,4 \mathrm{a}$ \\
\hline Arroz/Feijão/Algodão & 567 & $409 \mathrm{~b}$ & $27,2 \mathrm{a}$ \\
\hline Milho & 559 & $417 \mathrm{~b}$ & $25,2 \mathrm{a}$ \\
\hline Soja & 576 & $442 \mathrm{a}$ & $22,8 \mathrm{~b}$ \\
\hline Teste $\mathrm{F}^{1}$ & $2,1^{\text {ns }}$ & $10,2^{* *}$ & $6,6^{*}$ \\
\hline CV (\%) & 6,3 & 8,1 & 23,0 \\
\hline \multicolumn{4}{|l|}{ Cultivo de Inverno (I) } \\
\hline Milho & 532 & 407 & $23,1 \mathrm{~b}$ \\
\hline Girassol & 540 & 409 & $23,7 \mathrm{~b}$ \\
\hline Nabo Forrageiro & 552 & 416 & $24,3 \mathrm{~b}$ \\
\hline Milheto & 564 & 427 & $24,1 \mathrm{~b}$ \\
\hline Feiião Guandu & 578 & 426 & $25,9 a$ \\
\hline Sorgo & 594 & 439 & $25,9 a$ \\
\hline Crotalária & 610 & 443 & $27,2 \mathrm{a}$ \\
\hline Teste $\mathrm{F}^{1}$ & $2,1^{\text {ns }}$ & $1,1^{\text {ns }}$ & $8,9^{\star *}$ \\
\hline CV $(\%)$ & 21,1 & 19,1 & 11,9 \\
\hline \multicolumn{4}{|l|}{ Interação V x I } \\
\hline Teste $\mathrm{F}^{1}$ & $0,7^{\text {ns }}$ & $1,6^{\text {ns }}$ & $1,2^{\text {ns }}$ \\
\hline \multicolumn{4}{|l|}{ Camadas (C) } \\
\hline $0-0,1 \mathrm{~m}$ & $541 \mathrm{c}$ & $389 \mathrm{c}$ & $27,8 \mathrm{a}$ \\
\hline $0,1-0,2 \mathrm{~m}$ & $570 \mathrm{~b}$ & $429 \mathrm{~b}$ & $24,3 \mathrm{~b}$ \\
\hline $0,2-0,3 \mathrm{~m}$ & $592 \mathrm{a}$ & $455 \mathrm{a}$ & $22,6 \mathrm{c}$ \\
\hline Teste $\mathrm{F}^{1}$ & $314,0^{* *}$ & $447,9^{* *}$ & $69,7^{* *}$ \\
\hline CV (\%) & 3,8 & 3,6 & 9,7 \\
\hline \multicolumn{4}{|l|}{$\begin{array}{c}\text { Interação V } \times \text { C } \\
\text { Teste } \mathrm{F}^{1}\end{array}$} \\
\hline \multicolumn{4}{|l|}{$\begin{array}{c}\text { Interação I x C } \\
\text { Teste } F^{1}\end{array}$} \\
\hline \multicolumn{4}{|l|}{$\begin{array}{c}\text { Interação } \mathrm{V} \times \mathrm{I} \text { × C } \\
\text { Teste } \mathrm{F}^{1}\end{array}$} \\
\hline
\end{tabular}

Segundo SILVA et al. (2000), a explicação para esse comportamento pode estar ligada aos aspectos relacionados à gênese e mineralogia do solo. Logo, pode-se 
atribuir parte da variação encontrada no presente estudo às propriedades intrínsecas do solo, como por exemplo, a diferença granulométrica entre as camadas do solo.

Para as condições do presente trabalho, notou-se que o grau de dispersão do solo não foi afetado pelos sistemas de rotação de culturas. O estudo da dispersão do solo sob rotação de culturas não foi eficiente até o momento para detectar alterações na qualidade física do solo.

\section{Atributos físicos: densidade do solo, poros totais, micro e macro poros e índice de estabilidade de agregados}

Verificou-se que os atributos físicos densidade do solo (Ds), poros totais (Pt), micro (Mi) e macro (Ma) poros e índice de estabilidade de agregados (IEA) foram influenciados pelas sequências de culturas sob sistema de semeadura direta (SSD) de modo isolado (Tabela 4). Porém nas camadas de solo ocorreram diferenças para todos esses atributos físicos. As sequências de culturas de verão não influenciaram significativamente os resultados dos atributos Ds, Mi e Ma. Porém, observou-se que as sequências de culturas de verão influenciaram a Pt e o IEA $(p<0,05)$, sendo verificada a menor Pt no SSD sob a seqüência de cultura verão com rotação soja/milho (RT). As sequências de culturas de verão com monocultura de milho (MV) e soja (SV) foram as que proporcionaram os maiores valores de IEA. Resultados semelhantes foram observados por MARTINS (2008), que verificou maior IEA na seqüência MV na camada de $0-0,05 m$.

Considerando as sequências de culturas de inverno, enfatiza-se que não foram detectados seus efeitos sobre os atributos Mi e IEA. Porém, verificou-se que as sequências de culturas de inverno influenciaram a Ds, a Pt e o Ma $(\mathrm{p}<0,05)$. De modo geral, foi observado que as menores Ds estavam relacionadas às maiores $\mathrm{Pt}$ e Ma no SSD, principalmente sob as sequências de culturas inverno com crotalária e o sorgo. CORÁ (2006) corrobora os resultados, pois ao estudar os atributos Ds, Pt, Mi e Ma, na mesma área do presente estudo, porém, no ano agrícola 2004/2005, salientou que os 
valores desses atributos estavam dentro das faixas esperadas para um SSD, o que se repetiu no presente estudo.

Tabela 4. Densidade do solo (Ds), poros totais (Pt), micro (Mi) e macro (Ma) poros e índice de estabilidade de agregados (IEA) do Latossolo Vermelho sob sistema de semeadura direta

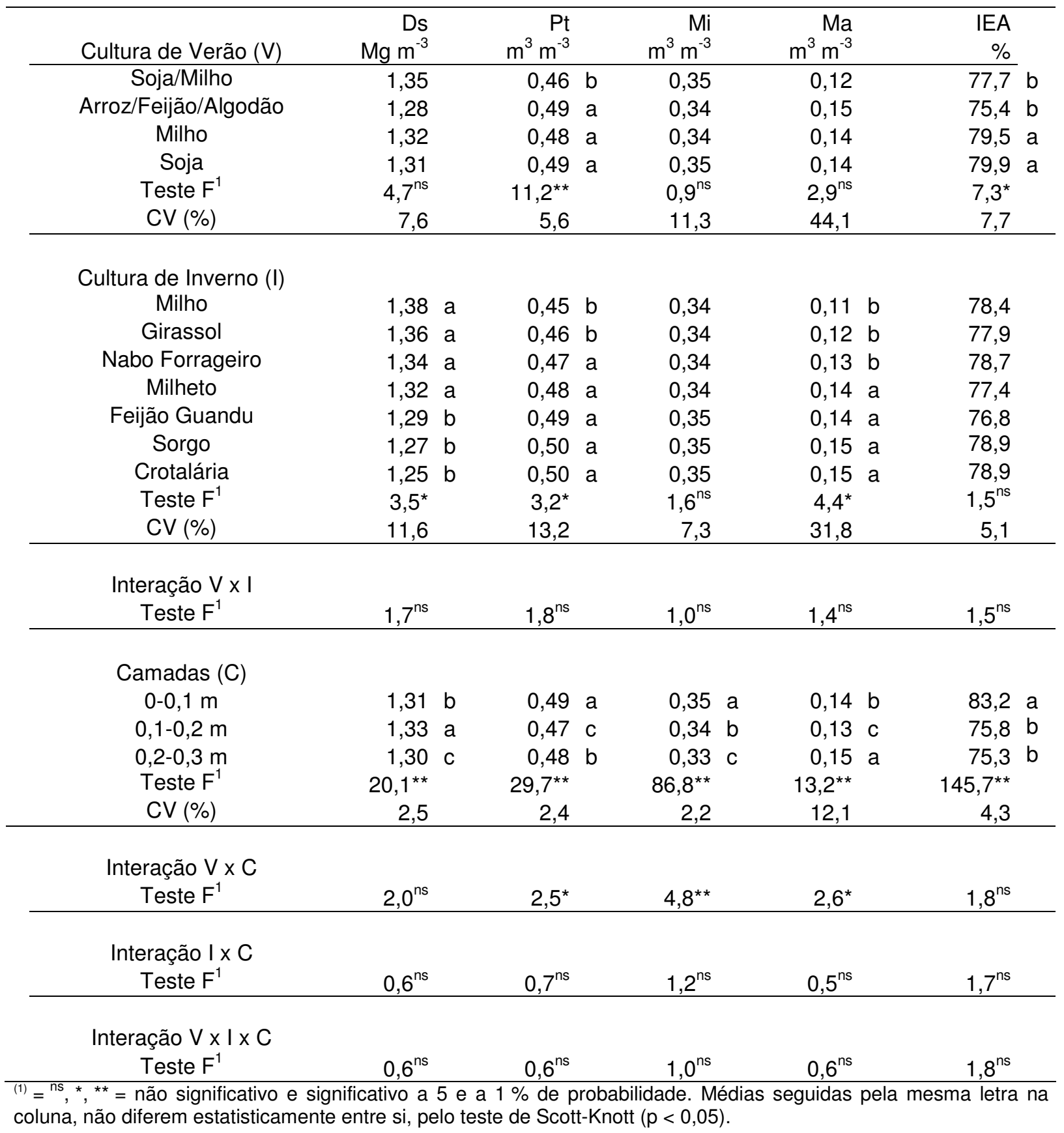


Percebeu-se com relação às camadas de solo, que os resultados observados na camada de $0,1-0,2 m$ sugerem que nessa camada ocorreram modificações que culminaram com o relativo aumento da compactação em relação às outras camadas. $O$ efeito compressivo, causado pelo trafego de máquinas e implementos, que acarretam no aumento da Ds na superfície do solo (CAVALIERI et al., 2009), possivelmente foi diminuído pela ação conjunta das hastes sulcadoras da semeadora, do vigor do sistema radicular das sequências de culturas e do incremento de matéria orgânica na camada superficial do solo.

De acordo com REICHERT et al. (2003), em SSD, a compactação ocorre principalmente na camada de 0,08-0,15 m de profundidade. Ao estudar um Latossolo Vermelho eutrófico do Paraná, STRECK et al. (2008) observaram que esse solo, quando em SSD, apresentou na camada de 0,15-0,20 m maior Ds e menor Pt e Ma. E isso foi, segundo esses autores, reflexo da compactação do solo, o que pode ser justificado pelo tráfego de máquinas e implementos agrícolas sobre a superfície do solo (REICHERT et al. 2003, CAVALIERI et al., 2009).

Para os atributos $\mathrm{Pt}$, Mi e Ma houve interação significativa entre as sequências de culturas de verão e as camadas de solo (Tabela 5). Verificou-se que os maiores valores de $\mathrm{Pt}$, Mi e Ma estiveram geralmente associados à camada de 0-0,1m para todas as sequências de culturas de verão.

Entre as sequências de culturas de verão, na seqüência RT foram observados os menores valores de Pt para todas as camadas de solo, correndo ainda na seqüência RT o menor valor de Ma na camada de 0,2-0,3m. No entanto, esses resultados estão em acordo com os resultados observados por CORÁ (2006), que detectou o menor valor médio de Ma na seqüência de culturas de verão RT. Contudo, essa diferença não deve ser atribuída apenas ao efeito dos distintos sistemas de manejo do solo, pois esses atributos físicos são influenciados por diversos fatores, dentre eles, a umidade no momento da amostragem do solo (DEXTER et al., 2005). 
Tabela 5. Atributos físicos do Latossolo Vermelho sob sistema de semeadura direta nas sequências de culturas de verão e nas camadas amostradas

\begin{tabular}{|c|c|c|c|c|c|}
\hline \multirow[b]{2}{*}{ Camadas } & \multicolumn{4}{|c|}{ Sequências de culturas de verão(1) } & \multirow[b]{2}{*}{ Teste $\mathrm{F}^{2}$} \\
\hline & MV & SV & $\mathrm{RT}$ & $\mathrm{AF}$ & \\
\hline & \multicolumn{4}{|c|}{ Poros totais $\left(\mathrm{m}^{3} \mathrm{~m}^{-3}\right)$} & \\
\hline $0-0,1 \mathrm{~m}$ & $0,48 \mathrm{Aa}$ & $0,49 \mathrm{Aa}$ & $0,47 \mathrm{Ab}$ & $0,50 \mathrm{Aa}$ & $5,9^{* *}$ \\
\hline $0,1-0,2 \mathrm{~m}$ & $0,47 \mathrm{Bb}$ & $0,48 \mathrm{Ba}$ & $0,46 \mathrm{Bb}$ & $0,48 \mathrm{Ba}$ & $7,7^{* *}$ \\
\hline $0,2-0,3 \mathrm{~m}$ & $0,48 \mathrm{Aa}$ & $0,49 \mathrm{Aa}$ & $0,46 \mathrm{Bb}$ & $0,49 \mathrm{Ba}$ & $12,9^{\star *}$ \\
\hline \multirow[t]{2}{*}{ Teste $\mathrm{F}^{2}$} & $11,0^{\star \star}$ & $4,5^{\star}$ & $12,6^{\star \star}$ & $9,1^{* \star}$ & \\
\hline & \multicolumn{2}{|c|}{$C V-1=5,6 \%$} & \multicolumn{2}{|c|}{ CV $-2=3,4 \%$} & \\
\hline & \multicolumn{4}{|c|}{ Microporos $\left(\mathrm{m}^{3} \mathrm{~m}^{-3}\right)$} & \\
\hline $0-0,1 \mathrm{~m}$ & $0,35 \mathrm{~A}$ & $0,36 \mathrm{~A}$ & $0,35 \mathrm{~A}$ & $0,35 \mathrm{~A}$ & $0,4^{\mathrm{ns}}$ \\
\hline $0,1-0,2 \mathrm{~m}$ & $0,34 \mathrm{~B}$ & $0,35 \mathrm{~B}$ & $0,35 \mathrm{~A}$ & $0,34 \mathrm{~B}$ & $0,5^{\mathrm{ns}}$ \\
\hline $0,2-0,3 \mathrm{~m}$ & $0,33 \mathrm{C}$ & $0,34 \mathrm{C}$ & $0,34 \mathrm{~B}$ & $0,33 \mathrm{C}$ & $0,7^{\text {ns }}$ \\
\hline \multirow{2}{*}{ Teste $\mathrm{F}^{2}$} & $18,2^{\star \star}$ & $21,8^{\star \star}$ & $5,2^{\star \star}$ & $55,9^{\star \star}$ & \\
\hline & \multicolumn{2}{|c|}{$\mathrm{CV}-1=11,9 \%$} & \multicolumn{2}{|c|}{ CV $-2=3,1 \%$} & \\
\hline & \multicolumn{4}{|c|}{ Macroporos $\left(\mathrm{m}^{3} \mathrm{~m}^{-3}\right)$} & \\
\hline $0-0,1 \mathrm{~m}$ & $0,14 \mathrm{~A}$ & $0,13 \mathrm{~A}$ & 0,12 & $0.14 \mathrm{~A}$ & $1,2^{\text {ns }}$ \\
\hline $0,1-0,2 \mathrm{~m}$ & $0,13 \mathrm{~B}$ & $0,13 \mathrm{~B}$ & 0,11 & $0,14 \mathrm{~B}$ & $2,4^{\mathrm{ns}}$ \\
\hline $0,2-0,3 \mathrm{~m}$ & $0,14 \mathrm{Ca}$ & $0,15 \mathrm{Ca}$ & $0,11 \mathrm{~b}$ & $0,16 \mathrm{Ca}$ & $5,1^{*}$ \\
\hline \multirow[t]{2}{*}{ Teste $\mathrm{F}^{2}$} & $5,5^{\star \star}$ & $6,9^{\star *}$ & \multirow{2}{*}{\multicolumn{2}{|c|}{$\begin{array}{c}3,0^{\text {ns }} \\
\text { CV-2 }=18,7 \%\end{array}$}} & - \\
\hline & \multicolumn{2}{|c|}{$C V-1=44,1 \%$} & & & \\
\hline
\end{tabular}

Retenção de água do solo sob sistema de semeadura direta

No levantamento do conteúdo de água retido no solo, observou-se que houve efeito das sequências de culturas de verão e de inverno e das camadas de solo sobre a retenção de água (Tabela 6). Porém, esses resultados variaram de modo diferente para cada um dos fatores. Considerando-se as sequências de culturas de verão, verificou-se que houve variação no conteúdo de água retido nas tensões do ponto de saturação a $40 \mathrm{hPa}$ e de 300 a $5000 \mathrm{hPa}$, ocorrendo, de modo geral, maior retenção de água no solo com as sequências de culturas de verão com monocultura de soja (SV) e na rotação arroz/feijão/algodão (AF) no verão. Possivelmente, uma melhor distribuição de poros de maior diâmetro nesses sistemas sob SSD foi o que modificou esse ambiente agrícola para que ocorressem essas condições de retenção de água no solo. 


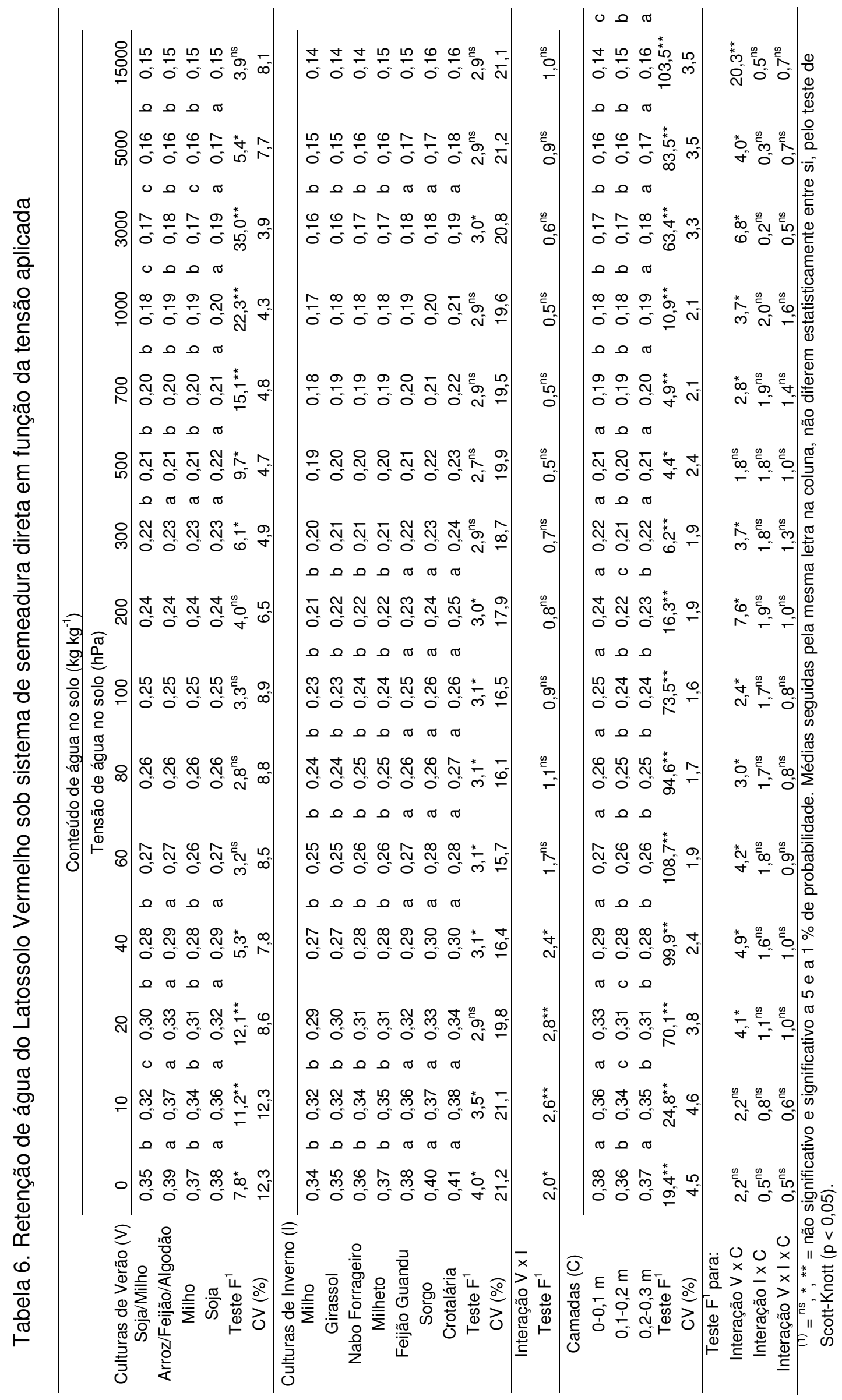


Considerando as sequências de culturas de inverno não houve variação na retenção de água a partir da tensão de $300 \mathrm{hPa}$, sendo que os maiores conteúdos de água ficaram retidos nos sistemas de manejo cultivados com crotalária, sorgo e feijão guandu. Nestas situações, também foram observadas as menores Ds, o que pode estar relacionado à maior retenção de água no solo sob esses cultivos.

Para as camadas de solo, verificou-se que a camada de 0,1-0,2 $\mathrm{m}$ foi a que reteve o menor conteúdo de água para a maioria das tensões utilizadas no presente estudo, principalmente a menores tensões $(<20 \mathrm{hPa})$. Isso pode ser justificado pelo menor volume de macroporos e o maior valor de Ds detectados nesta camada. $E$ isto permite pressupor que na camada de 0,1-0,2 m ocorreram processos mecânicos que ocasionaram a diminuição dos poros de maior diâmetro, aumentando assim a Ds (LIMA et al., 2005), o que pode contribuir para a compactação dessa camada do solo.

Conforme relatado por REICHERT et al. (2003), em SSD, a compactação ocorre principalmente na camada de 0,08-0,15 m de profundidade. Ao estudar um LVe do Paraná, STRECK et al. (2008) observaram que esse solo, quando em SSD, apresentou na camada de $0,15-0,20 \mathrm{~m}$ maior densidade do solo e menor porosidade total $\mathrm{e}$ macroporos. Isso, segundo esses autores foi reflexo da compactação do solo, o que pode ser justificado pelo tráfego de máquinas e implementos agrícolas sobre a superfície do solo (REICHERT et al. 2003).

O efeito da compactação do solo na camada de 0,1-0,2 m refletiu-se na CRA, sendo evidenciado pelo menor conteúdo de água verificado na parte inicial da curva (Figura 2), quando se ajustou pelo modelo de van GENUCHTEN (1980) os dados de retenção de água. STRECK et al. (2008) corroboram os resultados, pois também observaram menor teor de água retido a tensões mais baixas na parte inicial da CRA, em solos com indícios de compactação (aumento nos valores da Ds).

Quando se avaliou o efeito das interações entre os sistemas de sequências de culturas, verificou-se que houve variação na retenção de água do ponto de saturação a tensão de $40 \mathrm{hPa}$ (Tabela 6). Isso sugere que a alteração física imposta ao solo pelo sistema de manejo exerceu maior influência nos poros de maior diâmetro, ocasionando 
sua diminuição, como o verificado para as camadas do solo, em que o aumento da Ds condicionou o detrimento do volume de poros.

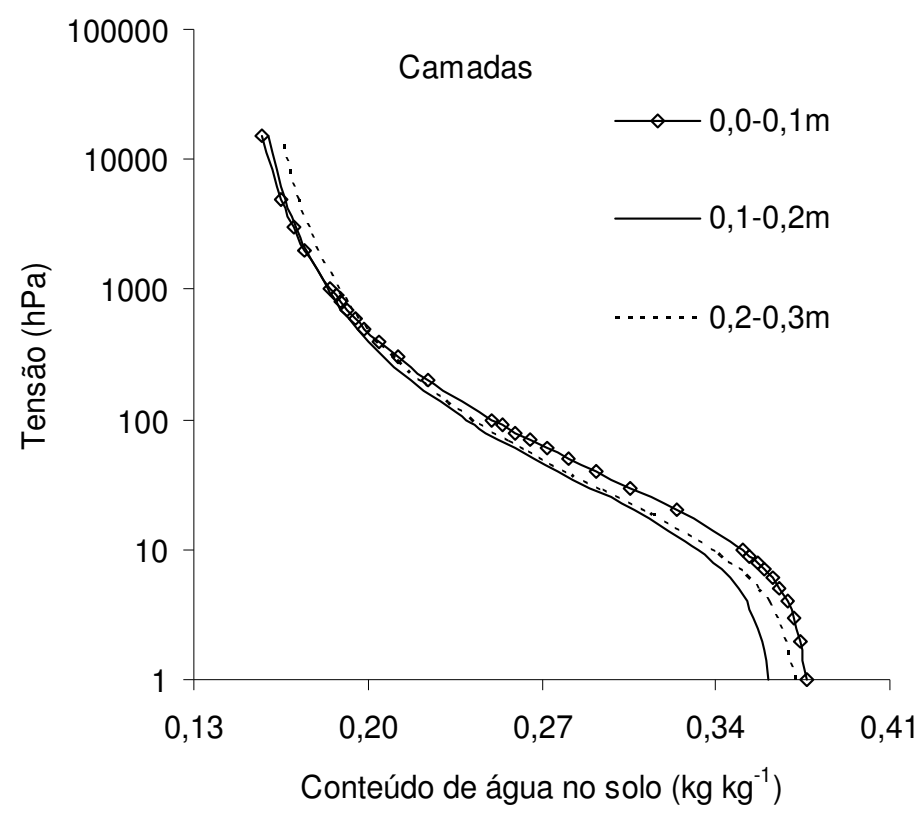

Figura 2. Curvas de retenção de água ajustadas pelo modelo de van GENUCHTEN (1980), em função de camadas do Latossolo Vermelho sob sistema de semeadura direta.

Percebeu-se que de modo geral, e independentemente dos demais fatores, o sistema sob a seqüência de cultura de verão AF foi o que propiciou condições que contribuíram para uma maior retenção de água no solo em relação aos cultivos de verão, como pode ser observado na CRA desses sistemas (Figura 3). Logo, sistemas de manejo do solo com maior diversidade de sequências de culturas de verão beneficiaram sua boa qualidade física, o que pode favorecer o armazenamento de água para o desenvolvimento das culturas.

Levando-se em consideração o efeito da interação das sequências de culturas de inverno com as sequências de culturas de verão, verificou-se que de modo geral, e para todos os sistemas sob as sequências de culturas de verão, os sistemas de manejo com crotalária e sorgo no inverno foram os manejos do solo que possibilitaram maior retenção de água, como pode ser observado na CRA desses sistemas (Figura 4). Com isso, pode-se deduzir que sistemas de rotações de culturas sob SSD, que utilizarem 
como plantas de cobertura do solo no inverno a crotalária ou o sorgo podem proporcionar melhores condições para a boa qualidade física do solo.

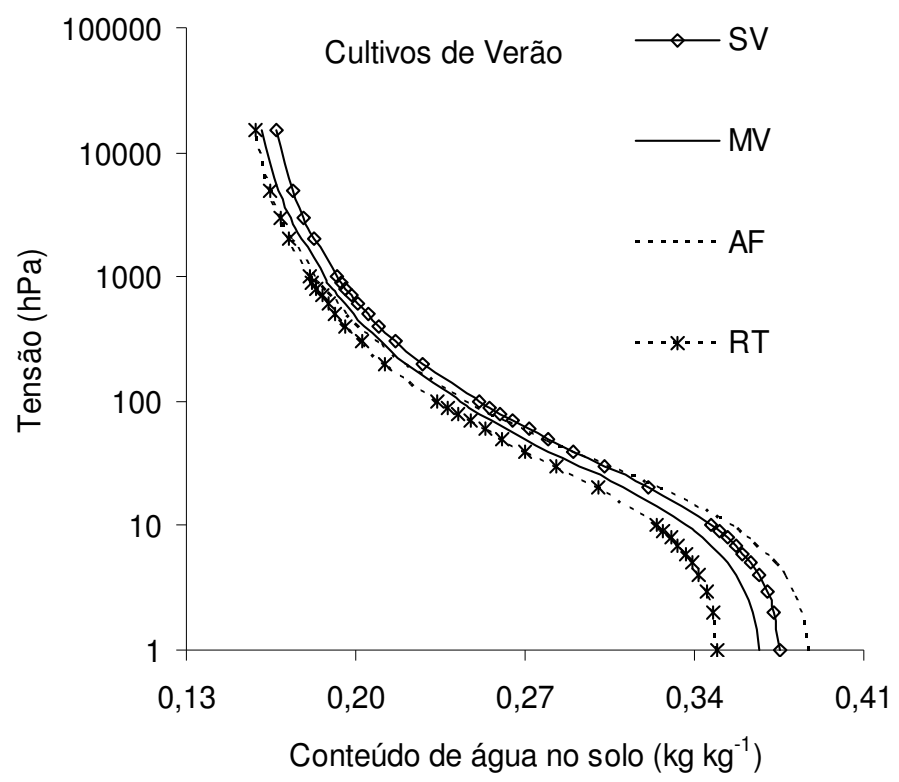

Figura 3. Curvas de retenção de água ajustadas pelo modelo de van GENUCHTEN (1980), em função das sequências de culturas de verão: soja (SV), milho (MV), arroz/feijão/algodão (AF) e soja/milho (RT) no Latossolo Vermelho sob sistema de semeadura direta.

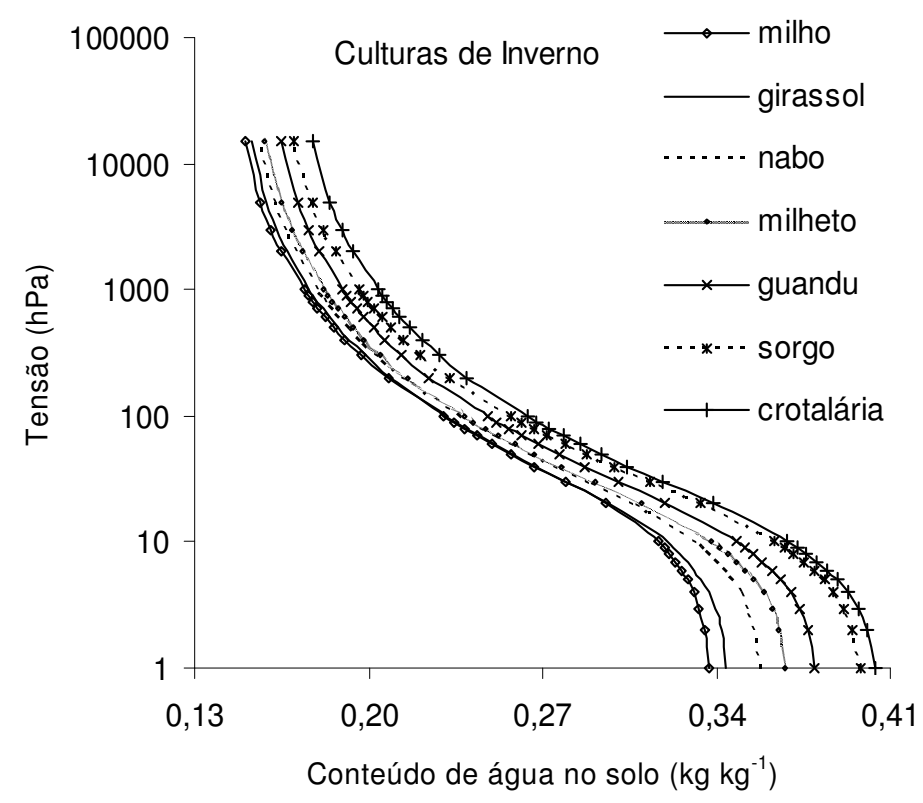

Figura 4. Curvas de retenção de água ajustada pelo modelo de van GENUCHTEN (1980), em função de sete sequências de culturas de inverno no Latossolo Vermelho sob sistema de semeadura direta. 


\section{Índice S e qualidade física do solo sob sistema de semeadura direta}

Quando se utilizou o índice $S$, para avaliação da qualidade física do LVe sob SSD, verificou-se que houve interação significativa entre as sequências de culturas de verão e de inverno, bem como, entre as sequências de culturas de verão e camadas de solo (Tabela 7). Portanto, assim como argumentaram DEXTER (2004a); STRECK et al. (2008) e ANDRADE \& STONE (2009), o índice $S$ foi eficientemente sensível em detectar modificações na CRA, que possibilitaram demonstrar que houve interferência dos sistemas de manejo sobre as alterações físicas no solo dos distintos sistemas agrícolas em estudo. Com relação às sequências de culturas de verão, observou-se que o sistema de cultivo AF proporcionou, de modo geral, valores de " $S$ " significativamente maiores que as demais sequências de culturas de verão, independentemente da interação com as sequências de culturas inverno ou camada de solo, indicando a melhor qualidade física do solo sob SSD.

Para as sequências de culturas de inverno ocorreram diferentes valores de índice $S$ que variaram de acordo com as interações e sequências de culturas. Comparando a diferença entre as sequências de culturas de inverno dentro da sequência de culturas de verão com MV, verificou-se que as sequências de culturas de inverno com crotalária, sorgo, milheto e guandu propiciaram os maiores valores de índice $S$. Considerando-se a seqüência de culturas de verão com SV, observou-se que para esse esquema de rotações de cultuas a sequência de culturas de inverno com sorgo foi a que possibilitou o maior valor de índice $S$. As sequências de culturas de inverno com milho e girassol na sequência de cultura de verão RT reduziram a qualidade do solo, coincidindo com os menores valores de índice $S$ para esses esquemas de rotações de culturas sob SSD. Quando os valores de índice $S$ foram comparados na seqüência de culturas de verão $A F$, detectou-se que a seqüência de culturas de inverno com crotalária foi a que apresentou o maior valor de índice $S$, sendo, portanto, superior as demais as sequências de culturas de inverno. Assim, denota-se que as sequências de culturas de inverno com crotalária e sorgo foram as 
que melhor condicionam a qualidade física do solo, possibilitam os melhores resultados de índice $S$.

Tabela 7. Valores de índice S para o Latossolo Vermelho sob sistema de semeadura direta em diferentes sequências de culturas e camadas amostradas

\begin{tabular}{|c|c|c|c|c|c|}
\hline \multirow[b]{2}{*}{ Cultivo de Inverno } & \multicolumn{4}{|c|}{ Sequências de culturas de verão(1) } & \multirow[b]{2}{*}{ Teste $\mathrm{F}^{2}$} \\
\hline & MV & SV & RT & $\mathrm{AF}$ & \\
\hline Milho & $0,036 \mathrm{Bb}$ & $0,042 \mathrm{Bb}$ & $0,038 \mathrm{Bb}$ & $0,050 \mathrm{Ba}$ & $6,3^{* *}$ \\
\hline Girassol & $0,038 \mathrm{Bb}$ & $0,041 \mathrm{Bb}$ & $0,037 \mathrm{Bb}$ & $0,053 \mathrm{Ba}$ & $8,8^{* *}$ \\
\hline Nabo Forrageiro & $0,043 \mathrm{~B}$ & $0,045 \mathrm{~B}$ & $0,042 \mathrm{~A}$ & $0,049 \mathrm{~B}$ & $1,8^{\text {ns }}$ \\
\hline Milheto & $0,048 \mathrm{~A}$ & $0,044 \mathrm{~B}$ & $0,046 \mathrm{~A}$ & $0,049 \mathrm{~B}$ & $0,8^{\text {ns }}$ \\
\hline Feijão Guandu & $0,046 \mathrm{~A}$ & $0,046 \mathrm{~B}$ & $0,045 \mathrm{~A}$ & $0,051 \mathrm{~B}$ & $1,5^{\mathrm{ns}}$ \\
\hline Sorgo & $0,049 \mathrm{Ab}$ & $0,058 \mathrm{Aa}$ & $0,044 \mathrm{Ab}$ & $0,052 \mathrm{Ba}$ & $5,9^{* *}$ \\
\hline Crotalária & $0,050 \mathrm{Ab}$ & $0,045 \mathrm{Bb}$ & $0,044 \mathrm{Ab}$ & $0,059 \mathrm{Aa}$ & $8,0^{* *}$ \\
\hline Teste $\mathrm{F}^{2}$ & $5,2^{\star \star}$ & $5,5^{\star \star}$ & $2,2^{*}$ & $2,1^{*}$ & CV (\%) \\
\hline Camadas & MV & SV & RT & $\mathrm{AF}$ & \\
\hline $0-0,1 \mathrm{~m}$ & $0,047 \mathrm{Ab}$ & $0,047 \mathrm{Ab}$ & $0,046 \mathrm{Ab}$ & $0,055 \mathrm{Aa}$ & $5,9^{* *}$ \\
\hline $0,1-0,2 \mathrm{~m}$ & $0,042 \mathrm{Bb}$ & $0,043 \mathrm{Bb}$ & $0,042 \mathrm{Bb}$ & 0,051 Ba & $6,1^{* *}$ \\
\hline $0,2-0,3 \mathrm{~m}$ & $0,044 \mathrm{Bb}$ & $0,048 \mathrm{Aa}$ & $0,040 \mathrm{Bb}$ & $0,051 \mathrm{Ba}$ & $8,1^{* *}$ \\
\hline
\end{tabular}

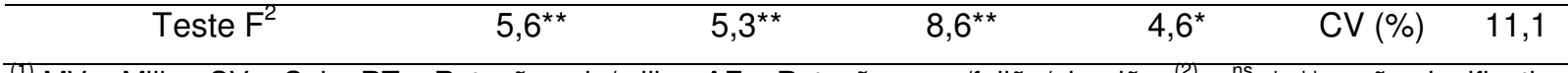

(1) MV = Milho; SV = Soja; RT = Rotação soja/milho; AF = Rotação arroz/feijão/algodão. ${ }^{(2)}={ }^{\text {ns }},{ }^{*},{ }^{* *}=$ não significativo e significativo a 5 e a $1 \%$ de probabilidade. Médias seguidas pela mesma letra (maiúscula na coluna e minúscula na linha), não diferem estatisticamente entre si, pelo teste de Scott-Knott $(p<0,05)$.

No levantamento das interações entre as sequências de culturas de verão com as camadas de solo, observou-se que a camada de 0-0,1 m e a seqüência de culturas de verão $A F$ foram as que proporcionaram, de modo geral, valores de " $S$ " significativamente maiores que as demais interações, indicando que nessa condição houve a melhor qualidade física do solo agrícola manejado sob SSD.

Os valores de índice $S$ obtidos no presente estudo são maiores que 0,035 , que representa, de acordo com DEXTER (2004a), para solos europeus, o limite no qual o solo não tem restrições ao desenvolvimento das culturas, ou seja, os valores de índice $S>0,035$ representam a extremidade inferior da classe dos solos com boa 
qualidade física e foram associados a solos com condições físicas favoráveis para o crescimento das raízes das plantas (DEXTER, 2004a).

\section{Relação do índice Se os atributos do solo}

O estudo da relação do índice $S$ com os atributos físicos e a matéria orgânica do solo indica que a maior parte desses atributos apresentou correlação significativa e positiva com o índice $S$ (Tabela 8). Verificou-se que para o IEA e a Ds, ao contrario do ocorrido com os demais atributos físicos, apresentaram relação negativa com o índice $S$ $(p<0,001)$. Isso indica que com o aumento da Ds houve diminuição dos valores do índice $S$, o que demonstra a relação inversa entre esses indicadores de qualidade do solo, o que também foi confirmado por pesquisadores em diferentes regiões e classes de solos (DEXTER, 2004a; STRECK et al., 2008; ANDRADE \& STONE, 2009).

DEXTER (2004a) observou, para solos da Espanha, com aproximadamente $27 \%$ de argila, decréscimo linear do índice $S$ em função do aumento da Ds, corroborando os resultados do presente estudo. Porém, em solos de textura média a muito argilosa da Região Sul do Brasil, STRECK et al. (2008) detectaram uma variação exponencial decrescente do índice $S$ em função do aumento da Ds. Assim como verificado no presente estudo, DEXTER (2004a) e STRECK et al. (2008), também verificaram que com o aumento da Ds, houve redução do volume de poros. $E$ isto pode ser explicado, de acordo com HORN et al. (1995), pelos processos que resultam na compactação do solo, onde os poros grandes são destruídos primeiro (poros intraagregados), para depois ocorrer a destruição dos agregados e, conseqüentemente, dos poros menores (poros inter-agregados). STRECK et al. (2008) relatou em sua discussão ao citar outras pesquisas, que um exame das CRAs na literatura mostra que a degradação física do solo leva sempre a uma mudança na forma das curvas, com uma redução da inclinação da CRA no ponto de inflexão.

De modo contrário a Ds, as relações do índice $S$ com os atributos $\mathrm{Pt}$, Mi e Ma, bem como, aqueles ligados a CRA (conteúdo de água no solo na saturação ( $0 \mathrm{hPa}$ ), na capacidade de campo (CC) e no ponto de murcha permanente (PMP), respectivamente) 
foram positivas $(p<0,001)$. Esses atributos físicos relacionam-se intima e intrinsecamente com a estrutura do solo, que é um fator importante na determinação do conteúdo de água na CC, por controlar a distribuição do tamanho de poros e a retenção de água contra a força da gravidade em diferentes valores de tensão da água no solo. Esses resultados estão de acordo com observado por ANDRADE \& STONE (2009), para solo com textura variando de muito argilosa à arenosa.

Tabela 8. Coeficientes de correlação de Pearson $(r)$ entre o índice $S$ e os atributos físicos e matéria orgânica do Latosolo Vermelho sob sistema de semeadura direta

\begin{tabular}{|c|c|c|c|}
\hline Atributo dependente & Correlação (r) & Atributo dependente & Correlação (r) \\
\hline Argila total & $0,35^{\star \star \star}$ & $\mathrm{Pt}$ & $0,37^{\star \star \star}$ \\
\hline ADA & $0,33^{* * *}$ & $\mathrm{Mi}$ & $0,31^{* * *}$ \\
\hline GF & $0,14^{* \star *}$ & $\mathrm{Ma}$ & $0,31^{* * *}$ \\
\hline IEA & $-0,22 * * *$ & $0 \mathrm{hPa}$ & $0,37^{* * *}$ \\
\hline Ds & $-0,37^{* \star *}$ & CC & $0,38^{* * *}$ \\
\hline $\mathrm{MO}$ & $0,61^{* \star *}$ & PMP & $0,30^{* \star *}$ \\
\hline
\end{tabular}

ADA: argila dispersa em água. GF: grau de floculação. IEA: índice de estabilidade de agregados. Ds: densidade do solo. Pt: poros totais. Mi: microporos. Ma: macroporos. $0 \mathrm{hPa}$ : solo saturado. CC: capacidade de campo (100 hPa). PMP: ponto de murcha permanente $(15000 \mathrm{hPa})$. MO: matéria orgânica do solo ${ }^{* * *} P<0,001$.

Para as sequências de culturas e o manejo do solo utilizados neste trabalho, observou-se haver relação positiva e significativa $(p<0,001)$ do valor de " $S$ " com o teor de argila, ADA e GF. No entanto, STRECK et al. (2008) não detectaram dependência entre os valores de índice $S$ com o teor ADA dos solos. STRECK et al. (2008) atribuíram isso aos diferentes sistemas de manejo utilizados nos solos por eles estudados (plantio direto estabilizado, floresta e campo nativo). Porém, segundo STRECK et al. (2008) seus resultados foram contrários aos encontrados por GATE et al. (2006), que trabalharam com cinco solos da Polônia e encontraram, no primeiro ano de trabalho, acentuada redução do índice $S$ com o aumento do teor de ADA do solo, até atingir determinado valor a partir do qual a redução do valor de $S$ estabilizou-se. Contudo, esse assunto carece de informações, pois STRECK et al. (2008) argumentaram que ao repetirem o mesmo trabalho no segundo ano, GATE et al. (2006) não obtiveram relação entre argila dispersa e o valor de S. GATE et al. (2006) relacionaram esses resultados ao alto conteúdo de água com o qual as amostras de 
solo foram coletadas no segundo ano. Isso mostra que, mesmo para solos cultivados com o preparo convencional, ainda não é clara a relação entre argila dispersa e o valor de S, podendo a relação também estar sendo influenciada por outros fatores.

Os resultados de matéria orgânica (MO) obtidos por MARCELO et al. (2009), no ano agrícola 2006/2007, na área do presente estudo, foram utilizados para verificar sua relação com o índice $S$. Os valores de MO observados por MARCELO et al. (2009) variaram de $30 \mathrm{~g} \mathrm{dm}^{-3}$ (camada de 0-0,1 m) a $16 \mathrm{~g} \mathrm{dm}^{-3}$ (camada de 0,2-0,3 m). Os valores de índice $S$ relacionam-se positivamente com os teores de $\mathrm{MO}$ do solo (correlação de 0,61 com $p<0,001$ ). Esses resultados equivalem-se com aqueles encontrados por STRECK et al. (2008) em solos da Região Sul do Brasil e DEXTER (2004a) em solos da Inglaterra e da Polônia. Para STRECK et al. (2008) o modelo exponencial crescente apresentou o melhor ajuste para a relação entre $S$ e a $M O$. Contudo, no presente estudo, observou-se uma relação linear do valor de $S$ com o aumento do teor de MO, corroborando DEXTER (2004a) que destacou o efeito mais expressivo do teor de $\mathrm{MO}$ sobre o valor de $S$ em solos arenosos. Porém, em sua revisão de literatura, STRECK et al. (2008) e outros pesquisadores, não apontaram um nível crítico de MO abaixo do qual a estrutura do solo entra em colapso. No entanto, STRECK et al. (2008) comentaram que há uma vasta literatura que associa a redução da qualidade física do solo com a redução do teor de $\mathrm{MO}$.

Ao avaliar as produtividades das culturas de verão no ano agrícola 2006/2007, na área do presente estudo, MARCELO et al. (2009) verificaram que as produtividades de todas as sequências de verão foram influenciadas pelas sequências de culturas de inverno. Os resultados dessas produtividades foram correlacionados com os valores de $S$ e não se verificou relação significativa entre a produtividade das sequências de culturas de verão com o índice $S$. Os coeficientes de correlação de Pearson ( $r$ ) entre as produtividades com os valores do índice $S$ foram de $-0,14(p=0,54)$ para a seqüência de verão $A F$, de $0,09(p=0,67)$ para a seqüência de verão $R T, 0,02(p=0,92)$ para a seqüência de verão $S V$ e de $0,20(p=0,38)$ para a seqüência de verão $M V$.

No entanto, FREDDI et al. (2009) verificaram que o índice $S$ apresentou correlação positiva com a produtividade de milho, ao avaliar o efeito da compactação do 
solo e produtividade de cultivares de milho em Latossolo Vermelho ( $21 \%$ de argila), sob irrigação. Porém, a redução do índice $S$, a partir de 0,085, no estudo de FREDDI et al. (2009), proporcionou diminuição da produtividade de milho, numa relação não linear. Contudo, FREDDI et al. (2009) relataram ainda, que somente com valores de S abaixo de 0,035 observaram-se queda acentuada na produtividade. A variação do índice $S$ de 0,035 para 0,020, proporcionou uma redução na produtividade de $1,201 \mathrm{t} \mathrm{ha}^{-1}$, numa variação de apenas 0,015 no valores de $S$, o que não se verificou quando o índice $S$ variou de 0,085 para 0,035 , que reduziu a produtividade em $1,052 \mathrm{t} \mathrm{ha}^{-1}$, numa variação em $S$ de 0,05 (FREDDI et al., 2009). O que não foi possível verificar com o presente estudo, onde a produtividade média da cultura do milho ficou próximo a $7 \mathrm{tha}^{-1}$. Provavelmente essa diferença de produtividades do milho, mesmo que alta para a média brasileira, não pode ser atribuída à qualidade física do solo, pois os valores de $\mathrm{S}$ ficaram acima de 0,035, como observando no presente estudo, o que não restringiria, portanto, o crescimento das culturas (DEXTER, 2004a). Desse modo, as informações a respeito das relações entre os valores do índice $S$ e as produtividades das culturas ainda não são claras e carecem de informação sobre o tema qualidade física do solo, requerendo assim novas pesquisas, principalmente para as condições que envolvem o sistema de semeadura direta, nas diferentes regiões do Brasil. 


\subsection{CONCLUSÕES}

1. A seqüência de culturas de verão cultivadas com arroz/feijão/algodão proporcionou os maiores valores médios do índice $S$.

2. Para as sequências de culturas de inverno os maiores valores médios de $S$ foram observados nas culturas de crotalária e sorgo.

3. Verificou-se a diminuição da qualidade física do solo na camada de 0,1-0,2 m onde ocorreram os menores valores médios do índice $S$.

4. O índice S é eficaz na avaliação da qualidade física do solo, apresentando correlação significativa com os atributos físicos do solo, contudo, não foi verificada a relação do índice $\mathrm{S}$ com a produtividade das culturas. 


\section{REFERÊNCIAS}

ALBUQUERQUE, J.A.; ARGENTON, J.; BAYER, C.; WILDNER, L.P.;KUNTZE, M.A.G. Relação de atributos do solo com a agregação de um latossolo vermelho sob sistemas de preparo e plantas de verão para cobertura do solo. Revista brasileira de ciência do solo, Viçosa, v.29, n.1, p.415-424, 2005.

ALLISON, F.E. Soil organic matter and its role in crop production. Amsterdam: Elsevier, 1973. p.315-345.

ALVES, M. C.; SUZUKI, L. G. A. S.; SUZUKI, L. E. A. S. Densidade do solo e infiltração de água como indicadores da qualidade física de um Latossolo Vermelho distrófico em recuperação. Revista Brasileira de Ciência do Solo, Viçosa, v.31, n.4, p. 617-625, 2007.

AMADO, T. J. C.; BAYER, C.; ELTZ, F. L. F.; BRUM, A. C. R. Potencial de culturas de cobertura em acumular carbono e nitrogênio no solo no plantio direto e a melhoria da qualidade ambiental. Revista Brasileira de Ciência do Solo, Viçosa, v.25, n.1, p.189197, 2001.

ANDRADE, R. S.; STONE, L. F. Índice S como indicador da qualidade física de solos do cerrado brasileiro. Revista Brasileira de Engenharia Agrícola e Ambiental, Campina Grande, v.13, n.4, p.382-388, 2009.

ANDRADE, R. S.; STONE, L. F.; SILVEIRA, P. M. Culturas de cobertura e qualidade física de um Latossolo em plantio direto. Revista Brasileira de Engenharia Agrícola e Ambiental, Campina Grande, v.13, n.4, p.411-418, 2009. 
ARAÚJO, M. A.; TORMENA, C. A.; SILVA, A. P. Propriedades físicas de um Latossolo Vermelho distrófico cultivado e sob mata nativa. Brasileira de Ciência do Solo, Viçosa, v.28, n.3, 495-504, 2004.

ARGENTON, J.; ALBUQUERQUE, J. A.; BAYER, C.; WILDNER, L. P. Comportamento de atributos relacionados com a forma da estrutura de Latossolo Vermelho sob sistemas de preparo e plantas de cobertura. Revista Brasileira de Ciência do Solo, Viçosa, v.29, n.3, p.425-435, 2005.

AZEVEDO, A. C.; BONUMÁ, A. S. Partículas coloidais, dispersão e agregação em latossolos. Ciência Rural, Santa Maria, v.34, n.2, p.609-617, 2004.

BAStOS, R. S.; MENDONÇA, E. S.; ALVAREZ, V. H.; CORRÊA, M. M.; COSTA, L. M. Formação e estabilização de agregados do solo influenciados por ciclos de umedecimento e secagem após adição de compostos orgânicos com diferentes características hidrofóbicas. Revista Brasileira de Ciência do Solo, Viçosa, v.29, n.1, p.21-31, 2005.

BAYER, C.; MARTIN-NETO, L.; MIELNICZUK, J.; PAVINATO, A. Armazenamento de carbono em frações lábeis de matéria orgânica de um Latossolo Vermelho sob plantio direto. Pesquisa Agropecuária Brasileira, Brasília, v.39, n.7, p.677-683, 2004.

BAYER, C.; MIELNICZUK, J. Nitrogênio total de um solo submetido a diferentes métodos de preparo e sistemas de cultura. Revista Brasileira de Ciência do Solo, Campinas, v.21, n.2, p.235-239, 1997.

BAVER, L. D.; GARDNER, W. H.; GARDNER, W. R. Soil physics. 4.ed. New York: John Wiley \& Sons, 1972. 529p 
BERTOL, I.; ALBUQUERQUE, J. A.; LEITE, D.; AMARAL, A. J.; ZOLDAN JUNIOR, W. A. Propriedades físicas do solo sob preparo convencional e semeadura direta em rotação e sucessão de culturas, comparadas às do campo nativo. Revista Brasileira de Ciência do Solo, Viçosa, v.28, n.1, p.155-163, 2004.

BERTOL, I.; BEUTLER, J.F.; LEITE, D.; BATISTELA, O. Propriedades físicas de um Cambissolo Húmico afetadas pelo tipo de manejo do solo. Scientia Agrícola, Piracicaba, v.58, n.3, p.555-560, 2001.

BEUtLeR, A. N.; CENTURION, J. F.; ROQUE, C. G. \& FERRAZ, M. V. Densidade relativa ótima de Latossolos Vermelhos para a produtividade de soja. Revista Brasileira de Ciência do Solo, Viçosa, v.29, n.5, p.843-849, 2005.

BEUTLER, A.N.; CENTURION, J.F. \& SILVA, A.P. Intervalo hídrico ótimo e a produção de soja e arroz em dois Latossolos. Irriga, Botucatu, v.9, n.2, p.181-192, 2004.

BEUTLER, A. N.; SILVA, M. L. N.; CURI, N.; FERREIRA, M. M.; CRUZ, J. C. \& PEREIRA FILHO, I. A. Resistência à penetração e permeabilidade de latossolo vermelho distrófico típico sob sistemas de manejo na região dos cerrados. Revista Brasileira de Ciência do Solo, viçosa, n.25, n.2, p.167-177, 2001.

BLAKE, G.R.; HARTGE, K.H., 1986. Bulk density. In: KLUTE, A. (Ed.). Methods of soil analysis: Part 1 - Physical and Mineralogical Methods. Madison: ASA-SSSA, 1986. p.363-375.

BLAINSKI, E.; TORMENA, C. A.; FIDALSKI, J.; GUIMARAES, R. M. L. Quantificação da degradação física do solo por meio da curva de resistência do solo à penetração. Revista Brasileira de Ciência do Solo, Viçosa, v.32, n.5, 975-983, 2008. 
BRADY, N.C.; WEIL, R.P. The nature and properties of soils. New Jersey: Prentice Hall, 2002. 1000p.

BRONICK, C. J.; LAL, R. Soil structure and management: a review. Geoderma, Amsterdam, v.124, p.3-22, 2005.

BROOKS, R.H.; COREY, A.T. Hydraulic properties of porous media. Fort Collins: Colorado State University, 1964. (Hydrology Paper, 3).

BRUCE, R.R.; LUXMORE, R.J. 1986. Water retention: field methods. In: KLUTE, A. (Ed.). Methods of soil analysis: Part 1 - Physical and Mineralogical Methods. Madison: ASA-SSSA, 1986. p.663-686.

CAMARGO, O. A.; MONIZ, A. C.; JORGE, J. A.; VALADARES, J. M. A. S. Métodos de análise química, mineralógica e física de solos do Instituto Agronômico de São Paulo. Campinas: Instituto Agronômico, 1986. 94 p. (Boletim Técnico, 106).

CAMPBELL, D. J. Determination and use of soil bulk density in relation to soil compaction. In: SOANE, B. D.; OUWERKERK, C. van (Ed.). Soil compaction in crop production. Amsterdam: Elsevier, 1994. p.113-139.

CAMPOS, B.C.; REINERT, D.J.; NICOLODI, R.; RUEDELL, J.; PETRERE, C. Estabilidade estrutural de um Latossolo Vermelho-Escuro distrófico após sete anos de rotação de culturas e sistemas de manejo de solo. Revista Brasileira de Ciência do Solo, Campinas, v.19, n.2, p.121-126, 1995.

CARDOSO, A.; POTTER, R.; DEDECEK, R.A. Estudo comparativo da degradação de solos pelo uso agrícola no Noroeste do Estado do Paraná. Pesquisa Agropecuária Brasileira, Brasília, v.27, n.3, p.349-353, 1992. 
CARPENEDO, V.; MIELNICZUK, J. Estado de agregação e qualidade de agregados de Latossolos Roxos submetidos a diferentes sistemas de manejo. Revista Brasileira de Ciência do Solo, Campinas, v.14, n.2, p.99-105, 1990.

CARVALHO, R.; GOEDERT, W. J.; ARMANDO, M. S. Atributos físicos da qualidade de um solo sob sistema agroflorestal. Pesquisa Agropecuária Brasileira. Brasília, v.39, n.11, p.1153-1155, 2004.

CASTRO FILHO, C.; LOURENÇO, A.; GUIMARÃES; M. F.; FONSECA, I. C. B. Aggregate stability under different soil management systems in a red latosol in the state of Parana, Brazil. Soil and Tillage Research, Amsterdam, v.65, p.45-51, 2002.

CASTRO FILHO, C.; MUZILLI, O.; PADANOSCHI, A. L. Estabilidade dos agregados e sua relação com o teor de carbono orgânico num Latossolo Roxo distrófico, em função de sistemas de plantio, rotações de culturas e métodos de preparo das amostras. Revista Brasileira de Ciência do Solo, Viçosa, v.22, n.3, p.527-538, 1998.

CAVALIERI, K. M. V.; SILVA, Á. P.; ARVIDSSON, J.; TORMENA, C. A. Influência da carga mecânica de máquina sobre propriedades físicas de um cambissolo háplico. Revista Brasileira de Ciência do Solo, Viçosa, v.33, n.3, p. 477-485, 2009.

CONCEIÇÃO, P. C.; AMADO, T. J. C.; MIELNICZUK, J.; SPAGNOLLO, E. Qualidade do solo em sistemas de manejo avaliada pela dinâmica da matéria orgânica e atributos relacionados. Brasileira de Ciência do Solo, Viçosa, v.29, n.3, p.777-788, 2005.

CORÁ, J. E. Sistema de semeadura direta na região do município de Jaboticabal, SP: efeitos em atributos do solo e produtividade de culturas. 2006, xv, $87 \mathrm{f}$.; il. Tese (Livre-Docência) - Universidade Estadual Paulista, Faculdade de Ciências Agrárias e Veterinárias, Jaboticabal, 2006. 
CORÁ, J. E.; FERNANDES, C.; BERALDO, J. M. G.; MARCELO, A. V. Adição de areia para dispersão de solos na análise granulométrica. Revista Brasileira de Ciência do Solo, Viçosa, v.33, n.2, p. 255-262, 2009.

CORAZZA, E. J.; SILVA, J. E.; RESCK, D. V. S.; GOMES, A. C. Comportamento de diferentes sistemas de manejo como fonte ou depósito de carbono em relação à vegetação de cerrado. Revista Brasileira de Ciência do Solo, Viçosa, v.23, n.2, p.425432, 1999.

COSTA, F. S.; ALBUQUERQUE, J. A.; BAYER, C.; FONTOURA, S. M. V.; WOBETO, C. Propriedades físicas de um Latossolo Bruno afetadas pelos sistemas de plantio direto e preparo convencional. Revista Brasileira de Ciência do Solo, Viçosa, v.27, n.3, p.527-535, 2003.

COSTA, W. A.; OLIVEIRA, C. A. S.; KATO, E. Modelos de ajuste e métodos para a determinação da curva de retenção de água de um latossolo vermelho-amarelo. Revista Brasileira de Ciência do Solo, Viçosa, v.32, n.2, p.515-523, 2008.

CUNHA, T. J. F.; MACEDO, J. R.; RIBEIRO, L. P.; PALMIERI, F.; FREITAS, P. L.; AGUIAR, A. C. Impacto do manejo convencional sobre propriedades físicas e substâncias húmicas de solos sob cerrado. Ciência Rural, Santa Maria, v.31, n.1, p.2736, 2001.

D'ANDRÉA, A.F.; SILVA, M.L.N.; CURI, N.; FERREIRA, M.M. Atributos de agregação indicadores da qualidade do solo em sistemas de manejo na região dos Cerrados no Sul do Estado de Goiás. Revista Brasileira de Ciência do Solo, Viçosa, v.26, n.4, p.1047-1054, 2002. 
DANIELSON, R.E.; SUTHERLAND, P.L., 1986. Porosity. In: KLUTE, A. (Ed.). Methods of soil analysis: Part 1 - Physical and Mineralogical Methods. Madison: ASA-SSSA, 1986. p.443-461.

DERPSCH, R. et al. Manejo do solo com coberturas verdes de inverno. Pesquisa Agropecuária Brasileira, Brasília, v.20, n.6, p.761-773, 1985.

DE MARIA, I.C.; CASTRO, O.M.; SOUZA DIAS, H. Atributos físicos do solo e crescimento radicular de soja em Latossolo Roxo sob diferentes métodos de preparo do solo. Revista Brasileira de Ciência do Solo, Viçosa, v.23, n.4, p.703-709, 1999.

DEXTER, A. R. Soil physical quality - Part I. Theory, effects of soil texture, density, and organic matter, and effects on root growth. Geoderma, Amsterdam, v.120, p.201-214, 2004a.

DEXTER, A. R. Soil physical quality: Part II. Friability, tillage, tilth and hard-setting. Geoderma, Amsterdam, v.120, p.215-225, 2004b.

DEXTER, A. R. Soil physical quality - Part III: Unsaturated hydraulic conductivity and general conclusions about S-theory. Geoderma, Amsterdam, v.120, p.227-239, 2004c.

DEXTER, A. R. Strenght of soil aggregates and of aggregate beds. Catena, Amsterdam, v.11 (supplement), p. 35-52, 1988.

DEXTER, A.R.; BIRD, N.R.A. Methods for predicting the optimum and the range of water contents for tillage based on the water retention curve. Soil and Tillage Research, Amsterdam, v.57, p.203-212, 2001.

DEXTER, A.R.; BIRKAS, M. Prediction of the soil structures produced by tillage. Soil and Tillage Research, Amsterdam, v.79, p.233-238, 2004. 
DEXTER, A.R.; CZYŻ, E.A.; BIRKÁS, M.; DIAZ-PEREIRA, E.; DUMITRU, E.; ENACHE, R.; H.; FLEIGE, R.; HORN, K.; RAJKAJ, DE LA ROSA, D.; SIMOTA, C. SIDASS project: Part 3 - The optimum and the range of water content for tillage - further developments. Soil and Tillage Research, Amsterdam, v.88, p.29-37, 2005.

DEXTER, A. R.; CZYŻ, E. A.; GAȚE. O. P. A method for prediction of soil penetration resistance. Soil and Tillage Research, Amsterdam, v.93, p.412-419, 2007.

DEXTER, A.R.; CZYŻ, E.A.; RICHARD, G.; RESZKOWSKA, A. A user-friendly water retention function that takes account of the textural and structural pore spaces in soil. Geoderma, Amsterdam, v.143, p.243-253, 2008.

DEXTER, A. R.; KROESBERGEN, B. Methodology for determination of tensile strength of soil aggregates. Journal of Agricultural Engineering Research, England v.31, p.139-147, 1985.

DEXTER, A.R.; YOUNGS, I.M. Soil physics toward 2000. Soil and Tillage Research, Amsterdam, v.24, p.101-106, 1992.

DORAN, J.W.; PARKING, T.B. Defining and assessing soil quality. In: DORAN, J.W., COLEMAN, D.C., BEZDICEK, D.F.; STEWART, B.A. (eds.) Defining soil quality for a sustainable environment. Madison, Soil Science Society of America, 1994. p.3-21. (Special publication, 35).

DOURADO-NETO, D.; JONG VAN LIER, Q.; BOTREL, T.A.; LIBARDI, P.L. Programa para confecção da curva de retenção de água no solo utilizando o modelo de Genuchten. Engenharia Rural, Piracicaba, v.1, p.92-102, 1990. 
DOURADO-NETO, D. NIELSEN, D.R.; HOPMANS, J.W.; REICHARDT, K.; BACCHI, O.O.S. Software to model soil water retention curves (SWRC, version 2.00). Scientia Agrícola, Piracicaba, v.57, n.1, p.191-192, 2000.

DRIESSEN, P.M. Land use system analysis. Wageningen, 1986.

EMBRAPA - EMPRESA BRASILEIRA DE PESQUISA AGROPECUÁRIA. Centro Nacional de Pesquisa de Solos. Sistema Brasileiro de Classificação de Solos. Brasília, 2006. 412p.

EMPRESA BRASILEIRA DE PESQUISA AGROPECUÁRIA. Serviço Nacional de Levantamento e Conservação de Solos. Manual de métodos de análise de solo. 2.ed. Rio de Janeiro, Ministério da Agricultura, 1997. 212p.

FARREL, D.A.; LARSON, W.E. Modeling the pore structure of porous media. Water Resources Research, v.8, p.699-706, 1972.

FASSBENDER, H. W.; BORNEMISZA, E. Química de suelos: Com énfasis en suelos de América Latina. 2.ed. San José: IICA, 1994. 420p.

FREDDI, O. S.; CENTURION, J. F.; DUARTE, A. P.; LEONEL, C. L. Compactação do solo e produção de cultivares de milho em latossolo vermelho: I - características de planta, solo e índice S. Revista Brasileira de Ciência do Solo, Viçosa, v.33, n.4, p.793-803, 2009.

GARDNER, W. H. Water content. In: KLUTE, A. (Ed.). Methods of soil analysis: Part 1 - Physical and Mineralogical Methods. Madison: ASA-SSSA, 1986. p.493-544.

GATE, O.P.; CZYZ, E.A.; DEXTER, A.R. Soil physicalquality $S$ as a basis for relationships between some key physical properties of arable soils. In: HORN, R.; 
FLEIGE, H.;PETH, S.; PENG, X. Soil management for sustainability. Reiskirchen, Catena Verlang, 2006. p.102-109.

GERSCOVICH, D. M. S. Equações para a Modelagem da Curva Característica Aplicada a Solos Brasileiros. In: 4 Simpósio Brasileiro de Solos Não Saturados, Porto Alegre, p.76-93, 2001.

GREGORICH, E.G. Quality. In: LAL, R. (ed.). Encyclopedia of Soil Science. Marcel Dekker, Inc., New York, p.1058-1061, 2002.

GUIMARÃES, C.M.; STONE, L.F. \& MOREIRA, J.A.A. Compactação do solo na cultura do feijoeiro. II: efeito sobre o desenvolvimento radicular e da parte aérea. Revista Brasileira de Engenharia Agrícola e Ambiental, Campina Grande, v.6, n.2, p.213218, 2002.

GUPTA, S. C.; ALLMARAS, R. R. Models to access the susceptibility of soil to excessive compaction. Advances in Soil Sciences, v.6, p.65-100, 1987.

HAJABBASI, M.A; JALALIAN, A.; KARIMZADEH, H.R. Deforestatioin effects on soil physical and chemical properties, Lordegan, Iran. Plant and Soil, v.190, p.301-308, 1997.

HARGROVE, W. L. Winter legumes as a nitrogen source for no-till grain sorghum. Agronomy Journal, v.78, n.1, p.70-74, 1986.

HODNETT, M. G.; TOMASELLA, J. Marked differences between van Genuchten soil water-retention parameters for temperate and tropical soils: a new water-retention pedotransfer functions developed for tropical soils. Geoderma, Amsterdam, v.108, p.155180, 2002. 
HORN, R.; DOMZAL, H.; SLOWINSKA-JURKIEWICZ, A.; van OUWERKERK, C. Soil compaction processes and their effects on the structure of arable soils and the environment. Soil and Tillage Research, Amsterdam, v.35, p.23-26, 1995.

HUTSON, J.L.; CASS, A. A retentivity function for use in soil-water simulation models. Journal Soil Science, Madison, v.38, p.105-113, 1987.

IMHOFF, S. D. C. Indicadores de Qualidade Estrutural e trafegabilidade de Latossolos e Argissolos Vermelhos. 2002, 94p. Tese (doutorado), ESALQ-USP, Piracicaba, 2002.

IMHOFF, S.; DA SILVA, A.P.; DIAS JÚNIOR, M.S.; TORMENA, C.A. Quantificação de pressões críticas para o crescimento de plantas. Revista Brasileira de Ciência do Solo, Viçosa, v.25, p.1, p.11-18, 2001.

KARLEN, D.L.; STOTT, D.E. A framework for evaluating physical and chemical indicators of soil quality. In: DORAN, J.W.; COLEMAN, D.C.; BEZDICEK, D.F.; STEWART, B.A.(eds.) Defining soil quality for a sustainable environment. SSSA, Madison, 1994, p.53-72. (Special publication, 35).

KEMPER, W.D. Aggregate stability. In: Black, C.A. et al. (Eds.), Methods of Soil Analysis. Part I. Madison: ASA and SSSA, 1965. p.511-519.

KEMPER, W.D.; ROSENAU, R.C. Aggregate stability and size distribution. In: KLUTE, A. (Ed.), Methods of soil analysis: Part 1 - Physical and Mineralogical Methods. Madison: ASA-SSSA, 1986. p.425-442.

KIEHL, E. J. Manual de edafologia. São Paulo: Agronômica Ceres, 1979. 262p. 
KLUTE, A. Water retention: laboratory methods. In: KLUTE, A. (Ed.), Methods of soil analysis: Part 1 - Physical and Mineralogical Methods. Madison: ASA-SSSA, 1986. p.635-662.

KLUTHCOUSKI, J.; FANCELLI, A.L.; DOURADO-NETO, D.; RIBEIRO, C,M.; FERRARO, L.A. Manejo do solo e o rendimento de soja, milho, feijão e arroz em plantio direto. Scientia Agricola, Piracicaba, v.57, p.97-104, 2000.

LAL, R.; GREENLAND, B.J. Soil physical properties and crop production in tropics. Chischester, John Willey, 1979. p.7-85.

LARSON, W. E.; PIERCE, F. J. The dynamics of soil quality as a measure of sustainable management. In: DORAN, J.W.; COLEMAN, D.C.; BEZDICEK, D.F.; STEWART, B.A. (Ed.) Defining soil quality for a sustainable environment. Soil Science Society of America: American Society of Agronomy, 1994. p. 37-51.

LEAL, A. J. F.; LAZARINI, E.; RODRIGUES, L. R.; MURAISHI, C. T.; BUZETTI, S.; MASCARENHAS, H. A. A. Aplicação de calcário e culturas de cobertura na implantação do sistema plantio direto em cerrado. Revista Brasileira de Ciência do Solo, Viçosa, v.32, n.spe, p.2771-2777, 2008.

LEÃO, T. P.; SILVA, A. P.; MACEDO, M. C. M., IMHOFF, S.; EUCLIDES, V. P. B. Intervalo hídrico ótimo na avaliação de sistemas de pastejo contínuo e rotacionado. Revista Brasileira de Ciência do Solo, Viçosa, v.28, n.3, p.415-422, 2004.

LEONARDO, H. C. L. Indicadores de qualidade do solo e água para a avaliação do uso sustentável da microbacia hidrográfica do Rio Passo Cue, Região Oeste do Estado do Paraná. 2002. 121p. Dissertação (mestrado) Escola Superior de Agricultura “Luiz de Queiroz" - Universidade de São Paulo, Piracicaba, 2002. 
LETEY, J. Relationship between soil physical properties and crop production. Advances in Soil Science, New York, v.1, p.277-294, 1985.

LEY, G.J.; MULLINS, C.E.; LAL, R. Effects of soil properties on the strength of weakly structures tropical soils. Soil and Tillage Research, Amsterdam, v.28, n.1, p.1-13, 1993.

LIBARDI, P.L.; REICHARDT, K.; NASCIMENTO-FILHO, V. F. Análise da redistribuição da água visando a condutividade hidráulica do solo. Energia Nuclear \& Agricultura, Piracicaba, v.1, p.108-122, 1979.

LIMA, C. L. R.; REINERT, D. J.; REICHERT, J. M.; SUZUKI, L. E. A. S.; GUBIANI, P. I. Qualidade físico-hídrica e rendimento de soja (Glycine max L.) e feijão (Phaseolus vulgaris L.) de um Argissolo Vermelho distrófico sob diferentes sistemas de manejo. Ciência Rural, Santa Maria, v.36, p.1172-1178, 2006.

LIMA, H. V.; LIMA, C. L. R.; LEÃO, T. P.; COOPER, M.; SILVA, A. P.; ROMERO, R. E. Tráfego de máquinas agrícolas e alterações de bioporos em área sob pomar de laranja. Revista Brasileira de Ciência do Solo, Viçosa, v.29, n.3, p.677-684, 2005.

LIMA, H. V.; SILVA, A. P. Mesa de tensão com areia: Procedimentos para montagem e validação. Revista Brasileira de Ciência do Solo, Viçosa, v.32, n.6, p.2209-2214, 2008.

LLANILLO, R. F.; RICHART, A.; TAVARES FILHO, J.; GUIMARÃES, M. F.; FERREIRA, R. R. M. Evolução de propriedades físicas do solo em função dos sistemas de manejo em culturas anuais. Semina: Ciências Agrárias, Londrina, v.27, n.2, p.205-220, 2006.

LOVATO, T.; MIELNICZUK, J.; BAYER, C.; F. VEZZANI. Adição de carbono e nitrogênio e sua relação com os estoques no solo e com o rendimento do milho em 
sistemas de manejo. Revista Brasileira de Ciência do Solo, Viçosa, v.28, n.2, p.175187, 2004.

MACHADO, J.L.; TORMENA, C.A.; FIDALSKI, J.; SCAPIM, C.A. Inter-relações entre as propriedades físicas e os coeficientes da curva de retenção de água de um latossolo sob diferentes sistemas de uso. Revista Brasileira de Ciência do Solo, Viçosa, v.32, n.3, p.495-502, 2008.

MADARI, B.; MACHADO, P. L. O. A.; TORRES, E.; ANDRADE, A. G.; VALENCIA; L. I. $O$. No tillage and crop rotation effects on soil aggregation and organic carbon in a Rhodic Ferralsol from southern Brazil. Soil and Tillage Research, Amsterdam, v.80, p.185-200, 2005.

MARCELO, A. V. CORA, J. E.; FERNANDES, C.; Martins, M. R.; Jorge, R. F. Crop sequences in no-tillage system: effects on soil fertility and soybean, maize and rice yield. Revista Brasileira de Ciência do Solo, Viçosa, v.33, n.3, p.417-428, 2009.

MARTINS, R.M.G.; ROSA JUNIOR, E.J. Culturas antecessoras influenciando a cultura de milho e os atributos do solo no sistema de plantio direto. Acta Scientiarum. Agronomy, Maringá, v.27, n.2, p.225-232. 2005.

MARTINS, M. R. Carbono orgânico e polissacarídeos em agregados de um latossolo vermelho eutrófico em sequências de culturas sob semeadura direta. Jaboticabal, 2008. 45 f. il. Dissertação (mestrado) - Universidade Estadual Paulista, Faculdade de Ciências Agrárias e Veterinárias, Jaboticabal, 2008.

MARUN, F. Propriedades físicas e biológicas de um Latossolo Vermelho-Escuro do Arenito Caiuá sob pastagens e culturas anuais. Pesquisa Agropecuária Brasileira, Brasília, v.31, n.5, p.593-597, 1996. 
MORAES, S.O.; LIBARDI, P.L.; DOURADO NETO, D. Problemas metodológicos na obtenção da curva de retenção. Scientia Agrícola, Piracicaba, v.50, n.2, p.383-392, 1993.

NASCIMENTO, J. T.; SILVA; I.F.; SANTIAGO, R.D.; SILVANETO, L.F. Efeito de leguminosas nos atributos físicos e carbono orgânico de um Luvissolo. Revista Brasileira de Ciência do Solo, Viçosa, v.29, n.4, p.825-831, 2005.

OLIVEIRA, G.C.; DIAS JUNIOR, M.S.; RESCK, D.V.S.; CURI, N. Alterações estruturais e comportamento compressivo de um Latossolo Vermelho distrófico argiloso sob diferentes sistemas de uso e manejo. Pesquisa Agropecuária Brasileira, Brasília, v.38, n.3, p.291-299, 2003.

OLIVEIRA, J. O. A. P.; VIDIGAL FILHO, P. S.; TORMENA, C. A.; PEQUENO, M. G.; SCAPIM, C. A.; MUNIZ, A. S.; SAGRILO, E. Influência de sistemas de preparo do solo na produtividade da mandioca (Manihot esculenta, Crantz). Revista Brasileira de Ciência do Solo, Viçosa, v.25, n.3, p.443-450, 2001.

PAGLIAI, M.; VIGNOZZI, N.; PELLEGRINI S. Soil structure and the effect of management practices. Soil and Tillage Research, Amsterdam, v.79, p.131-143, 2004.

PASSIOURA, J.B.; GARDNER, P.A. Control of leaf expansion in wheat seedlings growing in drying soil. Australian Journal Plant Physiology, Collingwood, v.17, p.149$157,1990$.

PASSOS, R.R. Carbono orgânico e nitrogênio em agregados de um latossolo vermelho sob duas coberturas vegetais. 2000. 89f. Tese (Doutorado) Universidade Federal de Viçosa, Viçosa, 2000. 
PASSOS, R. R.; RUIZ, H. A.; CANTARUTTI, R. B.; MENDONCA, E. S. Carbono orgânico e Nitrogênio em agregados de um Latossolo Vermelho distrófico sob duas coberturas vegetais. Revista Brasileira de Ciência do Solo, Viçosa, v.31, n.5, p.11091118, 2007.

PRIMAVESI, A. O manejo ecológico do solo. 4.ed. São Paulo: Nobel, 1982. 541p.

RICHART, A.; TAVARES FILHO, J.; BRITO, O. R.; LLANILLO, R. F.; FERREIRA, R. Compactação do solo: Causas e efeitos. Semina, v.26, n.3, p.321-344, 2005.

REICHERT, J.M.; REINERT, D.J.; BRAIDA, J.A. Qualidade dos solos e sustentabilidade de sistemas agrícolas. Ciência Ambiental, Viçosa, v.27, n.2, p.29-48, 2003.

ROSOLEM, C.A.; FERNANDEZ, E.M.; ANDREOTTI; M.; CRUSCIOL, C.A.C. Crescimento radicular de plântulas de milho afetado pela resistência do solo à penetração. Pesquisa Agropecuária Brasileira, Brasília, v.34, n.8, p.821-828, 1999.

SHUKLA, M.K.; LAL, R.; EBINGER, M. Determining soil quality indicators by factor analysis. Soil and Tillage Research, Amsterdam, v.87, p.194-204, 2006.

SILVA, A. P.; KAY, B. D.; PERFECT, E. Characterization of the least limiting water range. Soil Science Society of America Journal, Madison, v.58, p.1775-1781, 1994.

SILVA, A. P.; TORMENA, C. A.; FIDALSKI, J.; IMHOFF, S. Funções de pedotransferência para as curvas de retenção de água e de resistência do solo à penetração. Revista Brasileira de Ciência do Solo, Viçosa, v.32, n.1, p.1-10, 2008.

SILVA, E.M.; LIMA, J.E.F.W.; AZEVEDO, J.A.; RODRIGUES, L.N. Valores de tensão na determinação da curva de retenção de água de solos do Cerrado. Pesquisa Agropecuária Brasileira, Brasília, v.41, n.3, p.323-330, 2006 a. 
SILVA, M.L.N.; CURI, N.; BLANCANEAUX, P. Sistemas de manejo e qualidade estrutural de Latossolo Roxo. Pesquisa Agropecuária Brasileira. Brasília, v.35, n.12, p.2485-2492, 2000.

SILVA, S. R.; BARROS, N. F.; COSTA, L. M. Atributos físicos de dois Latossolos afetados pela compactação do solo. Revista Brasileira de Engenharia Agrícola e Ambiental, Campina Grande, v.10, n.4, p.842-847, 2006 b.

SILVEIRA NETO, A. N. ; SILVEIRA, P. M.; STONE, L. F.; OLIVEIRA, L. F. C. Efeitos de manejo e rotação de culturas em atributos físicos do solo. Pesquisa Agropecuária Tropical, Goiânia, v.36, n.1, p.29-35, 2006.

SIMMONS, C.S.; NIELSEN, D.R.; BIGGAR, J.W. Scaling of field-measured soil water properties. Hilgardia, California, v.47, p.77-173, 1979.

SIX, J., ELLIOTT, E.T.; PAUSTIAN, K.. Aggregate and soil organic matter dynamics under conventional and no-tillage systems. Soil Science Society of America Journal, Madison, v.63, p.1350-1358, 1999.

SPERA, S. T.; SANTOS, H. P.; FONTANELI, R. S.; TOMM, G. O. Integração lavoura e pecuária e os atributos físicos de solo manejado sob sistema plantio direto. Revista Brasileira de Ciência do Solo, Viçosa, v.33, n.1, p. 129-136, 2009.

STONE, L. F.; GUIMARÃES, C. M.; MOREIRA, J. A. A. Compactação do solo na cultura do feijoeiro. I: Efeitos nas propriedades físico-hídricas do solo. Revista Brasileira de Engenharia Agrícola e Ambiental, Campina Grande, v.6, n.2, p.207-212, 2002. 
STONE, L.F.; SILVEIRA, P.M. Efeitos do sistema de preparo e da rotação de culturas na porosidade e densidade do solo. Revista Brasileira de Ciência do Solo, Viçosa, v.25, n.3, p.395-401, 2001.

STRECK, C. A.; REINERT, D. J.; REICHERT, J. M.; HORN, R. Relações do parâmetro $S$ para algumas propriedades físicas de solos do sul do Brasil. Revista Brasileira de Ciência do Solo, Viçosa, v.32, n.spe, p.2603-2612, 2008.

TISDALL, J. M.; OADES, J. M. Organic matter and water-stable aggregates in soil. Journal of Soil Science, London, v.33, p.141-163, 1982.

TOPP, G.C.; REYNOLDS, F.J.; COOK, J.M.; KIRBY, J.M.; CARTER, M.R. Physical attributes of soil quality. In: GREGORICH, E.G.; CARTER, M.R.(eds.) Soil quality for crop production and ecosystem health. Developments in Soil Science, Amsterdam, n.25, p.21-58, 1997.

TORMENA, C.A.; FIDALSKI, J.; ROSSI JUNIOR, W. Resistência tênsil e friabilidade de um latossolo sob diferentes sistemas de uso. Revista Brasileira de Ciência do Solo, Viçosa, v.32, n.1, p.33-42, 2008 a.

TORMENA, C.A.; ROLOFF, G. Dinâmica da resistência à penetração de um solo sob plantio direto. Revista Brasileira de Ciência do Solo, Campinas, v.20, n.3, p.333-339, 1996.

TORMENA, C. A.; SILVA, A. P.; IMHOFF, S. D. C.; DEXTER, A. R. Quantification of the soil physical quality of a tropical oxisol using the $S$ index. Scientia Agrícola, Piracicaba, v.65, n.1, p.56-60, 2008 b. 
TORMENA, C.A.; SILVA, A.P.; LIBARDI, P.L. Caracterização do intervalo hídrico ótimo de um Latossolo Roxo sob plantio direto. Revista Brasileira de Ciência do Solo, Viçosa, v.22, n.3, p.573-581, 1998.

TORRES, E.; SARAIVA, O. F. Estudo das causas da compactação do solo e do seu efeito sobre a soja. Resultados de pesquisa da Embrapa Soja. Embrapa, Londrina, 1998. p.177-181.

VAN GENUCHTEN, M.T.A. A closed-form equation for predicting the hydraulic conductivity of unsaturated soils. Soil Science Society of America Journal, Madison, v.44, p.892-897, 1980.

VEZZANI, F. Qualidade do sistema solo na produção agrícola. 2001. 184p. Tese (Doutorado) Universidade Federal do Rio Grande do Sul, Porto Alegre, 2001.

VEZZANI, F. M.; MIELNICZUK, J. Uma visão sobre qualidade do solo. Revista Brasileira de Ciência do Solo, Viçosa, v.33, n.4, p.743-755, 2009.

VOORHEES, N.M.; SENST, C.G.; NELSON, W.W. Compaction and soil structure modification by wheel traffic in the Northern corn belt. Soil Science Society of America Journal, Madison, v.42, p.344-349, 1978.

WALCZAK, R.T.; MORENO, F.; FERNANDEZ, E.; ARRUE, J.L. Modeling of soil water retention curve using soil solid phase parameters. Journal of Hydrology, Amsterdam, v.329, p.527-533, 2006.

WENDLING, B.; JUCKSCH, I.; MENDONÇA, E. S.; NEVES, J. C. L. Carbono orgânico e estabilidade de agregados de um Latossolo Vermelho sob diferentes manejos. Pesquisa Agropecuária Brasileira, Brasília, v.40, n.4, p.487-494, 2005. 
YODER, R.E. A direct method of aggregate analysis of soil and a study of physical nature of soil erosion losses. Journal of American Society of Agronomy, Madison, v.28, p.337-351, 1936. 


\section{APÊNDICES}

Tabela 1a. Tensões das 450 curvas de retenção de água utilizadas para o ajuste dos parâmetros do modelo de van Genuchten (1980)

\begin{tabular}{|c|c|c|c|c|c|c|c|c|c|c|c|c|c|c|c|c|}
\hline \multirow{2}{*}{$\begin{array}{l}\text { Curvas } \\
1 \text { (C1) }\end{array}$} & \multirow{2}{*}{$\begin{array}{l}\mathrm{Nt} \\
15\end{array}$} & \multicolumn{14}{|c|}{ Tensões (hPa) } & \multirow[b]{2}{*}{15000} \\
\hline & & 0 & 10 & 20 & 40 & 60 & 80 & 100 & 200 & 300 & 500 & 700 & 1000 & 3000 & 5000 & \\
\hline 2 & 14 & 0 & 10 & 20 & 40 & 60 & 80 & 100 & 200 & 300 & 500 & 700 & 1000 & 3000 & 5000 & \\
\hline 3 & 13 & 0 & 10 & 20 & 40 & 60 & 80 & 100 & 200 & & 500 & & 1000 & 3000 & 5000 & 15000 \\
\hline 4 & 13 & 0 & 10 & 20 & 40 & 60 & 80 & 100 & & 300 & & 700 & 1000 & 3000 & 5000 & 15000 \\
\hline 5 & 11 & 0 & 10 & 20 & 40 & 60 & 80 & 100 & 200 & & 500 & & 1000 & 3000 & & \\
\hline 6 & 11 & 0 & 10 & 20 & 40 & 60 & 80 & 100 & & 300 & & 700 & 1000 & 3000 & & \\
\hline 7 & 11 & 0 & 10 & 20 & 40 & 60 & 80 & 100 & 200 & & 500 & & 1000 & & 5000 & \\
\hline 8 & 11 & 0 & 10 & 20 & 40 & 60 & 80 & 100 & 200 & & 500 & & 1000 & & & 15000 \\
\hline 9 & 11 & 0 & 10 & 20 & 40 & 60 & 80 & 100 & & 300 & & 700 & 1000 & & & 15000 \\
\hline 10 & 8 & 0 & 10 & & & 60 & & 100 & & 300 & 500 & & 1000 & 3000 & & \\
\hline 11 & 8 & 0 & 10 & & & 60 & & 100 & & 300 & 500 & & 1000 & & 5000 & \\
\hline 12 & 8 & 0 & 10 & & & 60 & & 100 & & 300 & 500 & & 1000 & & & 15000 \\
\hline 13 & 13 & 0 & 10 & 20 & 40 & 60 & 80 & 100 & 200 & 300 & 500 & 700 & 1000 & & & 15000 \\
\hline 14 & 13 & 0 & 10 & 20 & 40 & 60 & 80 & 100 & 200 & 300 & 500 & 700 & & 3000 & 5000 & \\
\hline 15 & 8 & 0 & 10 & & & 60 & & 100 & & 300 & & 700 & & 3000 & & 15000 \\
\hline 16 & 8 & 0 & 10 & & & 60 & & 100 & & 300 & & 700 & 1000 & & & 15000 \\
\hline 17 & 8 & 0 & 10 & & & 60 & & 100 & & 300 & & 700 & 1000 & 3000 & & \\
\hline 18 & 8 & 0 & 10 & & & 60 & & 100 & & 300 & & 700 & 1000 & & 5000 & \\
\hline 19 & 8 & 0 & & 20 & & 60 & & 100 & & 300 & & 700 & 1000 & & & 15000 \\
\hline 20 & 11 & 0 & 10 & 20 & 40 & 60 & 80 & 100 & & 300 & & 700 & 1000 & & 5000 & \\
\hline 21 & 7 & 0 & 10 & & & & 80 & & & 300 & & 700 & 1000 & & & 15000 \\
\hline 22 & 7 & 0 & & 20 & & & 80 & & & 300 & & 700 & 1000 & & & 15000 \\
\hline 23 & 10 & 0 & 10 & 20 & 40 & 60 & 80 & 100 & & & 500 & & & 3000 & & 15000 \\
\hline 24 & 7 & 0 & & & & 60 & & 100 & & 300 & & 700 & 1000 & 3000 & & \\
\hline 25 & 9 & 0 & 10 & 20 & 40 & 60 & 80 & 100 & & & & 700 & & & & 15000 \\
\hline 26 & 6 & 0 & & 20 & & 60 & & 100 & & & & 700 & & & & 15000 \\
\hline 27 & 8 & 0 & 10 & 20 & 40 & 60 & 80 & 100 & & & & & & & & 15000 \\
\hline 28 & 12 & 0 & 10 & 20 & 40 & 60 & 80 & 100 & 200 & 300 & 500 & 700 & 1000 & & & \\
\hline 29 & 10 & 0 & 10 & 20 & 40 & & 80 & & & 300 & & 700 & 1000 & & 5000 & 15000 \\
\hline 30 & 9 & 0 & 10 & 20 & 40 & & 80 & & & 300 & & 700 & 1000 & & & 15000 \\
\hline 31 & 7 & 0 & & 20 & & 60 & & 100 & & 300 & & 700 & & & & 15000 \\
\hline 32 & 7 & 0 & & 20 & & 60 & & 100 & & 300 & & & 1000 & & & 15000 \\
\hline 33 & 6 & 0 & 10 & & & 60 & & 100 & & & & 700 & & & & 15000 \\
\hline 34 & 6 & 0 & 10 & & & 60 & & & 200 & & & & 1000 & & & 15000 \\
\hline 35 & 6 & 0 & 10 & & & 60 & & & & 300 & & & 1000 & & & 15000 \\
\hline 36 & 6 & 0 & & 20 & & 60 & & & & 300 & & & 1000 & & & 15000 \\
\hline 37 & 6 & 0 & 10 & & & & 80 & & & 300 & & & 1000 & & & 15000 \\
\hline 38 & 6 & 0 & & 20 & & & 80 & & & 300 & & & 1000 & & & 15000 \\
\hline
\end{tabular}

Continua... 
Tabela 1a. Continuação

\begin{tabular}{|c|c|c|c|c|c|c|c|c|c|c|c|c|c|c|c|c|}
\hline 39 & 7 & 0 & 10 & & & 60 & & 100 & & & 500 & & 1000 & & & 15000 \\
\hline 40 & 7 & 0 & 10 & & & 60 & 80 & & & & 500 & & 1000 & & & 15000 \\
\hline 41 & 7 & 0 & 10 & 20 & 60 & & & & & 300 & & & 1000 & & & 15000 \\
\hline 42 & 7 & 0 & & 20 & & 60 & 80 & & & 300 & & & 1000 & & & 15000 \\
\hline 43 & 7 & 0 & & 20 & & 60 & 80 & & & 300 & & & 1000 & 3000 & & \\
\hline 44 & 7 & 0 & & 20 & & 60 & 80 & & & 300 & & & 1000 & & 5000 & \\
\hline 45 & 7 & 0 & & & & 60 & & 100 & & 300 & & 700 & 1000 & & 5000 & \\
\hline 46 & 14 & 0 & 10 & 20 & 40 & 60 & 80 & 100 & 200 & 300 & 500 & 700 & 1000 & 3000 & & 15000 \\
\hline 47 & 14 & 0 & 10 & 20 & 40 & 60 & 80 & 100 & 200 & 300 & 500 & 700 & 1000 & & 5000 & 15000 \\
\hline 48 & 12 & 0 & 10 & 20 & 40 & 60 & 80 & 100 & & 300 & & 700 & 1000 & 3000 & & 15000 \\
\hline 49 & 12 & 0 & 10 & 20 & 40 & 60 & 80 & 100 & & 300 & & 700 & 1000 & & 5000 & 15000 \\
\hline 50 & 5 & 0 & & 20 & & 60 & & & & & & 700 & & & & 15000 \\
\hline 51 & 5 & 0 & & & & 60 & & 100 & & & & 700 & & & & 15000 \\
\hline 52 & 5 & 0 & & 20 & & & & 100 & & & & 700 & & & & 15000 \\
\hline 53 & 5 & 0 & & & & & 80 & & & 300 & & & 1000 & & & 15000 \\
\hline 54 & 4 & 0 & & & & 60 & & & & 300 & & & & & & 15000 \\
\hline 55 & 4 & 0 & & & & 60 & & & & & & 700 & & & & 15000 \\
\hline 56 & 12 & 0 & 10 & 20 & 40 & 60 & 80 & 100 & 200 & 300 & 500 & 700 & 3000 & & & \\
\hline 57 & 12 & 0 & 10 & 20 & 40 & 60 & 80 & 100 & 200 & 300 & 500 & 700 & & & 5000 & \\
\hline 58 & 12 & 0 & 10 & 20 & 40 & 60 & 80 & 100 & 200 & 300 & 500 & 700 & & & & 15000 \\
\hline 59 & 12 & 0 & 10 & 20 & 40 & 60 & 80 & 100 & 200 & & & 700 & 1000 & 3000 & 5000 & \\
\hline 60 & 11 & 0 & 10 & 20 & 60 & 80 & 100 & 200 & 300 & 500 & 700 & & & 3000 & & \\
\hline 61 & 11 & 0 & 10 & 20 & & 60 & 80 & 100 & 200 & 300 & 500 & 700 & & & 5000 & \\
\hline 62 & 11 & 0 & 10 & 20 & 60 & 80 & 100 & & 200 & 300 & 500 & 700 & & & & 15000 \\
\hline 63 & 11 & 0 & 10 & 20 & & 60 & 80 & 100 & & 300 & & 700 & 1000 & 3000 & & 15000 \\
\hline 64 & 10 & 0 & 10 & 20 & & 60 & & 100 & 200 & 300 & 500 & 700 & & 3000 & & \\
\hline 65 & 10 & 0 & 10 & 20 & & 60 & & 100 & 200 & 300 & 500 & 700 & & & 5000 & \\
\hline 66 & 10 & 0 & 10 & 20 & & 60 & & 100 & 200 & 300 & 500 & 700 & & & & 15000 \\
\hline 67 & 10 & 0 & 10 & 20 & & 60 & & 100 & & 300 & & 700 & 1000 & 3000 & & 15000 \\
\hline 68 & 9 & 0 & & 20 & & 60 & & 100 & 200 & 300 & 500 & 700 & & 3000 & & \\
\hline 69 & 9 & 0 & & 20 & & 60 & & 100 & 200 & 300 & 500 & 700 & & & 5000 & \\
\hline 70 & 9 & 0 & & 20 & & 60 & & 100 & 200 & 300 & 500 & 700 & & & & 15000 \\
\hline 71 & 9 & 0 & & 20 & & 60 & & 100 & & 300 & & 700 & 1000 & 3000 & & 15000 \\
\hline 72 & 8 & 0 & & 20 & & 60 & & 100 & 200 & 300 & & 700 & & 3000 & & \\
\hline 73 & 8 & 0 & & 20 & & 60 & & 100 & 200 & 300 & & 700 & & & 5000 & \\
\hline 74 & 8 & 0 & & 20 & & 60 & & 100 & 200 & 300 & & 700 & & & & 15000 \\
\hline 75 & 8 & 0 & & 20 & & 60 & & 100 & & 300 & & 700 & & 3000 & & 15000 \\
\hline 76 & 7 & 0 & & 20 & & 60 & & 100 & 200 & 300 & & & & 3000 & & \\
\hline 77 & 7 & 0 & & 20 & & 60 & & 100 & 200 & 300 & & & & & 5000 & \\
\hline 78 & 7 & 0 & & 20 & & 60 & & 100 & 200 & 300 & & & & & & 15000 \\
\hline 79 & 7 & 0 & & 20 & & 60 & & 100 & & 300 & & & & 3000 & & 15000 \\
\hline 80 & 6 & 0 & & 20 & & 60 & & & 200 & 300 & & & & 3000 & & \\
\hline 81 & 6 & 0 & & 20 & & 60 & & & 200 & 300 & & & & & 5000 & \\
\hline 82 & 6 & 0 & & 20 & & 60 & & & 200 & 300 & & & & & & 15000 \\
\hline 83 & 6 & 0 & & 20 & & 60 & & & & 300 & & & & 3000 & & 15000 \\
\hline 84 & 6 & 0 & & 20 & & 60 & & 100 & & 300 & & & & 3000 & & \\
\hline
\end{tabular}

Continua... 
Tabela 1a. Continuação

\begin{tabular}{|c|c|c|c|c|c|c|c|c|c|c|c|c|c|c|c|}
\hline 85 & 6 & 0 & & 20 & & 60 & & 100 & & 300 & & & & 5000 & \\
\hline 86 & 6 & 0 & & 20 & & 60 & & 100 & & 300 & & & & & 15000 \\
\hline 87 & 6 & 0 & & 20 & & 60 & & 100 & & & & & 3000 & & 15000 \\
\hline 88 & 10 & 0 & 10 & 20 & & 60 & & 100 & 200 & & 700 & 1000 & 3000 & & 15000 \\
\hline 89 & 9 & 0 & & 20 & & 60 & & 100 & & 300 & 700 & 1000 & & 5000 & 15000 \\
\hline 90 & 7 & 0 & 10 & & & 60 & 80 & & & 300 & & 1000 & & 5000 & \\
\hline 91 & 7 & 0 & & 20 & & 60 & & 100 & 300 & & & 1000 & & 5000 & \\
\hline 92 & 7 & 0 & 10 & & & 60 & & 100 & & 300 & & 1000 & & 5000 & \\
\hline 93 & 7 & 0 & 10 & & & 60 & & 100 & 200 & 300 & & & 3000 & & \\
\hline 94 & 7 & 0 & 10 & & & 60 & & 100 & 200 & 300 & & & & 5000 & \\
\hline 95 & 7 & 0 & 10 & & & 60 & & 100 & 200 & 300 & & & & & 15000 \\
\hline 96 & 7 & 0 & 10 & & & 60 & & 100 & & 300 & & & 3000 & & 15000 \\
\hline 97 & 7 & 0 & 10 & & & 60 & & 100 & & 300 & & 1000 & & & 15000 \\
\hline 98 & 12 & 0 & 10 & 20 & 40 & 60 & 80 & 100 & & 300 & 700 & 1000 & 3000 & 5000 & \\
\hline 99 & 5 & 0 & & 20 & & 60 & & & & & & 1000 & & & 15000 \\
\hline 100 & 5 & 0 & & 20 & & & & 100 & & & & 1000 & & & 15000 \\
\hline 101 & 5 & 0 & & 20 & & & & 100 & & 300 & & & & & 15000 \\
\hline 102 & 5 & 0 & & 20 & & & & & 200 & & & 1000 & & & 15000 \\
\hline 103 & 5 & 0 & 10 & & & 60 & & & & & & 1000 & & & 15000 \\
\hline 104 & 5 & 0 & 10 & & & & & 100 & & & & 1000 & & & 15000 \\
\hline 105 & 5 & 0 & 10 & & & & & 100 & & 300 & & & & & 15000 \\
\hline 106 & 5 & 0 & 10 & & & & & & 200 & & & 1000 & & & 15000 \\
\hline 107 & 5 & 0 & & & & 60 & & 100 & & & & 1000 & & & 15000 \\
\hline 108 & 5 & 0 & & & & 60 & & & & 300 & & 1000 & & & 15000 \\
\hline 109 & 5 & 0 & & & & 60 & 80 & 100 & & & & & & & 15000 \\
\hline 110 & 5 & 0 & & & & 60 & & & 200 & & & 1000 & & & 15000 \\
\hline 111 & 5 & 0 & & & & 60 & & & 200 & & 700 & & & & 15000 \\
\hline 112 & 5 & 0 & & & & & & 100 & & 300 & 700 & & & & 15000 \\
\hline 113 & 5 & 0 & & & & & & 100 & & 300 & & 1000 & & & 15000 \\
\hline 114 & 5 & 0 & & & & & & 100 & & 300 & & & 3000 & & 15000 \\
\hline 115 & 5 & 0 & & & & 60 & & & & 300 & & & 3000 & & 15000 \\
\hline 116 & 5 & 0 & & & & 60 & & & 200 & & & & 3000 & & 15000 \\
\hline 117 & 5 & 0 & & 20 & & & & & 200 & & & & 3000 & & 15000 \\
\hline 118 & 5 & 0 & 10 & & & & & & 200 & & & & 3000 & & 15000 \\
\hline 119 & 5 & 0 & 10 & & & & & 100 & & & & & 3000 & & 15000 \\
\hline 120 & 5 & 0 & & 20 & & & & 100 & & & & & 3000 & & 15000 \\
\hline 121 & 5 & 0 & & & & 60 & & 100 & & & & & 3000 & & 15000 \\
\hline 122 & 5 & 0 & & & & 60 & 80 & & & 300 & & & & & 15000 \\
\hline 123 & 5 & 0 & 10 & & & & 80 & 100 & & & & & & & 15000 \\
\hline 124 & 5 & 0 & 10 & & & & 80 & & & 300 & & & & & 15000 \\
\hline 125 & 5 & 0 & 10 & & & & 80 & & & & 700 & & & & 15000 \\
\hline 126 & 5 & 0 & 10 & & & & 80 & & & & & 1000 & & & 15000 \\
\hline 127 & 5 & 0 & 10 & & & & 80 & & & & & & 3000 & & 15000 \\
\hline 128 & 5 & 0 & & 20 & & & 80 & 100 & & & & & & & 15000 \\
\hline 129 & 5 & 0 & & 20 & & & 80 & & & 300 & & & & & 15000 \\
\hline 130 & 5 & 0 & & 20 & & & 80 & & & & 700 & & & & 15000 \\
\hline
\end{tabular}

Continua... 
Tabela 1a. Continuação

\begin{tabular}{|c|c|c|c|c|c|c|c|c|c|c|c|c|}
\hline 131 & 5 & 0 & & 20 & & & 80 & & & & 1000 & 15000 \\
\hline 132 & 5 & 0 & & 20 & & & 80 & & & & 3000 & 15000 \\
\hline 133 & 5 & 0 & 10 & & & & 80 & & 200 & & & 15000 \\
\hline 134 & 5 & 0 & & 20 & & & 80 & & 200 & & & 15000 \\
\hline 135 & 4 & 0 & 10 & & & 60 & & & & & & 15000 \\
\hline 136 & 4 & 0 & 10 & & & & 80 & & & & & 15000 \\
\hline 137 & 4 & 0 & 10 & & & & & 100 & & & & 15000 \\
\hline 138 & 4 & 0 & 10 & & & & & & 200 & & & 15000 \\
\hline 139 & 4 & 0 & 10 & & & & & & 300 & & & 15000 \\
\hline 140 & 4 & 0 & 10 & & & & & & & 700 & & 15000 \\
\hline 141 & 4 & 0 & 10 & 20 & & & & & & & & 15000 \\
\hline 142 & 4 & 0 & 10 & & 40 & & & & & & & 15000 \\
\hline 143 & 4 & 0 & & 20 & & 60 & & & & & & 15000 \\
\hline 144 & 4 & 0 & & 20 & & & 80 & & & & & 15000 \\
\hline 145 & 4 & 0 & & 20 & & & & 100 & & & & 15000 \\
\hline 146 & 4 & 0 & & 20 & & & & & 200 & & & 15000 \\
\hline 147 & 4 & 0 & & 20 & & & & & 300 & & & 15000 \\
\hline 148 & 4 & 0 & & 20 & & & & & & 700 & & 15000 \\
\hline 149 & 4 & 0 & & 20 & 40 & & & & & & & 15000 \\
\hline 150 & 4 & 0 & & 20 & & & & & & 500 & & 15000 \\
\hline 151 & 4 & 0 & & & & 60 & 80 & & & & & 15000 \\
\hline 152 & 4 & 0 & & & & 60 & & 100 & & & & 15000 \\
\hline 153 & 4 & 0 & & & & 60 & & & 200 & & & 15000 \\
\hline 154 & 4 & 0 & & & & 60 & & & & & 1000 & 15000 \\
\hline 155 & 4 & 0 & & & & 60 & & & & & 3000 & 15000 \\
\hline 156 & 4 & 0 & & & & & 80 & 100 & & & & 15000 \\
\hline 157 & 4 & 0 & & & & & 80 & & 200 & & & 15000 \\
\hline 158 & 4 & 0 & & & & & 80 & & 300 & & & 15000 \\
\hline 159 & 4 & 0 & & & & & 80 & & & 700 & & 15000 \\
\hline 160 & 4 & 0 & & & & & 80 & & & & 1000 & 15000 \\
\hline 161 & 4 & 0 & & & & & 80 & & & & 3000 & 15000 \\
\hline 162 & 4 & 0 & & & & & & 100 & 300 & & & 15000 \\
\hline 163 & 4 & 0 & & & & & & 100 & & 700 & & 15000 \\
\hline 164 & 4 & 0 & & & & & & 100 & & & 1000 & 15000 \\
\hline 165 & 4 & 0 & & & & & & 100 & & & 3000 & 15000 \\
\hline 166 & 3 & 0 & 10 & & & & & & & & & 15000 \\
\hline 167 & 3 & 0 & & 20 & & & & & & & & 15000 \\
\hline 168 & 3 & 0 & & & & 60 & & & & & & 15000 \\
\hline 169 & 3 & 0 & & & & & 80 & & & & & 15000 \\
\hline 170 & 3 & 0 & & & & & & 100 & & & & 15000 \\
\hline 171 & 6 & 0 & 10 & 20 & & & & 100 & & 700 & & 15000 \\
\hline 172 & 6 & 0 & 10 & 20 & & & 80 & & & 700 & & 15000 \\
\hline 173 & 6 & 0 & 10 & & & & & 100 & 300 & & 1000 & 15000 \\
\hline 174 & 6 & 0 & & 20 & 40 & & & 100 & & 700 & & 15000 \\
\hline 175 & 6 & 0 & & 20 & 40 & & 80 & & & 700 & & 15000 \\
\hline 176 & 6 & 0 & & 20 & & 60 & 80 & & & 700 & & 15000 \\
\hline
\end{tabular}

Continua... 
Tabela 1a. Continuação

\begin{tabular}{|c|c|c|c|c|c|c|c|c|c|c|c|c|c|c|c|}
\hline 177 & 6 & 0 & & 20 & & & 80 & 100 & & & & 700 & & & 15000 \\
\hline 178 & 6 & 0 & & 20 & & & 80 & & 200 & & & 700 & & & 15000 \\
\hline 179 & 6 & 0 & & 20 & & & 80 & & & 300 & & 700 & & & 15000 \\
\hline 180 & 6 & 0 & & 20 & & & 80 & & & & & 700 & 1000 & & 15000 \\
\hline 181 & 6 & 0 & & 20 & & & 80 & & & & & 700 & & 3000 & 15000 \\
\hline 182 & 6 & 0 & & 20 & & & & 100 & & 300 & & & 1000 & & 15000 \\
\hline 183 & 6 & 0 & & 20 & & & & 100 & 200 & & & 700 & & & 15000 \\
\hline 184 & 6 & 0 & & 20 & & & & 100 & & 300 & & 700 & & & 15000 \\
\hline 185 & 6 & 0 & & & 40 & & & 100 & & 300 & & & 1000 & & 15000 \\
\hline 186 & 6 & 0 & & & & 60 & & 100 & & 300 & & & 1000 & & 15000 \\
\hline 187 & 6 & 0 & & & & & 80 & 100 & & 300 & & & 1000 & & 15000 \\
\hline 188 & 7 & 0 & & 20 & & 60 & 80 & 100 & & & & 700 & & & 15000 \\
\hline 189 & 7 & 0 & 10 & 20 & & & 80 & 100 & & & & 700 & & & 15000 \\
\hline 190 & 7 & 0 & & 20 & 40 & & 80 & 100 & & & & 700 & & & 15000 \\
\hline 191 & 11 & 0 & 10 & 20 & 40 & 60 & 80 & 100 & 200 & & & 700 & 1000 & & 15000 \\
\hline 192 & 11 & 0 & 10 & 20 & & 60 & 80 & 100 & 200 & 300 & 500 & & 1000 & & 15000 \\
\hline 193 & 11 & 0 & 10 & 20 & & 60 & 80 & 100 & 200 & 300 & & 700 & 1000 & & 15000 \\
\hline 194 & 11 & 0 & 10 & 20 & & 60 & 80 & 100 & 200 & & 500 & & 1000 & 3000 & 15000 \\
\hline 195 & 11 & 0 & & 20 & 40 & 60 & 80 & 100 & & 300 & & 700 & 1000 & 3000 & 15000 \\
\hline 196 & 11 & 0 & & 20 & 40 & 60 & 80 & 100 & 200 & 300 & 500 & 700 & & & 15000 \\
\hline 197 & 10 & 0 & & 20 & 40 & 60 & 80 & 100 & 200 & & & 700 & 1000 & & 15000 \\
\hline 198 & 10 & 0 & & 20 & & 60 & 80 & 100 & 200 & 300 & 500 & & 1000 & & 15000 \\
\hline 199 & 10 & 0 & & 20 & & 60 & 80 & 100 & 200 & 300 & & 700 & 1000 & & 15000 \\
\hline 200 & 10 & 0 & & 20 & & 60 & 80 & 100 & 200 & & 500 & & 1000 & 3000 & 15000 \\
\hline 201 & 10 & 0 & & 20 & & 60 & 80 & 100 & & 300 & & 700 & 1000 & 3000 & 15000 \\
\hline 202 & 10 & 0 & & 20 & & 60 & 80 & 100 & 200 & 300 & 500 & 700 & & & 15000 \\
\hline 203 & 9 & 0 & & 20 & & 60 & 80 & 100 & 200 & & 500 & & 1000 & & 15000 \\
\hline 204 & 9 & 0 & & 20 & & 60 & 80 & 100 & 200 & 300 & & & 1000 & & 15000 \\
\hline 205 & 9 & 0 & & 20 & 40 & 80 & & 100 & 200 & & 500 & & 1000 & & 15000 \\
\hline 206 & 9 & 0 & & 20 & & 60 & 80 & 100 & 200 & & 500 & & & 3000 & 15000 \\
\hline 207 & 9 & 0 & & 20 & 40 & 80 & & 100 & 200 & & & 700 & 1000 & & 15000 \\
\hline 208 & 9 & 0 & & 20 & & 60 & 80 & 100 & 200 & & & 700 & 1000 & & 15000 \\
\hline 209 & 9 & 0 & & 20 & 40 & 80 & & 100 & & 300 & & 700 & 1000 & & 15000 \\
\hline 210 & 9 & 0 & & 20 & & 60 & 80 & 100 & & 300 & & 700 & 1000 & & 15000 \\
\hline 211 & 9 & 0 & 10 & 20 & & 60 & 80 & & 200 & & & 700 & 1000 & & 15000 \\
\hline 212 & 9 & 0 & 10 & 20 & & 60 & 80 & & & 300 & & 700 & 1000 & & 15000 \\
\hline 213 & 9 & 0 & 10 & 20 & & 60 & 80 & & & & 500 & 700 & 1000 & & 15000 \\
\hline 214 & 9 & 0 & & 20 & & 60 & 80 & 100 & 200 & & & 700 & & 3000 & 15000 \\
\hline 215 & 9 & 0 & & 20 & & 60 & 80 & 100 & & 300 & & 700 & & 3000 & 15000 \\
\hline 216 & 9 & 0 & & 20 & & 60 & 80 & 100 & & & 500 & 700 & 1000 & & 15000 \\
\hline 217 & 8 & 0 & 10 & 20 & & 60 & 80 & & 200 & & & 700 & & & 15000 \\
\hline 218 & 8 & 0 & 10 & 20 & & 60 & 80 & & & 300 & & 700 & & & 15000 \\
\hline 219 & 8 & 0 & 10 & 20 & & 60 & 80 & & & & 500 & 700 & & & 15000 \\
\hline 220 & 8 & 0 & 10 & 20 & & & 80 & & 200 & & & 700 & 1000 & & 15000 \\
\hline 221 & 8 & 0 & 10 & 20 & & & 80 & & & 300 & & 700 & 1000 & & 15000 \\
\hline 222 & 8 & 0 & 10 & 20 & & & 80 & & & & 500 & 700 & 1000 & & 15000 \\
\hline
\end{tabular}

Continua... 
Tabela 1a. Continuação

\begin{tabular}{|c|c|c|c|c|c|c|c|c|c|c|c|c|c|c|c|}
\hline 223 & 8 & 0 & & 20 & 40 & & 80 & 100 & 200 & & 500 & & & & 15000 \\
\hline 224 & 8 & 0 & & 20 & 40 & & 80 & 100 & 200 & & & 700 & & & 15000 \\
\hline 225 & 8 & 0 & & 20 & 40 & & 80 & 100 & & 300 & & 700 & & & 15000 \\
\hline 226 & 8 & 0 & & 20 & 40 & & 80 & & 200 & & & 700 & 1000 & & 15000 \\
\hline 227 & 8 & 0 & & 20 & 40 & & 80 & & & 300 & & 700 & 1000 & & 15000 \\
\hline 228 & 8 & 0 & & 20 & 40 & & 80 & & & & 500 & 700 & 1000 & & 15000 \\
\hline 229 & 8 & 0 & & 20 & 40 & & 80 & & 200 & & 500 & & 1000 & & 15000 \\
\hline 230 & 8 & 0 & & 20 & 40 & & 80 & 100 & & & & 700 & & 3000 & 15000 \\
\hline 231 & 8 & 0 & & 20 & 40 & & 80 & 100 & & 300 & & & 1000 & & 15000 \\
\hline 232 & 8 & 0 & & 20 & 40 & & 80 & 100 & & & 500 & & 1000 & & 15000 \\
\hline 233 & 8 & 0 & & 20 & & 60 & 80 & 100 & 200 & & 500 & & & & 15000 \\
\hline 234 & 8 & 0 & & 20 & & 60 & 80 & 100 & 200 & & & 700 & & & 15000 \\
\hline 235 & 8 & 0 & & 20 & & 60 & 80 & 100 & & 300 & & 700 & & & 15000 \\
\hline 236 & 8 & 0 & & 20 & & 60 & 80 & 100 & 200 & & & & 1000 & & 15000 \\
\hline 237 & 8 & 0 & & 20 & & 60 & 80 & 100 & & 300 & & & 1000 & & 15000 \\
\hline 238 & 8 & 0 & & 20 & & 60 & 80 & 100 & & & 500 & 700 & & & 15000 \\
\hline 239 & 8 & 0 & & 20 & & & 80 & 100 & 200 & & & 700 & 1000 & & 15000 \\
\hline 240 & 8 & 0 & & 20 & & & 80 & 100 & & 300 & & 700 & 1000 & & 15000 \\
\hline 241 & 8 & 0 & & 20 & & & 80 & 100 & & & 500 & 700 & 1000 & & 15000 \\
\hline 242 & 7 & 0 & 10 & 20 & & & 80 & & 200 & & & 700 & & & 15000 \\
\hline 243 & 7 & 0 & 10 & 20 & & & 80 & & & 300 & & 700 & & & 15000 \\
\hline 244 & 7 & 0 & 10 & 20 & & & 80 & & & & 500 & 700 & & & 15000 \\
\hline 245 & 7 & 0 & 10 & 20 & & & 80 & & 200 & & & & 1000 & & 15000 \\
\hline 246 & 7 & 0 & 10 & 20 & & & 80 & & & 300 & & & 1000 & & 15000 \\
\hline 247 & 7 & 0 & 10 & 20 & & & 80 & & & & 500 & & 1000 & & 15000 \\
\hline 248 & 7 & 0 & & 20 & 40 & & 80 & & 200 & & & 700 & & & 15000 \\
\hline 249 & 7 & 0 & & 20 & 40 & & 80 & & & 300 & & 700 & & & 15000 \\
\hline 250 & 7 & 0 & & 20 & 40 & & 80 & & & & 500 & 700 & & & 15000 \\
\hline 251 & 7 & 0 & & 20 & 40 & & & 100 & & 300 & & & 1000 & & 15000 \\
\hline 252 & 7 & 0 & & 20 & & & 80 & 100 & 200 & & & 700 & & & 15000 \\
\hline 253 & 7 & 0 & & 20 & & & 80 & 100 & & 300 & & 700 & & & 15000 \\
\hline 254 & 7 & 0 & & 20 & & & 80 & 100 & & & 500 & 700 & & & 15000 \\
\hline 255 & 7 & 0 & & 20 & & & 80 & 100 & 200 & & & & 1000 & & 15000 \\
\hline 256 & 7 & 0 & & 20 & & & 80 & 100 & & 300 & & & 1000 & & 15000 \\
\hline 257 & 7 & 0 & & 20 & & & 80 & 100 & & & 500 & & 1000 & & 15000 \\
\hline 258 & 7 & 0 & & & & 60 & & 100 & & 300 & & 700 & 1000 & & 15000 \\
\hline 259 & 7 & 0 & & 20 & & & 80 & & & 300 & & 700 & & 3000 & 15000 \\
\hline 260 & 7 & 0 & & 20 & & & & 100 & 200 & 300 & & & 1000 & & 15000 \\
\hline 261 & 10 & 0 & 10 & 20 & 40 & & 80 & 100 & 200 & & 500 & & 1000 & & 15000 \\
\hline 262 & 10 & 0 & 10 & 20 & 40 & & 80 & 100 & & 300 & & 700 & 1000 & & 15000 \\
\hline 263 & 10 & 0 & 10 & 20 & & 60 & 80 & 100 & 200 & & 500 & & 1000 & & 15000 \\
\hline 264 & 10 & 0 & 10 & 20 & & 60 & 80 & 100 & & 300 & & 700 & 1000 & & 15000 \\
\hline 265 & 10 & 0 & & 20 & 40 & 60 & 80 & 100 & 200 & & 500 & & 1000 & & 15000 \\
\hline 266 & 10 & 0 & & 20 & 40 & 60 & 80 & 100 & & 300 & & 700 & 1000 & & 15000 \\
\hline 267 & 9 & 0 & 10 & 20 & 40 & & 80 & & 200 & & 500 & & 1000 & & 15000 \\
\hline 268 & 9 & 0 & 10 & 20 & 40 & & & 100 & 200 & & 500 & & 1000 & & 15000 \\
\hline
\end{tabular}

Continua... 
Tabela 1a. Continuação

\begin{tabular}{|c|c|c|c|c|c|c|c|c|c|c|c|c|c|c|c|}
\hline 269 & 9 & 0 & 10 & 20 & 40 & & & 100 & & 300 & & 700 & 1000 & & 15000 \\
\hline 270 & 9 & 0 & 10 & 20 & & 60 & 80 & & 200 & & 500 & & 1000 & & 15000 \\
\hline 271 & 9 & 0 & 10 & 20 & & 60 & & 100 & 200 & & 500 & & 1000 & & 15000 \\
\hline 272 & 9 & 0 & 10 & 20 & & 60 & & 100 & & 300 & & 700 & 1000 & & 15000 \\
\hline 273 & 9 & 0 & & 20 & 40 & 60 & 80 & & 200 & & 500 & & 1000 & & 15000 \\
\hline 274 & 9 & 0 & & 20 & 40 & 60 & 80 & & & 300 & & 700 & 1000 & & 15000 \\
\hline 275 & 9 & 0 & & 20 & 40 & 60 & & 100 & 200 & & 500 & & 1000 & & 15000 \\
\hline 276 & 9 & 0 & & 20 & 40 & 60 & & 100 & & 300 & & 700 & 1000 & & 15000 \\
\hline 277 & 6 & 0 & 10 & & 40 & & 80 & & & & & & 1000 & & 15000 \\
\hline 278 & 6 & 0 & & 20 & 40 & & 80 & & & & & & 1000 & & 15000 \\
\hline 279 & 6 & 0 & 10 & & 40 & & & 100 & & & & & 1000 & & 15000 \\
\hline 280 & 6 & 0 & & 20 & 40 & & & 100 & & & & & 1000 & & 15000 \\
\hline 281 & 9 & 0 & 10 & 20 & & & 80 & 100 & & 300 & & 700 & 1000 & & 15000 \\
\hline 282 & 9 & 0 & 10 & 20 & & & 80 & 100 & 200 & & 500 & & 1000 & & 15000 \\
\hline 283 & 9 & 0 & 10 & 40 & & & 80 & 100 & 200 & & 500 & & 1000 & & 15000 \\
\hline 284 & 9 & 0 & 10 & 40 & & & 80 & 100 & 200 & & & 700 & 1000 & & 15000 \\
\hline 285 & 9 & 0 & 10 & 40 & & & 80 & 100 & & 300 & & 700 & 1000 & & 15000 \\
\hline 286 & 9 & 0 & 10 & & & 60 & & 100 & & 300 & & 700 & 1000 & 5000 & 15000 \\
\hline 287 & 8 & 0 & 10 & 20 & & 60 & & 100 & & & 500 & 700 & & & 15000 \\
\hline 288 & 8 & 0 & 10 & & 40 & 60 & 80 & & & & 500 & 700 & & & 15000 \\
\hline 289 & 8 & 0 & 10 & & 40 & 60 & & 100 & & & 500 & 700 & & & 15000 \\
\hline 290 & 8 & 0 & 10 & & 40 & & 80 & & & 300 & 500 & & 1000 & & 15000 \\
\hline 291 & 8 & 0 & 10 & & 40 & & 80 & & & 300 & & 700 & 1000 & & 15000 \\
\hline 292 & 8 & 0 & 10 & & & 60 & 80 & & & 300 & 500 & & 1000 & & 15000 \\
\hline 293 & 8 & 0 & 10 & & & 60 & 80 & & & 300 & & 700 & 1000 & & 15000 \\
\hline 294 & 8 & 0 & & 20 & 40 & 60 & & 100 & 200 & & 500 & & & & 15000 \\
\hline 295 & 8 & 0 & & 20 & 40 & 60 & & 100 & & & & 700 & & 3000 & 15000 \\
\hline 296 & 8 & 0 & & 20 & & 60 & & 100 & 200 & & 500 & & 1000 & & 15000 \\
\hline 297 & 7 & 0 & 10 & 20 & & & & 100 & & & 500 & 700 & & & 15000 \\
\hline 298 & 7 & 0 & 10 & 20 & & & & 100 & & & 500 & & 1000 & & 15000 \\
\hline 299 & 7 & 0 & 10 & & 40 & & 80 & & & & 500 & 700 & & & 15000 \\
\hline 300 & 7 & 0 & 10 & & 40 & & 80 & & & & 500 & & 1000 & & 15000 \\
\hline 301 & 7 & 0 & 10 & & 40 & & 80 & 100 & & & & 700 & & & 15000 \\
\hline 302 & 7 & 0 & 10 & & 40 & & & 100 & & & 500 & 700 & & & 15000 \\
\hline 303 & 7 & 0 & 10 & & 40 & & & 100 & & & 500 & & 1000 & & 15000 \\
\hline 304 & 7 & 0 & 10 & & & & 80 & 100 & 200 & & & 700 & & & 15000 \\
\hline 305 & 7 & 0 & 10 & & & & 80 & 100 & 200 & & & & 1000 & & 15000 \\
\hline 306 & 7 & 0 & 10 & & & & 80 & 100 & & 300 & & & 1000 & & 15000 \\
\hline 307 & 7 & 0 & 10 & & & & 80 & 100 & & & 500 & & 1000 & & 15000 \\
\hline 308 & 7 & 0 & 10 & & & & 80 & & & 300 & & 700 & & 3000 & 15000 \\
\hline 309 & 6 & 0 & 10 & & 40 & & & & 200 & & & & 1000 & & 15000 \\
\hline 310 & 6 & 0 & 10 & & 40 & & & & & 300 & & & 1000 & & 15000 \\
\hline 311 & 6 & 0 & 10 & & & & 80 & & 200 & & & 700 & & & 15000 \\
\hline 312 & 6 & 0 & 10 & & & & 80 & & & 300 & & 700 & & & 15000 \\
\hline 313 & 6 & 0 & 10 & & & & & 100 & 200 & & & 700 & & & 15000 \\
\hline 314 & 6 & 0 & 10 & & & & & 100 & & 300 & & 700 & & & 15000 \\
\hline
\end{tabular}

Continua... 
Tabela 1a. Continuação

\begin{tabular}{|c|c|c|c|c|c|c|c|c|c|c|c|c|c|c|c|c|}
\hline 315 & 6 & 0 & 10 & & & & & 100 & & & 500 & & 1000 & & & 15000 \\
\hline 316 & 6 & 0 & & 20 & 40 & & & & 200 & & & & 1000 & & & 15000 \\
\hline 317 & 6 & 0 & & 20 & 40 & & & & & 300 & & & 1000 & & & 15000 \\
\hline 318 & 6 & 0 & & 20 & & & & 100 & & 300 & & & & 3000 & & 15000 \\
\hline 319 & 6 & 0 & & 20 & & & & 100 & & & 500 & & 1000 & & & 15000 \\
\hline 320 & 6 & 0 & & & & 60 & & 100 & 200 & & & & 1000 & & & 15000 \\
\hline 321 & 6 & 0 & & & & 60 & & 100 & & & 500 & & 1000 & & & 15000 \\
\hline 322 & 5 & 0 & 10 & & & & & 100 & & & 500 & & & & & 15000 \\
\hline 323 & 5 & 0 & 10 & & & & & 100 & & & & 700 & & & & 15000 \\
\hline 324 & 5 & 0 & & 20 & & & & 100 & & & 500 & & & & & 15000 \\
\hline 325 & 5 & 0 & & & 40 & & 80 & & & & & 700 & & & & 15000 \\
\hline 326 & 5 & 0 & & & 40 & & & 100 & & & 500 & & & & & 15000 \\
\hline 327 & 5 & 0 & & & 40 & & & 100 & & & & 700 & & & & 15000 \\
\hline 328 & 5 & 0 & & & 40 & & & & & 300 & & 700 & & & & 15000 \\
\hline 329 & 5 & 0 & & & & & 80 & & 200 & & & 700 & & & & 15000 \\
\hline 330 & 5 & 0 & & & & & 80 & & & 300 & & 700 & & & & 15000 \\
\hline 331 & 4 & 0 & 10 & & & & & & & & 500 & & & & & 15000 \\
\hline 332 & 4 & 0 & & & 40 & & 80 & & & & & & & & & 15000 \\
\hline 333 & 4 & 0 & & & 40 & & & 100 & & & & & & & & 15000 \\
\hline 334 & 4 & 0 & & & 40 & & & & 200 & & & & & & & 15000 \\
\hline 335 & 4 & 0 & & & 40 & & & & & 300 & & & & & & 15000 \\
\hline 336 & 4 & 0 & & & 40 & & & & & & 500 & & & & & 15000 \\
\hline 337 & 4 & 0 & & & 40 & & & & & & & 700 & & & & 15000 \\
\hline 338 & 4 & 0 & & & & 60 & & & & & 500 & & & & & 15000 \\
\hline 339 & 4 & 0 & & & & & 80 & & & & 500 & & & & & 15000 \\
\hline 340 & 4 & 0 & & & & & & 100 & & & 500 & & & & & 15000 \\
\hline 341 & 14 & 0 & 10 & 20 & 40 & 60 & 80 & 100 & 200 & 300 & 500 & 700 & & 3000 & 5000 & 15000 \\
\hline 342 & 14 & 0 & 10 & 20 & 40 & 60 & 80 & 100 & 200 & 300 & 500 & & 1000 & 3000 & 5000 & 15000 \\
\hline 343 & 14 & 0 & 10 & 20 & 40 & 60 & 80 & 100 & 200 & 300 & & 700 & 1000 & 3000 & 5000 & 15000 \\
\hline 344 & 14 & 0 & 10 & 20 & 40 & 60 & 80 & & 200 & 300 & 500 & 700 & 1000 & 3000 & 5000 & 15000 \\
\hline 345 & 14 & 0 & 10 & 20 & 40 & 60 & & 100 & 200 & 300 & 500 & 700 & 1000 & 3000 & 5000 & 15000 \\
\hline 346 & 14 & 0 & & 20 & 40 & 60 & 80 & 100 & 200 & 300 & 500 & 700 & 1000 & 3000 & 5000 & 15000 \\
\hline 347 & 13 & 0 & 10 & 20 & 40 & 60 & 80 & 100 & 200 & 300 & 500 & 700 & & & 5000 & 15000 \\
\hline 348 & 13 & 0 & 10 & 20 & 40 & 60 & 80 & 100 & 200 & 300 & 500 & & & 3000 & 5000 & 15000 \\
\hline 349 & 13 & 0 & 10 & 20 & 40 & 60 & 80 & 100 & 200 & 300 & & 700 & & 3000 & 5000 & 15000 \\
\hline 350 & 13 & 0 & 10 & 20 & 40 & 60 & 80 & 100 & 200 & 300 & & & 1000 & 3000 & 5000 & 15000 \\
\hline 351 & 13 & 0 & & 20 & 40 & 60 & 80 & 100 & 200 & 300 & 500 & 700 & 1000 & & 5000 & 15000 \\
\hline 352 & 13 & 0 & & 20 & 40 & 60 & 80 & 100 & 200 & 300 & 500 & & 1000 & 3000 & 5000 & 15000 \\
\hline 353 & 13 & 0 & & 20 & 40 & 60 & 80 & 100 & 200 & 300 & & 700 & 1000 & 3000 & 5000 & 15000 \\
\hline 354 & 12 & 0 & 10 & 20 & 40 & 60 & 80 & & 200 & & 500 & & 1000 & 3000 & 5000 & 15000 \\
\hline 355 & 12 & 0 & 10 & 20 & 40 & 60 & 80 & & 200 & & & 700 & 1000 & 3000 & 5000 & 15000 \\
\hline 356 & 12 & 0 & 10 & 20 & 40 & 60 & 80 & & & 300 & & 700 & 1000 & 3000 & 5000 & 15000 \\
\hline 357 & 12 & 0 & 10 & 20 & 40 & 60 & 80 & 100 & 200 & 300 & & 700 & & 3000 & & 15000 \\
\hline 358 & 12 & 0 & 10 & 20 & 40 & 60 & 80 & 100 & & 300 & & & 1000 & 3000 & 5000 & 15000 \\
\hline 359 & 12 & 0 & 10 & 20 & & 60 & 80 & 100 & 200 & & & 700 & 1000 & 3000 & 5000 & 15000 \\
\hline 360 & 12 & 0 & 10 & 20 & & 60 & 80 & 100 & & 300 & & 700 & 1000 & 3000 & 5000 & 15000 \\
\hline
\end{tabular}

Continua... 
Tabela 1a. Continuação

\begin{tabular}{|c|c|c|c|c|c|c|c|c|c|c|c|c|c|c|c|c|}
\hline 361 & 12 & 0 & 10 & 20 & & 60 & 80 & 100 & 200 & 300 & & 700 & 1000 & 3000 & & 15000 \\
\hline 362 & 12 & 0 & & 20 & 40 & 60 & 80 & 100 & 200 & & & 700 & 1000 & 3000 & 5000 & 15000 \\
\hline 363 & 12 & 0 & & 20 & 40 & 60 & 80 & 100 & & 300 & & 700 & 1000 & 3000 & 5000 & 15000 \\
\hline 364 & 12 & 0 & & 20 & 40 & 60 & 80 & 100 & 200 & 300 & & 700 & 1000 & 3000 & & 15000 \\
\hline 365 & 11 & 0 & & 20 & 40 & 60 & 80 & 100 & 200 & & & 700 & 1000 & 3000 & & 15000 \\
\hline 366 & 11 & 0 & & 20 & & 60 & 80 & 100 & 200 & 300 & 500 & & 1000 & 3000 & & 15000 \\
\hline 367 & 11 & 0 & & 20 & & 60 & 80 & 100 & 200 & 300 & & 700 & 1000 & 3000 & & 15000 \\
\hline 368 & 11 & 0 & 10 & 20 & 40 & 60 & 80 & 100 & 200 & & & & 1000 & 3000 & & 15000 \\
\hline 369 & 11 & 0 & 10 & 20 & & 60 & 80 & 100 & 200 & & 300 & & 1000 & 3000 & & 15000 \\
\hline 370 & 11 & 0 & 10 & 20 & & 60 & 80 & 100 & 200 & 500 & & & 1000 & & 5000 & 15000 \\
\hline 371 & 11 & 0 & 10 & 20 & & 60 & 80 & 100 & 200 & & & & 1000 & 3000 & 5000 & 15000 \\
\hline 372 & 11 & 0 & 10 & 20 & & 60 & 80 & 100 & & 300 & & & 1000 & 3000 & 5000 & 15000 \\
\hline 373 & 10 & 0 & 10 & 20 & 40 & & 80 & & 200 & & & 700 & 1000 & & 5000 & 15000 \\
\hline 374 & 10 & 0 & 10 & 20 & 40 & & 80 & & & 300 & & & 1000 & 3000 & 5000 & 15000 \\
\hline 375 & 10 & 0 & 10 & 20 & 40 & & 80 & & 200 & & 500 & & 1000 & 3000 & & 15000 \\
\hline 376 & 10 & 0 & 10 & 20 & 40 & & 80 & & & 300 & & 700 & 1000 & 3000 & & 15000 \\
\hline 377 & 10 & 0 & 10 & 20 & 40 & & 80 & & 200 & & 500 & & 1000 & & 5000 & 15000 \\
\hline 378 & 10 & 0 & 10 & 20 & 40 & & 80 & & & 300 & & 700 & & 3000 & 5000 & 15000 \\
\hline 379 & 10 & 0 & 10 & 20 & 40 & & 80 & & & 300 & & 700 & 1000 & 3000 & 5000 & \\
\hline 380 & 10 & 0 & 10 & 20 & 40 & & 80 & 100 & 200 & & 500 & & 1000 & 3000 & & \\
\hline 381 & 10 & 0 & 10 & 20 & 40 & & 80 & 100 & & 300 & & 700 & 1000 & 3000 & & \\
\hline 382 & 10 & 0 & 10 & 20 & 40 & & 80 & 100 & 200 & & 500 & & 1000 & & 5000 & \\
\hline 383 & 10 & 0 & 10 & 20 & 40 & & 80 & 100 & & 300 & & 700 & 1000 & & 5000 & \\
\hline 384 & 10 & 0 & & 20 & 40 & & 80 & 100 & 200 & & 500 & & 1000 & 3000 & & 15000 \\
\hline 385 & 10 & 0 & & 20 & 40 & & 80 & 100 & & 300 & & 700 & 1000 & 3000 & & 15000 \\
\hline 386 & 10 & 0 & & 20 & 40 & & 80 & 100 & 200 & & 500 & & 1000 & & 5000 & 15000 \\
\hline 387 & 10 & 0 & & 20 & 40 & & 80 & 100 & & 300 & & 700 & 1000 & & 5000 & 15000 \\
\hline 388 & 10 & 0 & & 20 & 40 & & 80 & 100 & & 300 & & & 1000 & 3000 & 5000 & 15000 \\
\hline 389 & 10 & 0 & & 20 & & 60 & 80 & 100 & & 300 & & & 1000 & 3000 & 5000 & 15000 \\
\hline 390 & 9 & 0 & 10 & 20 & 40 & & 80 & & 200 & & & 700 & 1000 & & & 15000 \\
\hline 391 & 9 & 0 & 10 & 20 & 40 & & 80 & & & 300 & & & 1000 & 3000 & & 15000 \\
\hline 392 & 9 & 0 & 10 & 20 & 40 & & 80 & & & 300 & & & 1000 & & 5000 & 15000 \\
\hline 393 & 9 & 0 & 10 & 20 & 40 & & 80 & & 200 & & & & 1000 & 3000 & & 15000 \\
\hline 394 & 9 & 0 & 10 & 20 & 40 & & & 100 & 200 & & & & 1000 & & 5000 & 15000 \\
\hline 395 & 9 & 0 & 10 & 20 & 40 & & 80 & & 200 & & & 700 & 1000 & & 5000 & \\
\hline 396 & 9 & 0 & 10 & 20 & 40 & & 80 & & & 300 & & & 1000 & 3000 & 5000 & \\
\hline 397 & 9 & 0 & 10 & 20 & 40 & & 80 & & & 300 & & 700 & 1000 & & 5000 & \\
\hline 398 & 9 & 0 & 10 & 40 & & & 80 & 100 & & 300 & & & 1000 & 3000 & & 15000 \\
\hline 399 & 9 & 0 & 10 & 40 & & & 80 & 100 & & 300 & & & 1000 & & 5000 & 15000 \\
\hline 400 & 9 & 0 & 10 & & 40 & & 80 & 100 & & 300 & & & 1000 & 3000 & 5000 & \\
\hline 401 & 9 & 0 & & 20 & 40 & & & 100 & & 300 & & 700 & 1000 & & 5000 & 15000 \\
\hline 402 & 9 & 0 & & 20 & 40 & & & 100 & & 300 & & & 1000 & 3000 & 5000 & 15000 \\
\hline 403 & 9 & 0 & & 20 & & 60 & & 100 & & 300 & & & 1000 & 3000 & 5000 & 15000 \\
\hline 404 & 8 & 0 & 10 & 20 & & & 80 & & 200 & & & & 1000 & 3000 & & 15000 \\
\hline 405 & 8 & 0 & 10 & 20 & & & 80 & & & 300 & & & 1000 & 3000 & & 15000 \\
\hline 406 & 8 & 0 & 10 & & 40 & & 80 & & & 300 & & & 1000 & 3000 & & 15000 \\
\hline
\end{tabular}

Continua... 
Tabela 1a. Continuação

\begin{tabular}{|c|c|c|c|c|c|c|c|c|c|c|c|c|c|c|c|c|}
\hline 407 & 8 & 0 & 10 & 20 & & & 80 & & 200 & & & & 1000 & 3000 & 5000 & \\
\hline 408 & 8 & 0 & 10 & 20 & & & 80 & & & 300 & & & 1000 & 3000 & 5000 & \\
\hline 409 & 8 & 0 & 10 & & 40 & & 80 & & & 300 & & & 1000 & 3000 & 5000 & \\
\hline 410 & 8 & 0 & 10 & 20 & & & 80 & & 200 & & & & 1000 & & 5000 & 15000 \\
\hline 411 & 8 & 0 & 10 & 20 & & & 80 & & & 300 & & & 1000 & & 5000 & 15000 \\
\hline 412 & 8 & 0 & 10 & & 40 & & 80 & & & 300 & & & 1000 & & 5000 & 15000 \\
\hline 413 & 8 & 0 & & 20 & 40 & & 80 & 100 & & & & 700 & & & 5000 & 15000 \\
\hline 414 & 8 & 0 & & 20 & 40 & & 80 & 100 & & & & & 1000 & & 5000 & 15000 \\
\hline 415 & 8 & 0 & & 20 & & 60 & 80 & 100 & 200 & & & & & 3000 & & 15000 \\
\hline 416 & 8 & 0 & & 20 & & 60 & 80 & 100 & & 300 & & & & 3000 & & 15000 \\
\hline 417 & 7 & 0 & & 20 & & 60 & 80 & & 200 & & & 700 & & & & 15000 \\
\hline 418 & 7 & 0 & & 20 & & 60 & 80 & & & 300 & & 700 & & & & 15000 \\
\hline 419 & 7 & 0 & & 20 & & 60 & 80 & & & & 500 & & & 3000 & & 15000 \\
\hline 420 & 7 & 0 & & 20 & 40 & & 80 & & & 300 & & & 1000 & & & 15000 \\
\hline 421 & 7 & 0 & & 20 & 40 & & 80 & & 200 & & & & 1000 & & & 15000 \\
\hline 422 & 7 & 0 & & 20 & 40 & & 80 & & & 300 & & & & 3000 & & 15000 \\
\hline 423 & 7 & 0 & & 20 & 40 & & 80 & & 200 & & & & & 3000 & & 15000 \\
\hline 424 & 7 & 0 & & 20 & & & 80 & & 200 & & & 700 & 1000 & & & 15000 \\
\hline 425 & 7 & 0 & & 20 & & & 80 & & & 300 & & 700 & & & 5000 & 15000 \\
\hline 426 & 7 & 0 & & 20 & & & 80 & & 200 & & & & 1000 & 3000 & & 15000 \\
\hline 427 & 7 & 0 & & 20 & & & 80 & & 200 & & & & 1000 & & 5000 & 15000 \\
\hline 428 & 7 & 0 & & 20 & & & 80 & & & 300 & & & 1000 & 3000 & & 15000 \\
\hline 429 & 7 & 0 & & 20 & & & 80 & & & 300 & & & 1000 & & 5000 & 15000 \\
\hline 430 & 6 & 0 & 10 & 20 & & & 80 & & & & & & 1000 & & & 15000 \\
\hline 431 & 6 & 0 & 10 & & 40 & & 80 & & & & & 700 & & & & 15000 \\
\hline 432 & 6 & 0 & 10 & & & 60 & & & & 300 & & & & 3000 & & 15000 \\
\hline 433 & 6 & 0 & & 20 & 40 & & & & 200 & & & & & 3000 & & 15000 \\
\hline 434 & 6 & 0 & & 20 & & & & 100 & 200 & & & & 1000 & & & 15000 \\
\hline 435 & 6 & 0 & & 20 & & & & 100 & 200 & & & & & 3000 & & 15000 \\
\hline 436 & 6 & 0 & & 20 & & & & 100 & 200 & & & & & & 5000 & 15000 \\
\hline 437 & 6 & 0 & & 20 & & & & 100 & & 300 & & & & & 5000 & 15000 \\
\hline 438 & 6 & 0 & & & 40 & & 80 & & 200 & & & & 1000 & & & 15000 \\
\hline 439 & 6 & 0 & & & 40 & & & 100 & 200 & & & & 1000 & & & 15000 \\
\hline 440 & 6 & 0 & & & 40 & & 80 & & 200 & & & & & 3000 & & 15000 \\
\hline 441 & 6 & 0 & & & 40 & & & 100 & 200 & & & & & 3000 & & 15000 \\
\hline 442 & 6 & 0 & & & 40 & & 80 & & & 300 & & & & 3000 & & 15000 \\
\hline 443 & 6 & 0 & & & 40 & & & 100 & & 300 & & & & 3000 & & 15000 \\
\hline 444 & 6 & 0 & & & & 60 & & 100 & & 300 & & & & 3000 & & 15000 \\
\hline 445 & 5 & 0 & & 20 & & 60 & & & 200 & & & & & & & 15000 \\
\hline 446 & 5 & 0 & & 20 & & 60 & & & & 300 & & & & & & 15000 \\
\hline 447 & 5 & 0 & & 20 & & 60 & & & & & 500 & & & & & 15000 \\
\hline 448 & 5 & 0 & & 20 & & & & 100 & 200 & & & & & & & 15000 \\
\hline 449 & 5 & 0 & & & & 60 & & 100 & & 300 & & & & & & 15000 \\
\hline 450 & 5 & 0 & & & & 60 & & 100 & & & 500 & & & & & 15000 \\
\hline
\end{tabular}


Tabela 2a. Valores médios dos parâmetros do modelo de van Genuchten (1980) usados na determinação da curva de retenção de água no solo em função do número de tensões

\begin{tabular}{|c|c|c|c|c|c|c|c|c|c|}
\hline \multirow{3}{*}{$\frac{\text { Curvas }}{1(\mathrm{C} 1)}$} & \multirow{3}{*}{$\frac{\text { Número de Tensões }}{15}$} & \multicolumn{8}{|c|}{ Parâmetros do modelo de van Genuchten (1980) } \\
\hline & & $\begin{array}{r}\alpha \\
h P a-1\end{array}$ & & $\begin{array}{l}\mathrm{m} \\
-\end{array}$ & & $\begin{array}{l}\mathrm{n} \\
-\end{array}$ & & $\begin{array}{r}U g_{\text {res }} \\
\mathrm{kg} \mathrm{kg}^{-1}\end{array}$ & \\
\hline & & 0,073 & $g$ & 0,292 & $y$ & 1,413 & w & 0,154 & $d$ \\
\hline 2 & 14 & 0,066 & i & 0,329 & $r$ & 1,493 & $r$ & 0,169 & $c$ \\
\hline 3 & 13 & 0,070 & $\mathrm{~h}$ & 0,299 & w & 1,428 & w & 0,154 & $d$ \\
\hline 4 & 13 & 0,071 & $\mathrm{~h}$ & 0,296 & $x$ & 1,422 & w & 0,154 & $d$ \\
\hline 5 & 11 & 0,063 & j & 0,358 & $\mathrm{n}$ & 1,560 & $\mathrm{n}$ & 0,177 & o \\
\hline 6 & 11 & 0,063 & j & 0,357 & $\mathrm{n}$ & 1,558 & $n$ & 0,177 & 0 \\
\hline 7 & 11 & 0,066 & $\mathrm{i}$ & 0,331 & $r$ & 1,498 & $r$ & 0,169 & $c$ \\
\hline 8 & 11 & 0,073 & $g$ & 0,293 & $x$ & 1,417 & w & 0,154 & $d$ \\
\hline 9 & 11 & 0,074 & $g$ & 0,290 & y & 1,410 & w & 0,154 & $d$ \\
\hline 10 & 8 & 0,055 & I & 0,367 & $\mathrm{~m}$ & 1,585 & $\mathrm{~m}$ & 0,177 & o \\
\hline 11 & 8 & 0,058 & $\mathrm{k}$ & 0,338 & $q$ & 1,514 & $q$ & 0,169 & $c$ \\
\hline 12 & 8 & 0,064 & j & 0,298 & $x$ & 1,426 & w & 0,154 & $d$ \\
\hline 13 & 13 & 0,077 & $f$ & 0,286 & z & 1,402 & $x$ & 0,154 & \\
\hline 14 & 13 & 0,065 & j & 0,334 & $q$ & 1,504 & $r$ & 0,169 & $c$ \\
\hline 15 & 8 & 0,060 & $\mathrm{k}$ & 0,308 & v & 1,446 & $\mathrm{u}$ & 0,154 & $d$ \\
\hline 16 & 8 & 0,066 & i & 0,294 & $x$ & 1,419 & w & 0,154 & \\
\hline 17 & 8 & 0,055 & I & 0,366 & $\mathrm{~m}$ & 1,582 & $\mathrm{~m}$ & 0,177 & o \\
\hline 18 & 8 & 0,059 & $\mathrm{k}$ & 0,336 & $q$ & 1,509 & $q$ & 0,169 & $c$ \\
\hline 19 & 8 & 0,085 & $c$ & 0,279 & \{ & 1,389 & $y$ & 0,154 & $d$ \\
\hline 20 & 11 & 0,067 & i & 0,329 & $r$ & 1,493 & $r$ & 0,169 & $c$ \\
\hline 21 & 7 & 0,061 & $\mathrm{k}$ & 0,296 & $x$ & 1,423 & w & 0,154 & $d$ \\
\hline 22 & 7 & 0,083 & $d$ & 0,280 & \{ & 1,390 & $y$ & 0,154 & $d$ \\
\hline 23 & 10 & 0,065 & i & 0,310 & $\mathrm{u}$ & 1,452 & u & 0,154 & $d$ \\
\hline 24 & 7 & 0,067 & i & 0,352 & 0 & 1,548 & 0 & 0,177 & o \\
\hline 25 & 9 & 0,067 & i & 0,307 & v & 1,446 & $\mathrm{u}$ & 0,154 & $d$ \\
\hline 26 & 6 & 0,076 & $f$ & 0,294 & $x$ & 1,418 & w & 0,154 & $d$ \\
\hline 27 & 8 & 0,056 & I & 0,344 & $p$ & 1,528 & $p$ & 0,154 & \\
\hline 28 & 12 & 0,055 & I & 0,451 & e & 1,829 & $f$ & 0,203 & a \\
\hline 29 & 10 & 0,070 & $\mathrm{~h}$ & 0,294 & $x$ & 1,418 & w & 0,154 & $d$ \\
\hline 30 & 9 & 0,073 & $g$ & 0,289 & $y$ & 1,407 & w & 0,154 & $d$ \\
\hline 31 & 7 & 0,079 & e & 0,290 & $y$ & 1,410 & w & 0,154 & $d$ \\
\hline 32 & 7 & 0,080 & e & 0,288 & $y$ & 1,406 & $x$ & 0,154 & $d$ \\
\hline 33 & 6 & 0,058 & $\mathrm{k}$ & 0,314 & $t$ & 1,460 & $t$ & 0,154 & $d$ \\
\hline 34 & 6 & 0,060 & $\mathrm{k}$ & 0,307 & v & 1,445 & u & 0,154 & $d$ \\
\hline 35 & 6 & 0,060 & $\mathrm{k}$ & 0,304 & v & 1,440 & v & 0,154 & $d$ \\
\hline 36 & 6 & 0,079 & e & 0,288 & $y$ & 1,406 & $x$ & 0,154 & $d$ \\
\hline 37 & 6 & 0,058 & $\mathrm{k}$ & 0,307 & v & 1,445 & $\mathrm{u}$ & 0,154 & $d$ \\
\hline 38 & 6 & 0,078 & e & 0,288 & $y$ & 1,406 & $x$ & 0,154 & $d$ \\
\hline 39 & 7 & 0,064 & j & 0,299 & w & 1,430 & w & 0,154 & $d$ \\
\hline 40 & 7 & 0,065 & j & 0,299 & w & 1,428 & w & 0,154 & d \\
\hline
\end{tabular}

Continua... 
Tabela 2a. Continuação

\begin{tabular}{|c|c|c|c|c|c|c|c|c|c|}
\hline 41 & 7 & 0,066 & $\mathrm{i}$ & 0,299 & w & 1,428 & w & 0,154 & $d$ \\
\hline 42 & 7 & 0,080 & e & 0,288 & $y$ & 1,406 & $x$ & 0,154 & $d$ \\
\hline 43 & 7 & 0,067 & i & 0,355 & $n$ & 1,555 & $n$ & 0,177 & $b$ \\
\hline 44 & 7 & 0,071 & $\mathrm{~h}$ & 0,328 & $r$ & 1,490 & $r$ & 0,169 & $c$ \\
\hline 45 & 7 & 0,077 & $f$ & 0,319 & $\mathrm{~s}$ & 1,471 & $\mathrm{~s}$ & 0,169 & c \\
\hline 46 & 14 & 0,075 & $f$ & 0,288 & $y$ & 1,406 & $x$ & 0,154 & $d$ \\
\hline 47 & 14 & 0,074 & $\mathrm{~g}$ & 0,290 & $y$ & 1,411 & w & 0,154 & $d$ \\
\hline 48 & 12 & 0,073 & $g$ & 0,292 & $y$ & 1,414 & w & 0,154 & $d$ \\
\hline 49 & 12 & 0,072 & $\mathrm{~h}$ & 0,295 & $x$ & 1,420 & w & 0,154 & $d$ \\
\hline 50 & 5 & 0,076 & $f$ & 0,293 & $x$ & 1,416 & w & 0,154 & $d$ \\
\hline 51 & 5 & 0,078 & e & 0,292 & $y$ & 1,413 & w & 0,154 & $d$ \\
\hline 52 & 5 & 0,075 & $f$ & 0,294 & $x$ & 1,417 & w & 0,154 & $d$ \\
\hline 53 & 5 & 0,078 & e & 0,288 & $y$ & 1,406 & $x$ & 0,154 & $d$ \\
\hline 54 & 4 & 0,064 & j & 0,316 & $t$ & 1,463 & $t$ & 0,154 & $d$ \\
\hline 55 & 4 & 0,077 & $f$ & 0,293 & $y$ & 1,415 & w & 0,154 & $d$ \\
\hline 56 & 12 & 0,063 & j & 0,355 & $n$ & 1,554 & $\mathrm{n}$ & 0,177 & $b$ \\
\hline 57 & 12 & 0,067 & $\mathrm{i}$ & 0,329 & $r$ & 1,493 & $r$ & 0,169 & c \\
\hline 58 & 12 & 0,073 & $g$ & 0,293 & $y$ & 1,415 & w & 0,154 & $d$ \\
\hline 59 & 12 & 0,064 & j & 0,336 & $q$ & 1,508 & $q$ & 0,169 & $c$ \\
\hline 60 & 11 & 0,062 & j & 0,356 & $n$ & 1,557 & $n$ & 0,177 & $b$ \\
\hline 61 & 11 & 0,064 & j & 0,331 & $r$ & 1,497 & $r$ & 0,169 & $c$ \\
\hline 62 & 11 & 0,070 & $\mathrm{~h}$ & 0,294 & $x$ & 1,419 & w & 0,154 & $d$ \\
\hline 63 & 11 & 0,062 & j & 0,337 & $q$ & 1,511 & $q$ & 0,169 & $c$ \\
\hline 64 & 10 & 0,061 & $\mathrm{j}$ & 0,356 & $n$ & 1,557 & $n$ & 0,177 & $b$ \\
\hline 65 & 10 & 0,064 & j & 0,330 & $r$ & 1,496 & $r$ & 0,169 & $c$ \\
\hline 66 & 10 & 0,069 & $\mathrm{~h}$ & 0,294 & $x$ & 1,419 & w & 0,154 & $d$ \\
\hline 67 & 10 & 0,062 & j & 0,337 & $q$ & 1,511 & $q$ & 0,169 & $c$ \\
\hline 68 & 9 & 0,070 & $\mathrm{~h}$ & 0,346 & 0 & 1,533 & $p$ & 0,177 & $b$ \\
\hline 69 & 9 & 0,074 & $g$ & 0,320 & $s$ & 1,474 & $\mathrm{~s}$ & 0,169 & $c$ \\
\hline 70 & 9 & 0,082 & $d$ & 0,283 & z & 1,397 & $y$ & 0,154 & $d$ \\
\hline 71 & 9 & 0,070 & $\mathrm{~h}$ & 0,328 & $r$ & 1,490 & $r$ & 0,169 & c \\
\hline 72 & 8 & 0,068 & $\mathrm{~h}$ & 0,350 & 0 & 1,542 & 0 & 0,177 & $b$ \\
\hline 73 & 8 & 0,072 & $\mathrm{~h}$ & 0,325 & $r$ & 1,484 & $s$ & 0,169 & c \\
\hline 74 & 8 & 0,079 & e & 0,289 & $y$ & 1,408 & w & 0,154 & $d$ \\
\hline 75 & 8 & 0,066 & i & 0,337 & $q$ & 1,510 & $q$ & 0,169 & $c$ \\
\hline 76 & 7 & 0,066 & $\mathrm{i}$ & 0,358 & $n$ & 1,562 & $n$ & 0,177 & $b$ \\
\hline 77 & 7 & 0,068 & i & 0,336 & $q$ & 1,510 & $q$ & 0,169 & $c$ \\
\hline 78 & 7 & 0,072 & $\mathrm{~h}$ & 0,303 & v & 1,438 & v & 0,154 & $d$ \\
\hline 79 & 7 & 0,061 & $\mathrm{k}$ & 0,353 & $n$ & 1,550 & $n$ & 0,169 & $c$ \\
\hline 80 & 6 & 0,066 & i & 0,359 & $\mathrm{n}$ & 1,565 & $n$ & 0,177 & $b$ \\
\hline 81 & 6 & 0,068 & i & 0,337 & $q$ & 1,511 & $q$ & 0,169 & $c$ \\
\hline 82 & 6 & 0,072 & $\mathrm{~h}$ & 0,304 & v & 1,438 & v & 0,154 & $d$ \\
\hline 83 & 6 & 0,061 & $\mathrm{k}$ & 0,356 & $\mathrm{n}$ & 1,555 & $\mathrm{n}$ & 0,169 & $c$ \\
\hline 84 & 6 & 0,064 & j & 0,365 & $\mathrm{~m}$ & 1,578 & $\mathrm{~m}$ & 0,177 & $b$ \\
\hline 85 & 6 & 0,066 & $\mathrm{i}$ & 0,343 & $p$ & 1,525 & $p$ & 0,169 & C \\
\hline
\end{tabular}


Tabela 2a. Continuação

\begin{tabular}{|c|c|c|c|c|c|c|c|c|c|}
\hline 86 & 6 & 0,070 & $\mathrm{~h}$ & 0,309 & $\mathrm{u}$ & 1,450 & $\mathrm{u}$ & 0,154 & $d$ \\
\hline 87 & 6 & 0,057 & $\mathrm{k}$ & 0,370 & I & 1,592 & 1 & 0,169 & c \\
\hline 88 & 10 & 0,069 & $\mathrm{~h}$ & 0,294 & $x$ & 1,418 & w & 0,154 & $d$ \\
\hline 89 & 9 & 0,073 & $g$ & 0,292 & $y$ & 1,415 & w & 0,154 & $d$ \\
\hline 90 & 7 & 0,056 & I & 0,347 & 0 & 1,535 & 0 & 0,169 & c \\
\hline 91 & 7 & 0,071 & $\mathrm{~h}$ & 0,327 & $r$ & 1,489 & $r$ & 0,169 & $c$ \\
\hline 92 & 7 & 0,056 & I & 0,347 & 0 & 1,535 & 0 & 0,169 & $c$ \\
\hline 93 & 7 & 0,051 & $\mathrm{~m}$ & 0,382 & k & 1,622 & k & 0,177 & $b$ \\
\hline 94 & 7 & 0,052 & $\mathrm{~m}$ & 0,359 & $n$ & 1,564 & $n$ & 0,169 & $c$ \\
\hline 95 & 7 & 0,054 & I & 0,325 & $r$ & 1,484 & $\mathrm{~s}$ & 0,154 & $d$ \\
\hline 96 & 7 & 0,055 & I & 0,326 & $r$ & 1,485 & $\mathrm{~s}$ & 0,154 & $d$ \\
\hline 97 & 7 & 0,061 & j & 0,306 & v & 1,442 & $\mathrm{u}$ & 0,154 & $d$ \\
\hline 98 & 12 & 0,064 & j & 0,335 & $q$ & 1,506 & $r$ & 0,169 & $c$ \\
\hline 99 & 5 & 0,077 & $f$ & 0,291 & $y$ & 1,412 & w & 0,154 & $d$ \\
\hline 100 & 5 & 0,076 & $f$ & 0,291 & $y$ & 1,413 & w & 0,154 & $d$ \\
\hline 101 & 5 & 0,069 & $\mathrm{~h}$ & 0,309 & $\mathrm{u}$ & 1,450 & $\mathrm{u}$ & 0,154 & $d$ \\
\hline 102 & 5 & 0,075 & $f$ & 0,290 & $y$ & 1,410 & w & 0,154 & $d$ \\
\hline 103 & 5 & 0,059 & $\mathrm{k}$ & 0,310 & $\mathrm{u}$ & 1,451 & $\mathrm{u}$ & 0,154 & $d$ \\
\hline 104 & 5 & 0,055 & I & 0,313 & u & 1,458 & $t$ & 0,154 & $d$ \\
\hline 105 & 5 & 0,048 & $n$ & 0,338 & $q$ & 1,513 & $q$ & 0,154 & $d$ \\
\hline 106 & 5 & 0,049 & $\mathrm{n}$ & 0,315 & $t$ & 1,463 & $t$ & 0,154 & $d$ \\
\hline 107 & 5 & 0,081 & $d$ & 0,289 & $y$ & 1,407 & $x$ & 0,154 & $d$ \\
\hline 108 & 5 & 0,082 & $d$ & 0,286 & z & 1,402 & $x$ & 0,154 & $d$ \\
\hline 109 & 5 & 0,044 & 0 & 0,373 & I & 1,598 & 1 & 0,154 & $d$ \\
\hline 110 & 5 & 0,080 & e & 0,288 & $y$ & 1,405 & $x$ & 0,154 & $d$ \\
\hline 111 & 5 & 0,077 & $f$ & 0,291 & $y$ & 1,411 & w & 0,154 & $d$ \\
\hline 112 & 5 & 0,070 & $\mathrm{~h}$ & 0,296 & $x$ & 1,421 & w & 0,154 & $d$ \\
\hline 113 & 5 & 0,074 & $g$ & 0,291 & $y$ & 1,412 & w & 0,154 & $d$ \\
\hline 114 & 5 & 0,056 & I & 0,320 & $\mathrm{~s}$ & 1,472 & $\mathrm{~s}$ & 0,154 & $d$ \\
\hline 115 & 5 & 0,066 & i & 0,311 & u & 1,452 & $\mathrm{u}$ & 0,154 & $d$ \\
\hline 116 & 5 & 0,063 & j & 0,316 & $t$ & 1,464 & $t$ & 0,154 & $d$ \\
\hline 117 & 5 & 0,067 & i & 0,312 & u & 1,455 & $t$ & 0,154 & $d$ \\
\hline 118 & 5 & 0,044 & 0 & 0,342 & $p$ & 1,525 & $p$ & 0,154 & d \\
\hline 119 & 5 & 0,047 & $\mathrm{n}$ & 0,349 & 0 & 1,541 & 0 & 0,154 & $d$ \\
\hline 120 & 5 & 0,065 & i & 0,321 & $s$ & 1,474 & $s$ & 0,154 & $d$ \\
\hline 121 & 5 & 0,059 & $\mathrm{k}$ & 0,329 & $r$ & 1,493 & $r$ & 0,154 & $d$ \\
\hline 122 & 5 & 0,065 & j & 0,315 & $t$ & 1,461 & $t$ & 0,154 & $d$ \\
\hline 123 & 5 & 0,042 & 0 & 0,385 & k & 1,638 & j & 0,154 & $d$ \\
\hline 124 & 5 & 0,050 & $\mathrm{~m}$ & 0,335 & $q$ & 1,506 & $r$ & 0,154 & $d$ \\
\hline 125 & 5 & 0,056 & I & 0,314 & $t$ & 1,460 & $\mathrm{t}$ & 0,154 & $d$ \\
\hline 126 & 5 & 0,057 & 1 & 0,312 & $\mathrm{u}$ & 1,455 & $t$ & 0,154 & $d$ \\
\hline 127 & 5 & 0,048 & $\mathrm{n}$ & 0,352 & 0 & 1,548 & 0 & 0,154 & $d$ \\
\hline 128 & 5 & 0,061 & j & 0,335 & $q$ & 1,508 & $q$ & 0,154 & $d$ \\
\hline 129 & 5 & 0,069 & $\mathrm{~h}$ & 0,310 & $\mathrm{u}$ & 1,451 & $\mathrm{u}$ & 0,154 & $d$ \\
\hline 130 & 5 & 0,075 & $f$ & 0,293 & $x$ & 1,417 & w & 0,154 & d \\
\hline
\end{tabular}

Continua... 
Tabela 2a. Continuação

\begin{tabular}{|c|c|c|c|c|c|c|c|c|c|}
\hline 131 & 5 & 0,077 & f & 0,291 & $y$ & 1,412 & w & 0,154 & $d$ \\
\hline 132 & 5 & 0,065 & j & 0,323 & $r$ & 1,480 & $\mathrm{~s}$ & 0,154 & $d$ \\
\hline 133 & 5 & 0,047 & $n$ & 0,346 & 0 & 1,532 & $p$ & 0,154 & $d$ \\
\hline 134 & 5 & 0,067 & i & 0,316 & $\mathrm{t}$ & 1,464 & $t$ & 0,154 & d \\
\hline 135 & 4 & 0,041 & 0 & 0,412 & $\mathrm{~h}$ & 1,717 & $\mathrm{~h}$ & 0,154 & $d$ \\
\hline 136 & 4 & 0,041 & 0 & 0,396 & j & 1,669 & i & 0,154 & $d$ \\
\hline 137 & 4 & 0,041 & 0 & 0,386 & $\mathrm{k}$ & 1,641 & j & 0,154 & $d$ \\
\hline 138 & 4 & 0,040 & 0 & 0,365 & $\mathrm{~m}$ & 1,584 & $\mathrm{~m}$ & 0,154 & $d$ \\
\hline 139 & 4 & 0,040 & 0 & 0,361 & $\mathrm{n}$ & 1,574 & $\mathrm{~m}$ & 0,154 & $d$ \\
\hline 140 & 4 & 0,035 & $p$ & 0,406 & i & 1,761 & $g$ & 0,154 & $d$ \\
\hline 141 & 4 & 0,045 & $n$ & 0,516 & $d$ & 2,194 & e & 0,154 & $d$ \\
\hline 142 & 4 & 0,042 & 0 & 0,443 & $f$ & 1,828 & $f$ & 0,154 & $d$ \\
\hline 143 & 4 & 0,057 & $\mathrm{k}$ & 0,357 & $n$ & 1,560 & $n$ & 0,154 & $d$ \\
\hline 144 & 4 & 0,060 & $\mathrm{k}$ & 0,345 & $p$ & 1,531 & $p$ & 0,154 & $d$ \\
\hline 145 & 4 & 0,061 & j & 0,337 & $q$ & 1,512 & $q$ & 0,154 & $d$ \\
\hline 146 & 4 & 0,066 & $\mathrm{i}$ & 0,317 & $t$ & 1,468 & $t$ & 0,154 & $d$ \\
\hline 147 & 4 & 0,068 & $\mathrm{~h}$ & 0,311 & u & 1,455 & $t$ & 0,154 & $d$ \\
\hline 148 & 4 & 0,073 & $g$ & 0,297 & $x$ & 1,427 & w & 0,154 & $d$ \\
\hline 149 & 4 & 0,053 & 1 & 0,388 & $\mathrm{k}$ & 1,641 & j & 0,154 & $d$ \\
\hline 150 & 4 & 0,071 & $\mathrm{~h}$ & 0,302 & w & 1,435 & v & 0,154 & $d$ \\
\hline 151 & 4 & 0,038 & $p$ & 0,404 & i & 1,681 & i & 0,154 & $d$ \\
\hline 152 & 4 & 0,044 & 0 & 0,374 & I & 1,599 & I & 0,154 & $d$ \\
\hline 153 & 4 & 0,058 & $\mathrm{k}$ & 0,327 & $r$ & 1,487 & $r$ & 0,154 & $d$ \\
\hline 154 & 4 & 0,080 & e & 0,289 & $y$ & 1,408 & w & 0,154 & $d$ \\
\hline 155 & 4 & 0,059 & $\mathrm{k}$ & 0,333 & $r$ & 1,500 & $r$ & 0,154 & $d$ \\
\hline 156 & 4 & 0,032 & $q$ & 0,418 & $g$ & 1,718 & $\mathrm{~h}$ & 0,154 & $d$ \\
\hline 157 & 4 & 0,050 & $\mathrm{~m}$ & 0,338 & $q$ & 1,512 & $q$ & 0,154 & $d$ \\
\hline 158 & 4 & 0,057 & I & 0,323 & $\mathrm{~s}$ & 1,478 & $\mathrm{~s}$ & 0,154 & $d$ \\
\hline 159 & 4 & 0,073 & $\mathrm{~g}$ & 0,295 & $x$ & 1,419 & w & 0,154 & $d$ \\
\hline 160 & 4 & 0,077 & $f$ & 0,291 & $y$ & 1,411 & w & 0,154 & $d$ \\
\hline 161 & 4 & 0,055 & 1 & 0,335 & $q$ & 1,506 & $r$ & 0,154 & $d$ \\
\hline 162 & 4 & 0,050 & $\mathrm{~m}$ & 0,332 & $r$ & 1,497 & $r$ & 0,154 & $d$ \\
\hline 163 & 4 & 0,069 & $\mathrm{~h}$ & 0,298 & w & 1,426 & w & 0,154 & $d$ \\
\hline 164 & 4 & 0,074 & $g$ & 0,293 & $x$ & 1,416 & w & 0,154 & $d$ \\
\hline 165 & 4 & 0,052 & $\mathrm{~m}$ & 0,338 & $q$ & 1,512 & $q$ & 0,154 & $d$ \\
\hline 166 & 3 & 0,049 & $\mathrm{n}$ & 0,628 & c & 2,688 & $d$ & 0,154 & $d$ \\
\hline 167 & 3 & 0,040 & 0 & 0,628 & $c$ & 2,689 & $d$ & 0,154 & $d$ \\
\hline 168 & 3 & 0,020 & $r$ & 0,640 & $b$ & 2,777 & c & 0,154 & $d$ \\
\hline 169 & 3 & 0,017 & $\mathrm{~s}$ & 0,646 & a & 2,823 & $b$ & 0,154 & $d$ \\
\hline 170 & 3 & 0,014 & $s$ & 0,651 & $a$ & 2,869 & a & 0,154 & $d$ \\
\hline 171 & 6 & 0,056 & 1 & 0,309 & u & 1,449 & $\mathrm{u}$ & 0,154 & $d$ \\
\hline 172 & 6 & 0,078 & e & 0,288 & $y$ & 1,407 & $x$ & 0,154 & $d$ \\
\hline 173 & 6 & 0,088 & $b$ & 0,282 & z & 1,394 & $y$ & 0,154 & $d$ \\
\hline 174 & 6 & 0,085 & $c$ & 0,285 & z & 1,400 & $x$ & 0,154 & $d$ \\
\hline 175 & 6 & 0,083 & $d$ & 0,286 & z & 1,402 & $x$ & 0,154 & d \\
\hline
\end{tabular}

Continua... 
Tabela 2a. Continuação

\begin{tabular}{|c|c|c|c|c|c|c|c|c|c|}
\hline 176 & 6 & 0,063 & j & 0,305 & v & 1,441 & v & 0,154 & $d$ \\
\hline 177 & 6 & 0,079 & e & 0,292 & $y$ & 1,413 & w & 0,154 & $d$ \\
\hline 178 & 6 & 0,076 & $f$ & 0,294 & $x$ & 1,418 & w & 0,154 & $d$ \\
\hline 179 & 6 & 0,076 & $f$ & 0,292 & $y$ & 1,414 & w & 0,154 & d \\
\hline 180 & 6 & 0,077 & $f$ & 0,290 & $y$ & 1,411 & w & 0,154 & $d$ \\
\hline 181 & 6 & 0,079 & e & 0,292 & $y$ & 1,414 & w & 0,154 & $d$ \\
\hline 182 & 6 & 0,077 & $f$ & 0,294 & $x$ & 1,417 & w & 0,154 & $d$ \\
\hline 183 & 6 & 0,077 & $f$ & 0,291 & $y$ & 1,413 & w & 0,154 & $d$ \\
\hline 184 & 6 & 0,077 & $f$ & 0,290 & $y$ & 1,410 & w & 0,154 & $d$ \\
\hline 185 & 6 & 0,083 & $d$ & 0,280 & \{ & 1,389 & $y$ & 0,154 & $d$ \\
\hline 186 & 6 & 0,074 & $g$ & 0,296 & $x$ & 1,421 & w & 0,154 & $d$ \\
\hline 187 & 6 & 0,064 & j & 0,305 & v & 1,442 & v & 0,154 & $d$ \\
\hline 188 & 7 & 0,077 & $f$ & 0,294 & $x$ & 1,418 & w & 0,154 & $d$ \\
\hline 189 & 7 & 0,064 & j & 0,307 & v & 1,445 & $\mathrm{u}$ & 0,154 & $d$ \\
\hline 190 & 7 & 0,079 & $\mathrm{e}$ & 0,292 & $y$ & 1,414 & w & 0,154 & $d$ \\
\hline 191 & 11 & 0,074 & $g$ & 0,291 & $y$ & 1,412 & w & 0,154 & $d$ \\
\hline 192 & 11 & 0,071 & $\mathrm{~h}$ & 0,293 & $x$ & 1,417 & w & 0,154 & $d$ \\
\hline 193 & 11 & 0,072 & $\mathrm{~h}$ & 0,291 & $y$ & 1,412 & w & 0,154 & $d$ \\
\hline 194 & 11 & 0,069 & $\mathrm{~h}$ & 0,297 & $x$ & 1,423 & w & 0,154 & $d$ \\
\hline 195 & 11 & 0,086 & $c$ & 0,282 & \{ & 1,393 & $y$ & 0,154 & $d$ \\
\hline 196 & 11 & 0,087 & $c$ & 0,281 & \{ & 1,393 & $y$ & 0,154 & d \\
\hline 197 & 10 & 0,089 & $b$ & 0,278 & \{ & 1,387 & $y$ & 0,154 & $d$ \\
\hline 198 & 10 & 0,085 & $c$ & 0,282 & \{ & 1,394 & $y$ & 0,154 & $d$ \\
\hline 199 & 10 & 0,087 & $c$ & 0,279 & \{ & 1,389 & $y$ & 0,154 & $d$ \\
\hline 200 & 10 & 0,081 & $d$ & 0,286 & z & 1,402 & $x$ & 0,154 & $d$ \\
\hline 201 & 10 & 0,083 & $d$ & 0,283 & z & 1,396 & $y$ & 0,154 & $d$ \\
\hline 202 & 10 & 0,084 & $c$ & 0,283 & z & 1,396 & $y$ & 0,154 & $d$ \\
\hline 203 & 9 & 0,084 & $c$ & 0,283 & z & 1,396 & $y$ & 0,154 & $d$ \\
\hline 204 & 9 & 0,082 & $d$ & 0,287 & z & 1,404 & $x$ & 0,154 & $d$ \\
\hline 205 & 9 & 0,086 & $c$ & 0,281 & \{ & 1,393 & $y$ & 0,154 & $d$ \\
\hline 206 & 9 & 0,075 & $g$ & 0,297 & $x$ & 1,424 & w & 0,154 & $d$ \\
\hline 207 & 9 & 0,088 & $b$ & 0,278 & \{ & 1,387 & $y$ & 0,154 & $d$ \\
\hline 208 & 9 & 0,086 & $c$ & 0,280 & \{ & 1,390 & $y$ & 0,154 & d \\
\hline 209 & 9 & 0,089 & $b$ & 0,278 & \{ & 1,386 & $y$ & 0,154 & $d$ \\
\hline 210 & 9 & 0,087 & $c$ & 0,279 & \{ & 1,389 & $y$ & 0,154 & $d$ \\
\hline 211 & 9 & 0,071 & $\mathrm{~h}$ & 0,291 & $y$ & 1,413 & w & 0,154 & $d$ \\
\hline 212 & 9 & 0,071 & $\mathrm{~h}$ & 0,290 & $y$ & 1,411 & w & 0,154 & $d$ \\
\hline 213 & 9 & 0,073 & $g$ & 0,287 & z & 1,404 & $x$ & 0,154 & $d$ \\
\hline 214 & 9 & 0,086 & $c$ & 0,280 & \{ & 1,390 & $y$ & 0,154 & $d$ \\
\hline 215 & 9 & 0,081 & $d$ & 0,289 & $y$ & 1,408 & w & 0,154 & $d$ \\
\hline 216 & 9 & 0,089 & $b$ & 0,276 & \{ & 1,383 & $y$ & 0,154 & $d$ \\
\hline 217 & 8 & 0,066 & i & 0,304 & $\mathrm{v}$ & 1,438 & $\mathrm{v}$ & 0,154 & $d$ \\
\hline 218 & 8 & 0,067 & i & 0,301 & w & 1,433 & $\mathrm{v}$ & 0,154 & $d$ \\
\hline 219 & 8 & 0,069 & $\mathrm{~h}$ & 0,296 & $x$ & 1,422 & w & 0,154 & $d$ \\
\hline 220 & 8 & 0,069 & $\mathrm{~h}$ & 0,291 & $y$ & 1,412 & w & 0,154 & d \\
\hline
\end{tabular}


Tabela 2a. Continuação

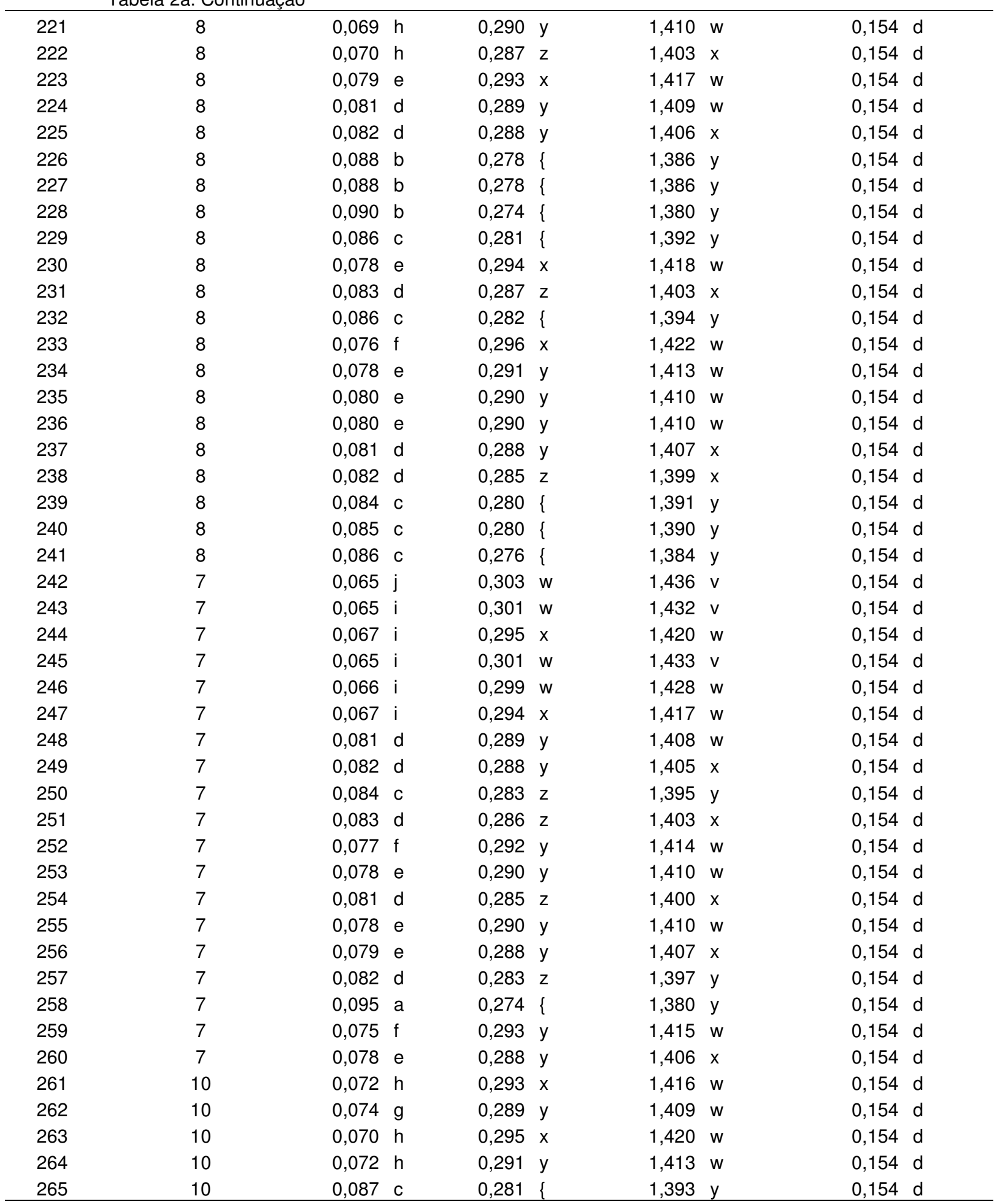

Continua... 
Tabela 2a. Continuação

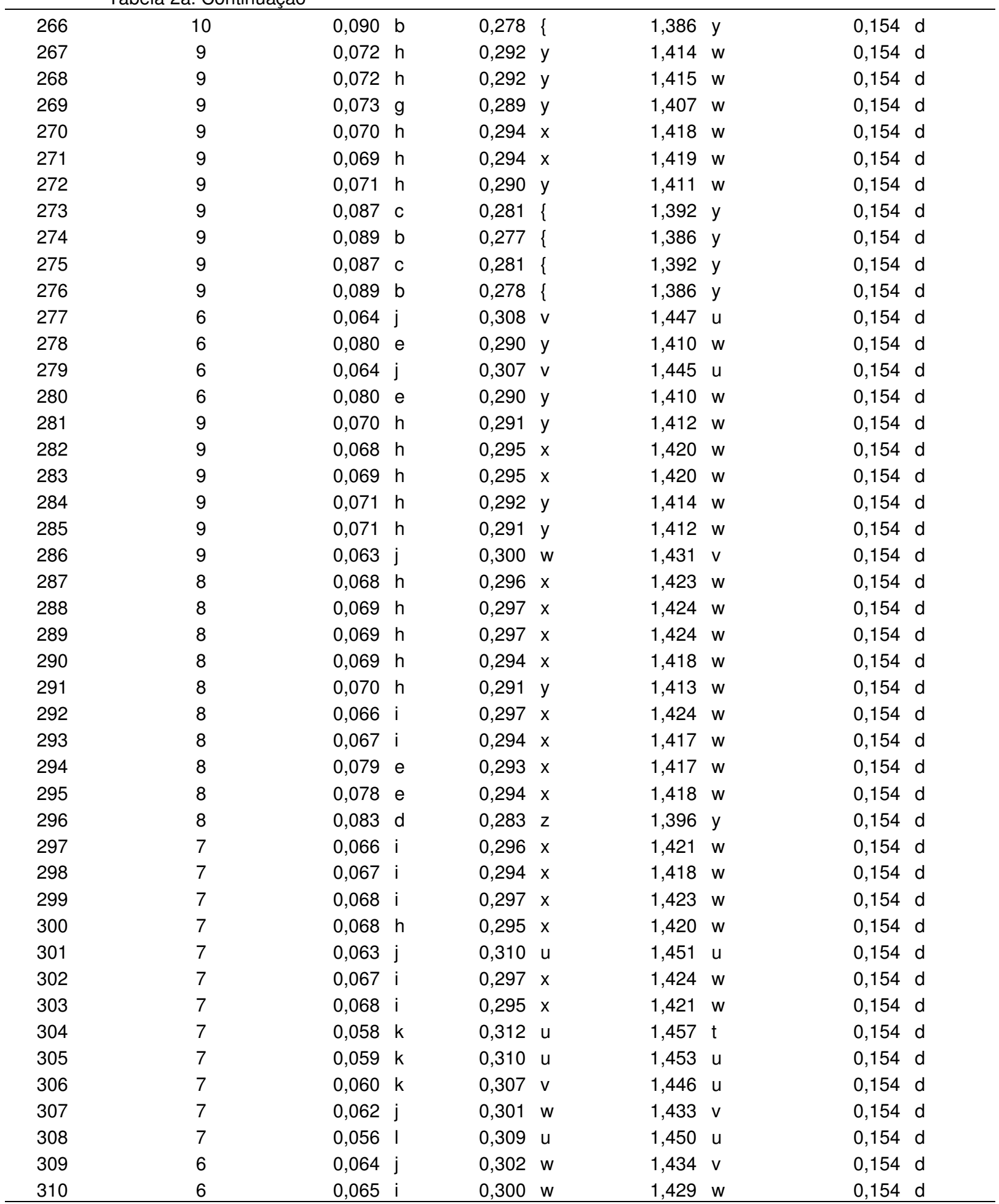


Tabela 2a. Continuação

\begin{tabular}{|c|c|c|c|c|c|c|c|c|c|}
\hline 311 & 6 & 0,056 & I & 0,312 & $\mathrm{u}$ & 1,456 & $t$ & 0,154 & $d$ \\
\hline 312 & 6 & 0,057 & I & 0,309 & $\mathrm{u}$ & 1,449 & $\mathrm{u}$ & 0,154 & $d$ \\
\hline 313 & 6 & 0,054 & I & 0,314 & $t$ & 1,461 & $t$ & 0,154 & $d$ \\
\hline 314 & 6 & 0,055 & I & 0,311 & $\mathrm{u}$ & 1,454 & $t$ & 0,154 & $d$ \\
\hline 315 & 6 & 0,058 & $\mathrm{k}$ & 0,302 & w & 1,435 & v & 0,154 & $d$ \\
\hline 316 & 6 & 0,082 & $d$ & 0,287 & $z$ & 1,404 & $x$ & 0,154 & $d$ \\
\hline 317 & 6 & 0,082 & $d$ & 0,286 & $z$ & 1,402 & $x$ & 0,154 & $d$ \\
\hline 318 & 6 & 0,077 & $f$ & 0,290 & $y$ & 1,411 & w & 0,154 & $d$ \\
\hline 319 & 6 & 0,080 & e & 0,283 & z & 1,397 & $y$ & 0,154 & $d$ \\
\hline 320 & 6 & 0,083 & $d$ & 0,287 & $z$ & 1,403 & $x$ & 0,154 & $d$ \\
\hline 321 & 6 & 0,090 & $b$ & 0,279 & \{ & 1,388 & $y$ & 0,154 & $d$ \\
\hline 322 & 5 & 0,052 & $\mathrm{~m}$ & 0,323 & s & 1,479 & s & 0,154 & $d$ \\
\hline 323 & 5 & 0,054 & 1 & 0,315 & $t$ & 1,463 & $t$ & 0,154 & $d$ \\
\hline 324 & 5 & 0,073 & $g$ & 0,299 & w & 1,428 & w & 0,154 & d \\
\hline 325 & 5 & 0,084 & $d$ & 0,288 & $y$ & 1,405 & $x$ & 0,154 & $d$ \\
\hline 326 & 5 & 0,079 & e & 0,294 & $x$ & 1,418 & $w$ & 0,154 & $d$ \\
\hline 327 & 5 & 0,083 & $d$ & 0,288 & $y$ & 1,405 & $x$ & 0,154 & $d$ \\
\hline 328 & 5 & 0,085 & $c$ & 0,285 & z & 1,400 & $x$ & 0,154 & $d$ \\
\hline 329 & 5 & 0,073 & $g$ & 0,294 & $x$ & 1,417 & $w$ & 0,154 & $d$ \\
\hline 330 & 5 & 0,075 & $g$ & 0,292 & $y$ & 1,413 & w & 0,154 & $d$ \\
\hline 331 & 4 & 0,038 & $p$ & 0,370 & I & 1,617 & $\mathrm{k}$ & 0,154 & $d$ \\
\hline 332 & 4 & 0,055 & 1 & 0,355 & $n$ & 1,553 & $n$ & 0,154 & $d$ \\
\hline 333 & 4 & 0,058 & $\mathrm{k}$ & 0,342 & $p$ & 1,522 & $p$ & 0,154 & $d$ \\
\hline 334 & 4 & 0,069 & $\mathrm{~h}$ & 0,314 & $t$ & 1,460 & $t$ & 0,154 & $d$ \\
\hline 335 & 4 & 0,073 & $g$ & 0,307 & v & 1,445 & $\mathrm{u}$ & 0,154 & $d$ \\
\hline 336 & 4 & 0,079 & e & 0,295 & $x$ & 1,420 & w & 0,154 & $d$ \\
\hline 337 & 4 & 0,083 & $d$ & 0,289 & $y$ & 1,407 & $x$ & 0,154 & $d$ \\
\hline 338 & 4 & 0,072 & $\mathrm{~h}$ & 0,300 & w & 1,431 & v & 0,154 & $d$ \\
\hline 339 & 4 & 0,067 & i & 0,304 & $\mathrm{v}$ & 1,438 & v & 0,154 & $d$ \\
\hline 340 & 4 & 0,062 & j & 0,309 & $\mathrm{u}$ & 1,448 & $\mathrm{u}$ & 0,154 & $d$ \\
\hline 341 & 14 & 0,070 & $\mathrm{~h}$ & 0,298 & $x$ & 1,425 & $w$ & 0,154 & $d$ \\
\hline 342 & 14 & 0,071 & $\mathrm{~h}$ & 0,297 & $x$ & 1,424 & w & 0,154 & $d$ \\
\hline 343 & 14 & 0,072 & $\mathrm{~h}$ & 0,295 & $x$ & 1,420 & $w$ & 0,154 & $d$ \\
\hline 344 & 14 & 0,073 & $g$ & 0,291 & $y$ & 1,412 & $w$ & 0,154 & $d$ \\
\hline 345 & 14 & 0,073 & $g$ & 0,291 & $y$ & 1,413 & w & 0,154 & $d$ \\
\hline 346 & 14 & 0,085 & $C$ & 0,283 & z & 1,396 & $y$ & 0,154 & $d$ \\
\hline 347 & 13 & 0,071 & $\mathrm{~h}$ & 0,297 & $x$ & 1,424 & $w$ & 0,154 & $d$ \\
\hline 348 & 13 & 0,067 & i & 0,305 & $\mathrm{v}$ & 1,441 & $v$ & 0,154 & $d$ \\
\hline 349 & 13 & 0,068 & $\mathrm{~h}$ & 0,303 & $\mathrm{v}$ & 1,436 & v & 0,154 & $d$ \\
\hline 350 & 13 & 0,069 & $\mathrm{~h}$ & 0,302 & w & 1,434 & v & 0,154 & $d$ \\
\hline 351 & 13 & 0,087 & $c$ & 0,281 & \{ & 1,392 & $y$ & 0,154 & $d$ \\
\hline 352 & 13 & 0,081 & $d$ & 0,288 & $y$ & 1,406 & $x$ & 0,154 & $d$ \\
\hline 353 & 13 & 0,083 & $d$ & 0,286 & $z$ & 1,402 & $x$ & 0,154 & $d$ \\
\hline 354 & 12 & 0,070 & $\mathrm{~h}$ & 0,299 & w & 1,427 & $w$ & 0,154 & $d$ \\
\hline 355 & 12 & 0,071 & $\mathrm{~h}$ & 0,296 & $x$ & 1,423 & $w$ & 0,154 & $d$ \\
\hline
\end{tabular}

Continua... 
Tabela 2a. Continuação

\begin{tabular}{|c|c|c|c|c|c|c|c|c|c|}
\hline 356 & 12 & 0,071 & $\mathrm{~h}$ & 0,295 & $x$ & 1,421 & w & 0,154 & $d$ \\
\hline 357 & 12 & 0,070 & $\mathrm{~h}$ & 0,299 & w & 1,429 & w & 0,154 & $d$ \\
\hline 358 & 12 & 0,068 & $\mathrm{~h}$ & 0,304 & $\mathrm{v}$ & 1,439 & $\mathrm{v}$ & 0,154 & $d$ \\
\hline 359 & 12 & 0,082 & $d$ & 0,288 & $y$ & 1,405 & $x$ & 0,154 & $d$ \\
\hline 360 & 12 & 0,082 & $d$ & 0,287 & z & 1,403 & $x$ & 0,154 & $d$ \\
\hline 361 & 12 & 0,087 & $c$ & 0,281 & \{ & 1,393 & $y$ & 0,154 & $d$ \\
\hline 362 & 12 & 0,068 & $\mathrm{~h}$ & 0,298 & w & 1,427 & w & 0,154 & $d$ \\
\hline 363 & 12 & 0,069 & $\mathrm{~h}$ & 0,297 & $x$ & 1,425 & w & 0,154 & $d$ \\
\hline 364 & 12 & 0,071 & $\mathrm{~h}$ & 0,293 & $x$ & 1,416 & w & 0,154 & $d$ \\
\hline 365 & 11 & 0,086 & $c$ & 0,282 & z & 1,394 & $y$ & 0,154 & $d$ \\
\hline 366 & 11 & 0,082 & $d$ & 0,285 & z & 1,400 & $x$ & 0,154 & $d$ \\
\hline 367 & 11 & 0,083 & $d$ & 0,283 & $z$ & 1,395 & $y$ & 0,154 & $d$ \\
\hline 368 & 11 & 0,069 & $\mathrm{~h}$ & 0,302 & w & 1,435 & v & 0,154 & $d$ \\
\hline 369 & 11 & 0,068 & i & 0,300 & w & 1,431 & $v$ & 0,154 & $d$ \\
\hline 370 & 11 & 0,068 & $\mathrm{~h}$ & 0,299 & w & 1,428 & w & 0,154 & $d$ \\
\hline 371 & 11 & 0,065 & j & 0,307 & $\mathrm{v}$ & 1,445 & $\mathrm{u}$ & 0,154 & $d$ \\
\hline 372 & 11 & 0,065 & $\mathrm{i}$ & 0,306 & v & 1,442 & $\mathrm{v}$ & 0,154 & $d$ \\
\hline 373 & 10 & 0,070 & $\mathrm{~h}$ & 0,295 & $x$ & 1,420 & w & 0,154 & $d$ \\
\hline 374 & 10 & 0,067 & i & 0,303 & v & 1,437 & $\mathrm{v}$ & 0,154 & $d$ \\
\hline 375 & 10 & 0,071 & $\mathrm{~h}$ & 0,294 & $x$ & 1,418 & w & 0,154 & $d$ \\
\hline 376 & 10 & 0,072 & $\mathrm{~h}$ & 0,291 & $y$ & 1,412 & w & 0,154 & $d$ \\
\hline 377 & 10 & 0,069 & $\mathrm{~h}$ & 0,297 & $x$ & 1,425 & w & 0,154 & $d$ \\
\hline 378 & 10 & 0,071 & $\mathrm{~h}$ & 0,294 & $x$ & 1,418 & w & 0,154 & $d$ \\
\hline 379 & 10 & 0,064 & j & 0,335 & $q$ & 1,506 & $r$ & 0,169 & c \\
\hline 380 & 10 & 0,063 & j & 0,357 & $n$ & 1,558 & $n$ & 0,177 & $b$ \\
\hline 381 & 10 & 0,063 & j & 0,356 & $n$ & 1,557 & $n$ & 0,177 & $b$ \\
\hline 382 & 10 & 0,066 & $\mathrm{i}$ & 0,331 & $r$ & 1,496 & $r$ & 0,169 & $c$ \\
\hline 383 & 10 & 0,067 & i & 0,328 & $r$ & 1,492 & $r$ & 0,169 & $c$ \\
\hline 384 & 10 & 0,083 & $d$ & 0,285 & z & 1,399 & $x$ & 0,154 & $d$ \\
\hline 385 & 10 & 0,085 & $c$ & 0,282 & \{ & 1,393 & $y$ & 0,154 & $d$ \\
\hline 386 & 10 & 0,081 & $d$ & 0,288 & $y$ & 1,406 & $x$ & 0,154 & $d$ \\
\hline 387 & 10 & 0,083 & $d$ & 0,285 & z & 1,400 & $x$ & 0,154 & $d$ \\
\hline 388 & 10 & 0,077 & $f$ & 0,295 & $x$ & 1,419 & w & 0,154 & $d$ \\
\hline 389 & 10 & 0,075 & $f$ & 0,296 & $x$ & 1,422 & w & 0,154 & $d$ \\
\hline 390 & 9 & 0,073 & $g$ & 0,289 & $y$ & 1,409 & w & 0,154 & $d$ \\
\hline 391 & 9 & 0,069 & $\mathrm{~h}$ & 0,299 & w & 1,429 & w & 0,154 & $d$ \\
\hline 392 & 9 & 0,067 & i & 0,303 & $\mathrm{v}$ & 1,437 & $\mathrm{v}$ & 0,154 & $d$ \\
\hline 393 & 9 & 0,068 & $\mathrm{~h}$ & 0,301 & w & 1,432 & v & 0,154 & $d$ \\
\hline 394 & 9 & 0,067 & i & 0,305 & $\mathrm{v}$ & 1,441 & v & 0,154 & $d$ \\
\hline 395 & 9 & 0,067 & i & 0,329 & $r$ & 1,492 & $r$ & 0,169 & C \\
\hline 396 & 9 & 0,062 & j & 0,344 & $p$ & 1,527 & $p$ & 0,169 & $c$ \\
\hline 397 & 9 & 0,067 & i & 0,328 & $r$ & 1,491 & $r$ & 0,169 & $c$ \\
\hline 398 & 9 & 0,065 & j & 0,317 & $t$ & 1,467 & $t$ & 0,158 & $d$ \\
\hline 399 & 9 & 0,064 & j & 0,307 & v & 1,444 & u & 0,154 & $d$ \\
\hline 400 & 9 & 0,058 & $\mathrm{k}$ & 0,348 & 0 & 1,536 & 0 & 0,169 & C \\
\hline
\end{tabular}


Tabela 2a. Continuação

\begin{tabular}{|c|c|c|c|c|c|c|c|c|c|}
\hline 401 & 9 & 0,082 & $d$ & 0,285 & z & 1,400 & $x$ & 0,154 & $d$ \\
\hline 402 & 9 & 0,077 & $f$ & 0,294 & $x$ & 1,419 & w & 0,154 & $d$ \\
\hline 403 & 9 & 0,075 & $g$ & 0,296 & $x$ & 1,422 & w & 0,154 & $d$ \\
\hline 404 & 8 & 0,065 & j & 0,302 & w & 1,435 & $\mathrm{v}$ & 0,154 & $d$ \\
\hline 405 & 8 & 0,065 & i & 0,301 & w & 1,431 & $v$ & 0,154 & $d$ \\
\hline 406 & 8 & 0,066 & $\mathrm{i}$ & 0,302 & w & 1,434 & v & 0,154 & $d$ \\
\hline 407 & 8 & 0,059 & $\mathrm{k}$ & 0,346 & 0 & 1,532 & $p$ & 0,169 & c \\
\hline 408 & 8 & 0,059 & $\mathrm{k}$ & 0,345 & $p$ & 1,528 & $p$ & 0,169 & C \\
\hline 409 & 8 & 0,058 & $\mathrm{k}$ & 0,349 & 0 & 1,538 & 0 & 0,169 & $c$ \\
\hline 410 & 8 & 0,063 & j & 0,307 & v & 1,444 & $u$ & 0,154 & $d$ \\
\hline 411 & 8 & 0,064 & j & 0,305 & v & 1,440 & v & 0,154 & $d$ \\
\hline 412 & 8 & 0,064 & j & 0,306 & v & 1,443 & $\mathrm{u}$ & 0,154 & $d$ \\
\hline 413 & 8 & 0,075 & $f$ & 0,300 & w & 1,429 & w & 0,154 & $d$ \\
\hline 414 & 8 & 0,076 & $f$ & 0,298 & w & 1,426 & w & 0,154 & $d$ \\
\hline 415 & 8 & 0,080 & e & 0,290 & $y$ & 1,410 & w & 0,154 & $d$ \\
\hline 416 & 8 & 0,070 & $\mathrm{~h}$ & 0,307 & v & 1,444 & $\mathrm{u}$ & 0,154 & $d$ \\
\hline 417 & 7 & 0,078 & e & 0,291 & $y$ & 1,412 & w & 0,154 & $d$ \\
\hline 418 & 7 & 0,079 & e & 0,289 & $y$ & 1,409 & w & 0,154 & $d$ \\
\hline 419 & 7 & 0,073 & $g$ & 0,300 & w & 1,429 & w & 0,154 & $d$ \\
\hline 420 & 7 & 0,083 & $d$ & 0,286 & $z$ & 1,402 & $x$ & 0,154 & $d$ \\
\hline 421 & 7 & 0,082 & $d$ & 0,287 & $y$ & 1,405 & $x$ & 0,154 & $d$ \\
\hline 422 & 7 & 0,073 & $g$ & 0,305 & v & 1,440 & v & 0,154 & $d$ \\
\hline 423 & 7 & 0,071 & $\mathrm{~h}$ & 0,308 & $\mathrm{u}$ & 1,448 & $\mathrm{u}$ & 0,154 & $d$ \\
\hline 424 & 7 & 0,083 & $d$ & 0,280 & \{ & 1,390 & $y$ & 0,154 & $d$ \\
\hline 425 & 7 & 0,073 & $g$ & 0,297 & $x$ & 1,424 & w & 0,154 & $d$ \\
\hline 426 & 7 & 0,076 & $f$ & 0,292 & $y$ & 1,414 & w & 0,154 & $d$ \\
\hline 427 & 7 & 0,073 & $g$ & 0,297 & $x$ & 1,424 & w & 0,154 & $d$ \\
\hline 428 & 7 & 0,076 & $f$ & 0,291 & $y$ & 1,412 & w & 0,154 & $d$ \\
\hline 429 & 7 & 0,074 & $g$ & 0,295 & $x$ & 1,421 & w & 0,154 & $d$ \\
\hline 430 & 6 & 0,065 & j & 0,304 & v & 1,438 & $\mathrm{v}$ & 0,154 & $d$ \\
\hline 431 & 6 & 0,063 & j & 0,309 & u & 1,450 & $u$ & 0,154 & $d$ \\
\hline 432 & 6 & 0,055 & 1 & 0,325 & $r$ & 1,483 & $s$ & 0,154 & $d$ \\
\hline 433 & 6 & 0,072 & $\mathrm{~h}$ & 0,309 & u & 1,448 & $\mathrm{u}$ & 0,154 & $d$ \\
\hline 434 & 6 & 0,077 & $f$ & 0,290 & $y$ & 1,410 & w & 0,154 & $d$ \\
\hline 435 & 6 & 0,068 & i & 0,311 & u & 1,453 & $\mathrm{u}$ & 0,154 & $d$ \\
\hline 436 & 6 & 0,065 & j & 0,319 & $s$ & 1,471 & $s$ & 0,154 & $d$ \\
\hline 437 & 6 & 0,067 & i & 0,314 & $t$ & 1,460 & $t$ & 0,154 & $d$ \\
\hline 438 & 6 & 0,087 & $c$ & 0,283 & $z$ & 1,396 & $y$ & 0,154 & $d$ \\
\hline 439 & 6 & 0,087 & $c$ & 0,283 & z & 1,397 & $y$ & 0,154 & $d$ \\
\hline 440 & 6 & 0,071 & $\mathrm{~h}$ & 0,308 & u & 1,447 & $\mathrm{u}$ & 0,154 & $d$ \\
\hline 441 & 6 & 0,071 & $\mathrm{~h}$ & 0,308 & v & 1,446 & $\mathrm{u}$ & 0,154 & $d$ \\
\hline 442 & 6 & 0,074 & $g$ & 0,304 & v & 1,438 & v & 0,154 & $d$ \\
\hline 443 & 6 & 0,074 & $g$ & 0,304 & v & 1,438 & v & 0,154 & $d$ \\
\hline 444 & 6 & 0,067 & i & 0,310 & u & 1,451 & u & 0,154 & $d$ \\
\hline 445 & 5 & 0,068 & $\mathrm{i}$ & 0,315 & $t$ & 1,463 & $t$ & 0,154 & d \\
\hline
\end{tabular}

Continua... 
Tabela 2a. Continuação

\begin{tabular}{|c|c|c|c|c|c|c|c|c|c|c|c|c|c|}
\hline 446 & 5 & 0,070 & $\mathrm{~h}$ & & 0,309 & $u$ & & 1,450 & $\mathrm{u}$ & & 0,154 & $d$ & \\
\hline 447 & 5 & 0,074 & $\mathrm{~g}$ & & 0,299 & w & & 1,428 & w & & 0,154 & $d$ & \\
\hline 448 & 5 & 0,067 & i & & 0,315 & $t$ & & 1,463 & $t$ & & 0,154 & $d$ & \\
\hline 449 & 5 & 0,064 & j & & 0,315 & $\mathrm{t}$ & & 1,462 & $\mathrm{t}$ & & 0,154 & d & \\
\hline \multirow[t]{7}{*}{450} & 5 & 0,073 & $g$ & & 0,300 & w & & 1,430 & w & & 0,154 & $d$ & \\
\hline & Média geral & 0,070 & $\mathrm{~g}$ & & 0,311 & & - & 1,464 & w & & 0,157 & & \\
\hline & Mínimo & 0,014 & & - & 0,274 & w & & 1,380 & & - & 0,154 & & \\
\hline & Máximo & 0,095 & & & 0,651 & & & 2,869 & & & 0,203 & $d$ & - \\
\hline & Desvio Padrão & 0,01 & & & 0,05 & & & 0,16 & & & 0,06 & & \\
\hline & CV $(\%)$ & 15,6 & & & 5,2 & & & 3,4 & & & 1,2 & & \\
\hline & Teste F & $73,9^{* *}$ & & & 485,2 & & & $622,2^{*}$ & & & $718,2^{* *}$ & & \\
\hline
\end{tabular}

${ }^{1} \mathrm{C} 1$ : curva de referência, ajustada a partir de 15 valores de tensão. Médias seguidas de mesma letra na coluna fazem parte do mesmo grupo estatístico (Scott-knott p > 0,05). **significativo a $1 \%$ de probabilidade. 